\title{
Quametopia, a new genus of Nearctic Anthomyzidae (Diptera), with description of two new species, immature stages and life history
}

\author{
JINDŘICH ROHÁČEK ${ }^{1}$ and KEVIN N. BARBER ${ }^{2}$ \\ ${ }^{1}$ Department of Entomology, Silesian Museum, Tyršova 1, CZ-746 01 Opava, Czech Republic; e-mail: rohacek@szmo.cz \\ ${ }^{2}$ Great Lakes Forestry Centre, Canadian Forest Service, Natural Resources Canada, 1219 Queen St. E., Sault Ste. Marie, Ontario, \\ P6A 2E5, Canada; e-mail: kbarber@NRCan.gc.ca
}

\begin{abstract}
Key words. Diptera, Anthomyzidae, Nearctic, taxonomy, Quametopia new genus, 2 new species, lectotype designations, relationships, immature stages, life history, distribution, keys
\end{abstract}

\begin{abstract}
Quametopia gen. n. is established on the basis of recent phylogenetic analysis of taxa formerly assembled under the genus Mumetopia Melander, 1913 to include M. terminalis (Loew, 1863) and two new closely related Nearctic species of Anthomyzidae. The new genus is diagnosed and its phylogenetic relationships discussed. Quametopia terminalis (Loew, 1863) comb. n. is transferred from Mumetopia and redescribed based on revision of the type material (lectotypes of Anthophilina terminalis Loew, 1863 and its synonym Mumetopia nitens Melander, 1913 are designated) and other extensive material. Quametopia clintonia sp. n. and Q. amplistylus sp. n. (both from Canada, USA) are described and relationships of all three Quametopia species discussed. Immature stages of $Q$. terminalis and $Q$. clintonia sp. n. obtained by means of adult-to-adult rearing are described (1st- and 2nd-instar larvae for the first time in the family Anthomyzidae) and illustrated. Keys to adults, eggs, larvae and puparia of Quametopia species are presented. Biology (habitat and host-plant associations, life history) of Q. terminalis and Q. clintonia sp. n. are studied in detail and their ecological separation demonstrated. Distribution of all Quametopia species is reviewed.
\end{abstract}

\section{INTRODUCTION}

The recent study by Roháček \& Barber (2009) on the phylogenetic relationships of species associated under the genus Mumetopia Melander, 1913 revealed that neither of its two other known species, viz. M. nigrimana (Coquillett, 1900) and M. terminalis (Loew, 1863), are congeneric with the type species Mumetopia occipitalis Melander, 1913. The species M. nigrimana (Coquillett, 1900) and number of its undescribed relatives proved to form a distinct unnamed genus-group taxon which belongs, as does the genus Mumetopia in a new restricted concept, to the Chamaebosca group of genera as defined by Roháček \& Barber (2009: 212) forming there a sistergroup to Stiphrosoma Czerny, 1928. On the other hand, M. terminalis had been considered unrelated to the Chamaebosca clade and was excluded from the genus Mumetopia as a species whose generic affiliation and relationships required further detailed study (see Roháček \& Barber, 2009).

Moreover, the examination of extensive material of Mumetopia terminalis from various parts of the Nearctic Region revealed that there were, in fact, three closely allied species involved under this name. To confirm their validity, successful rearing experiments were performed which obtained all preimaginal stages and first data for habitat and host-plant preferences of two of these species. These discoveries also raised the necessity to revise all available type specimens of Anthophilina terminalis Loew, 1863 (transferred to Mumetopia by Melander, 1913: 294) and of its synonym Mumetopia nitens
Melander, 1913 so that these names can be correctly applied to the species recognized here.

An analysis of morphological characters (particularly those of the male and female terminalia) found that this species complex cannot be affiliated with any of the described genera of Anthomyzidae. Therefore, a new genus Quametopia is established below to accommodate these three species and its phylogenetic affinities are discussed on the basis of analysis of a set of characters used as criteria in diagnoses of anthomyzid genera as standardized by Roháček (2006, 2009). All three members of Quametopia are (re)described in detail, including preimaginal stages (the first- and second-instar larvae are described for the first time in the family Anthomyzidae) in two of them, keyed, and their relationships, biology (including life history and host-plant preferences) and distribution discussed.

\section{MATERIAL AND METHODS}

The material examined is deposited in institutional and private collections as follows: AMNH - American Museum of Natural History, Division of Invertebrate Zoology, New York, NY, U.S.A.; BYUC - Brigham Young University, Monte L. Bean Life Science Museum, Provo, UT, U.S.A.; CASC - California Academy of Sciences, Department of Entomology, San Francisco, CA, U.S.A.; CNCI - Canadian National Collection of Insects, Arachnids and Nematodes, Agriculture and AgriFood Canada, Ottawa, ON, Canada; CSCA - California State Collection of Arthropods, Sacramento, CA, U.S.A.; DEBU University of Guelph Insect Collection, School of Environmental Sciences, University of Guelph, Guelph, ON, Canada; EMUS - Utah State University, Logan, UT, U.S.A.; INHS Illinois Natural History Survey, Champaign, IL, U.S.A.; LEMQ 
- Lyman Entomological Museum, McGill University, Macdonald Campus, Ste--Anne-de-Bellevue, QC, Canada; MBP collection of Prof. Dr. M. Barták, Praha, Czech Republic; MCZC - Museum of Comparative Zoology, Harvard University, Cambridge, MA, U.S.A.; SEMC - Snow Entomological Museum, University of Kansas, Lawrence, KS, U.S.A.; SMOC - Silesian Museum, Opava, Czech Republic; USNM - National Museum of Natural History, Smithsonian Institution, Department of Entomology, Washington, DC, U.S.A.; ZSMC - Zoologische Staatsammlung München, München, Germany.

Presentation of faunistic data. Label data of primary-type specimens and paralectotypes are presented strictly verbatim. Data from other type specimens (paratypes) of rare species are standardized; those from specimens (including paratypes) of common species are abbreviated, with only locality name, abbreviation of collector's name and depository collection and total number of specimens studied (separately for states/provinces). However, detailed information (including topograpical, phenological, habitat, cenological, host-plant, rearing and other important data) are provided in a supplementary file (Appendix) with complete list of material examined available at:

$<$ http://www.eje.cz/supplfiles/eje1618suppl.pdf>

Abbreviations of collectors' names are as follows: $\mathrm{Al}-\mathrm{J} . \mathrm{M}$. Aldrich, Ap - A. Applejohn, Ar - E.T. Armstrong, As - I.S. Askevold, At - W.A. Attwater, Ax - C.P. Alexander, Ba - K.N. Barber, Bc $-\mathrm{H}$. Blanchard, Bd - D. Bright, Be $-\mathrm{S}$. Beierl, BgM.D. Bergeron, $\mathrm{Bh}-$ G.H. Bohart, $\mathrm{Bj}-\mathrm{J}$. Bright, Bk - D.J. Bickel, Bl - G.E. Ball, Bn - D.F. Beneway, Bo - S. Boucher, Br - S.J. Brooks, Bt - M. Barták, Bu - M. Buck, Ca - J. Cappleman, $\mathrm{Cc}-$ V. Crecco, $\mathrm{Ce}-$ D.K.B. Cheung, $\mathrm{Ch}-$ J.G. Chillcott, $\mathrm{Cn}-$ C. Chenard, $\mathrm{Cr}-$ E.T. Cresson, Jr., $\mathrm{Cu}-$ J.M. Cumming, De - K.J.G. Deacon, Dr - R.R. Dreisbach, Fl - O.S. Flint, Fo J. Forrest, Ga - A.V. Gaimari, Gs - S.D. Gaimari, He - J.M. Heraty, Hg - G.F. Hevel, Ho - S.B. Holmes, Hs - S. Hevel, Ik E. Ikeda, Jo - C.W. Johnson, Ke - L.A. Kelton, Kn - L.V. Knutson, $\mathrm{Kr}-$ N.H.L. Krauss, Ma - S.A. Marshall, Mc - J.F. McAlpine, Me - A.L. Melander, Mh - W.N. Mathis, Ml - J.R. Malloch, Mn - J.C. Marlin, Mo - W.R.M. Mason, Mr - J.E.H. Martin, Ms - L. Masner, Mt - W.L. McAtee, Os - C.R. Osten Sacken, Pa - H.S. Parish, Pe - O. Peck, Ph - D.J. Peckham, Po - M. Pollet, Re - W. Reid, Ro - J. Roháček, Sc - A.W. Schaafsma, Sh - G.E. Shewell, Sl - A.T. Slosson, Sm - V.G. Smith, $\mathrm{Sn}-$ R.C. Shannon, $\mathrm{Sr}-$ M.J. Sharkey, St - A. Stone, $\mathrm{Su}-\mathrm{A} . \mathrm{H}$. Sturtevant, Sy - G.E. Steyskal, Te - H.J. Teskey, To - H.K. Townes, Ts - M. von Tschirnhaus, Vd - M.C. VanDuzee, Vo J.R. Vockeroth, Wb - D.W. Webb, We - T.A. Wheeler, Wh Whitney, Wi - W.W. Wirth, Wl - D.D. Wilder, Wn - F.G. Werner.

Abdomens of a large number of specimens were detached and genitalia dissected. After examination, all dissected parts were put into plastic tubes containing glycerine and pinned below the respective specimens; this is indicated in the text by the abbreviation "genit. prep.".

Morphological terminology follows that used in Roháček (2006, 2009) including terms of the male hypopygium. It is largely based on the "hinge" hypothesis of the origin of the eremoneuran hypopygium, re-discovered and documented by Zatwarnicki (1996) and, therefore, the following alterations of terms of the male genitalia (against those used by other hypotheses) need to be listed (new term first): ejacapodeme $=$ ejaculatory apodeme; epandrium = periandrium; gonostylus = surstylus; medandrium $=$ subepandrial sclerite, intraperiandrial sclerite; phallapodeme $=$ aedeagal apodeme; phallophore $=$ basiphallus; transandrium $=$ posterior hypandrial bridge. Morphological terms of the male genitalia are depicted in Figs 13-21 and 106, of the female postabdomen and genitalia in Figs 22-30 and of immature stages in Figs 46-67 and 96-101.

Field collections of $Q$. terminalis and $Q$. clintonia $\mathbf{s p .} \mathbf{n}$. Virtually all collections of Quametopia terminalis by the authors were made with a sweep net in habitats including a significant component of, or dominated by, Impatiens capensis Meerb. (Balsaminaceae) (Fig. 73). This host association was always clear.

Quametopia clintonia sp. n. was first suspected to be a distinct species when swept in wooded areas where I. capensis was absent. Collection efforts subsequent to 21 July 2009 were directed at identifying the host plant and, despite the relatively sparse occurrence of this fly and considerable heterogeneity of the plant communities, Clintonia borealis (Aiton) Raf. (Liliaceae) (Fig. 105) emerged as the most probable host plant.

Field collections of litter and soil, and stems of Impatiens capensis. Samples of litter and soil were taken in the spring of 1999 and 2002 at the Bristol Place Park (Sault Ste. Marie, Ontario) site where adults of $Q$. terminalis occur in a stand of $I$. capensis. On 10 May 1999, five samples of $\sim 13 \times 18 \mathrm{~cm}$ were cut from the patch and maintained in plastic boxes at $20^{\circ} \mathrm{C}, 50-70 \%$ $\mathrm{RH}$, and 16L : 8D photoperiod (standard conditions). On 25 May 2002, a horticultural bulb planter was used to cut 14 cores of $\sim 5.8 \mathrm{~cm}$ diameter each. The cores were pushed into plastic cylinders, placed in small plastic bags, and maintained at $25^{\circ} \mathrm{C}$, $30-50 \% \mathrm{RH}$, and $16 \mathrm{~L}: 8 \mathrm{D}$ photoperiod (the relative humidity within the plastic bags was considerably higher).

A small sample of dried, fallen stems of I. capensis from the previous season was collected from the Birchwood Park (Sault Ste. Marie) site on 1 May 2010. The stems were transferred to plastic boxes (Fig. 5) and held in standard conditions until 31 July 2010. A slightly larger sample of stems was collected on 17 May 2010 and handled in the same fashion. A subsample of 62 stems (only those including roots, Figs 6,7) was dissected in search of immature $Q$. terminalis. The maggots found were transferred to thawed (from frozen supply) sections of I. capensis stems until pupariation (larvae and puparia were handled as described below).

Rearing of $\boldsymbol{Q}$. terminalis. On 24 June 2002, $12 \widehat{\delta}$ and 24 from the Bristol Place Park site were divided between two small flight cages, each with a cylindrical soil core with $I$. capensis plants, provided with a bee pollen/sucrose mixture $(1: 1$ by volume, ground in a coffee grinder, sprinkled on the dampened screen), regularly misted with water, and held in standard conditions. By early July, eggs were observed on damaged leaves of the $I$. capensis plants. The soil cores with plants were then replaced by a plastic Petri plate $(9 \mathrm{~cm}$ diameter) with wet white sand and I. capensis leaves on the surface. By 22 July, the Petri plates with wet sand and rotting leaves had many larvae but since high mortality was observed, excess liquid was decanted off, and many larvae preserved in ethanol. Subsequently, for oviposition and for general rearing, short sections $(\sim 3 \mathrm{~cm})$ of $I$. capensis stems were split longitudinally and laid on the sand, outside surface facing up, in place of leaves. Larvae readily colonized these stems, rasping the inner flesh and also wedging themselves between the outer epidermis and the inner tissue.

A cup cage (plastic drinking cup with screen bottom, a stoppered hole in the side, inverted on a Petri plate lid filled with moist sand) replaced the flight cages when only $4 \hat{\sigma}$ and 69 remained (12 August 2002). Oviposition was later restricted to a small 5 cm-diameter Petri plate (Falcon ${ }^{\circledR} 1006$, Becton Dickinson Labware, Lincoln Park, NJ, USA) on the floor of the cage that was in turn lined with filter paper, the small plate supplied with moist sand and short sections of split stems of I. capensis (Figs 1, 2). 

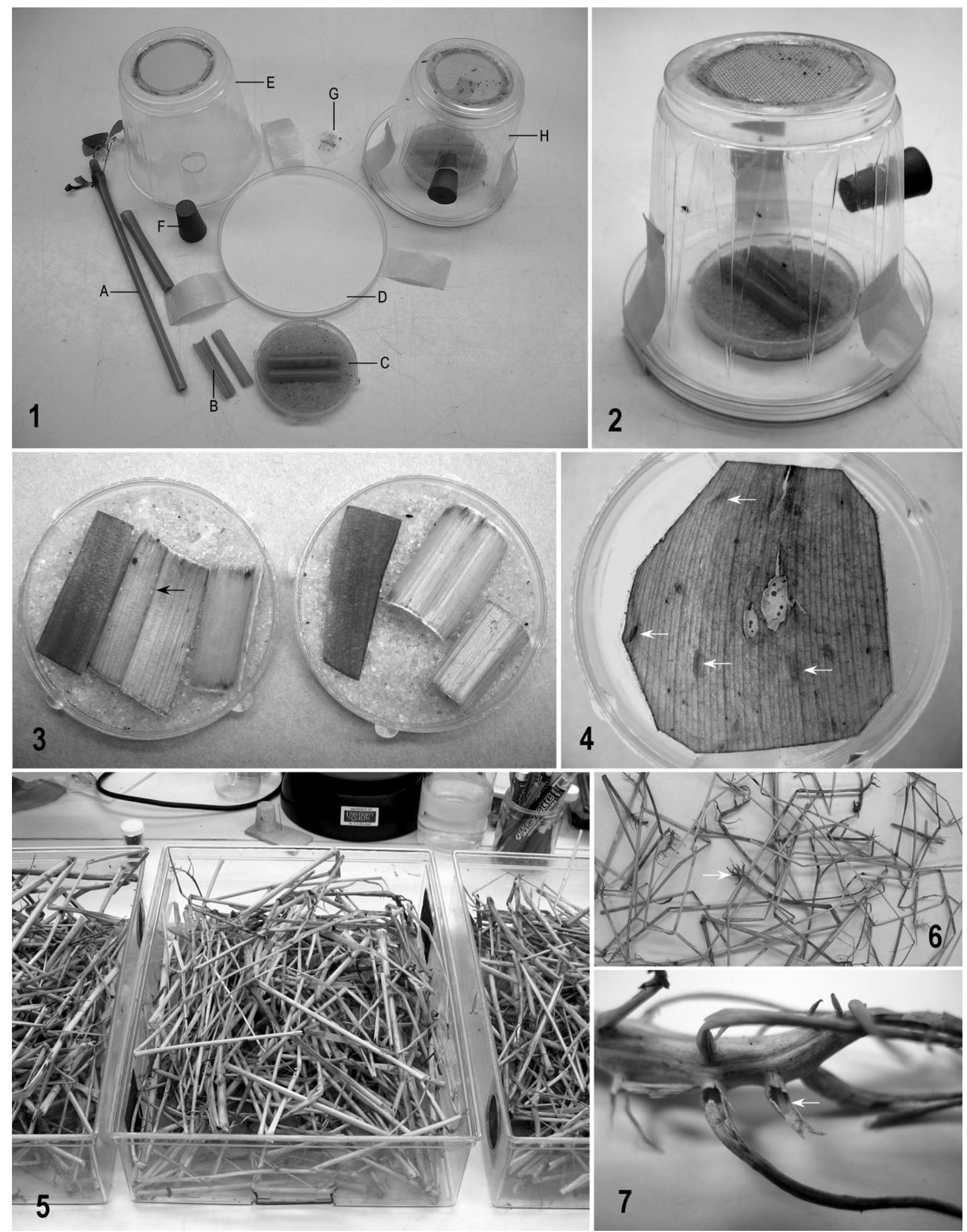

Figs 1-7. Rearing methods of Quametopia species: 1 - laboratory equipment for adult maintenance and oviposition (A - stem of Impatiens capensis, B - cut and split stem, $\mathrm{C}$ - pieces of split stem on sand in small (internal) Petri plate, D - bottom (external) Petri plate lined with filter paper, $\mathrm{E}$ - cup with screen bottom and lateral hole, F - rubber stopper, $\mathrm{G}$ - mixture (1:1) of ground sucrose and bee pollen, $\mathrm{H}$ - assembled cup cage); 2 - cup cage with adults of $Q$. terminalis used for oviposition; 3 - Petri plates with pieces of both Impatiens and Clintonia borealis for oviposition-choice trial (egg arrowed); 4 - a piece of dead Clintonia leaf with 3 larvae and 1 puparium inside (arrows); 5 - rearing boxes with dead stems of Impatiens; 6 - dead stems of Impatiens with roots (arrow), used for dissections; 7 - detail of hollow roots containing overwintering dipterous larvae (arrow). Photo: K.N. Barber. 
The small oviposition plate was replaced on a 3-4 day cycle and the eggs cleaned with a $2 \%$ solution of formaldehyde, rinsed in water, and transferred to damp filter paper in another small Petri plate. The plates of eggs were held under standard conditions, checked daily, and the filter paper moistened as required. Neonate larvae were transferred to split stems of $I$. capensis in small Petri plates (no sand), the stems checked daily, hydrated and replaced as required as the larvae developed.

Puparia were cleaned in dilute bleach, rinsed in water then individually held in small plastic pill vials at $20^{\circ} \mathrm{C}$. Larvae not pupariating by November were held over a simulated winter by placing them in small Petri plates with sections of $I$. capensis stems and maintained at $10^{\circ} \mathrm{C}, 12 \mathrm{~L}: 12 \mathrm{D}, 3$ November to 9 December, and then constant dark at $2^{\circ} \mathrm{C}$ until 17 March 2003 , then returned to standard conditions. The plates were checked, cleaned, and the stems replaced occasionally (from frozen supply) during the overwintering period. Other rearings of $Q$. terminalis used $5 \hat{\sigma}$ and $5 \%$ and $4 \hat{\sigma}$ and $4 \%$ collected at Birchwood Park, 29 July and 27 August 2010, respectively, principally to provide additional eggs and larvae.

Rearing of $\boldsymbol{Q}$. clintonia sp. n. On 23 August 2009, live adults of $Q$. clintonia sp. n. were collected from near Searchmont, Ontario (Whitman Dam Road - 20, $2 \%$, Ranger Lake Road $1 \%$ ). Cup cages and small Petri plates with wet sand and oviposition substrates were used and held at standard conditions.

Based on an oviposition trial (see below), short sections ( $\sim 3$ $\mathrm{cm}$ ) of $C$. borealis petioles were chosen as the initial larval rearing substrate. Neonate larvae were transferred to petioles where they readily entered the conductive channels of the severed ends. Surviving late-second instars were transferred to pieces of $C$. borealis leaf beginning 24 September. Pieces of leaf $(\sim 3 \times 3 \mathrm{~cm})$ were variously frozen then thawed, lightly heated, or allowed to "season" in water for a day or more before presentation. The limp leaf material adhered to the small Petri plate and larvae readily penetrated between the leaf surfaces along the severed edges (Fig. 4). The leaf pieces were hydrated as required. Additional rearings of $Q$. clintonia sp. n. used $2 \sigma^{\star}$ and $2 q$ collected at Batchawana Provincial Park, 20 September 2009, and $7 \delta$ and $5 \%$ collected at Lake Superior Provincial Park, 29 August 2010, principally to provide additional eggs and first-instar larvae for study.

Oviposition choices - $Q$. terminalis and $Q$. clintonia $\mathbf{s p .} \mathbf{n}$. On 23 August 2009, $2 \sigma^{\star}$ and $2 \%$ of $Q$. terminalis were collected from Birchwood Park (Sault Ste. Marie) for comparison with those of $Q$. clintonia (above). Small Petri plates with moist sand and sections of plant substrates were used in the two cup cages of $2 \hat{\delta}$ and $2 \%$ each for $Q$. clintonia and $Q$. terminalis and the lone female of $Q$. clintonia in a third cup cage. Choices of oviposition substrate were: a section of I. capensis stem $(\sim 3 \mathrm{~cm}$ longitudinally split, outer surface up); C. borealis petiole $(\sim 3$ $\mathrm{cm}$ of $\mathrm{V}$-shaped basal section of leaf, inverted with ventral surface up); and a piece of $C$. borealis leaf blade $(\sim 1 \times 3 \mathrm{~cm}$, dorsal surface up) (Fig. 3). Two oviposition periods of 3 days each were pooled for a total of 6 days beginning from 24 August.

Abbreviations of morphological terms used in text and/or figures:

$\mathrm{A}_{1}$ - anal vein

ac - acrostichal (seta)

afa - aedeagal part of folding apparatus

ag - accessory gland

an - "antenna" of larva

as - anus

asp - anterior spiracle (or spiracular process)

bm - basal membrane

$\mathrm{C}-$ costa

ce - cercus
$\mathrm{CP}$ - cephalic segment

$\mathrm{cp}$ - caudal process of transandrium

cps - cephalopharyngeal skeleton

cs - connecting sclerite

$\mathrm{Cs}_{3}, \mathrm{Cs}_{4}-3 \mathrm{rd}$, 4th costal section

$\mathrm{CuA}_{1}$ - cubitus

cup - posterior cubital cell

$\mathrm{da}$ - dorsal apodeme

$\mathrm{db}$ - dorsal bridge

$\mathrm{dc}-$ dorsocentral (seta)

dcr - dorsal cornu

$\mathrm{dm}-$ discal medial cell

$\mathrm{dm}$-cu - discal medial-cubital (= posterior, $\mathrm{t}_{\mathrm{p}}$ ) cross-vein

ds - dental sclerite

ea - ejacapodeme

ep - epandrium

es - epistomal plate

$\mathrm{f}$ - filum of distiphallus

$f_{1}, f_{2}, f_{3}$ - fore, mid, hind femur

$\mathrm{fc}-$ fulcrum of phallapodeme

gs - gonostylus

hl - hypandrial lobe

hu - humeral (= postpronotal) (seta)

hy - hypandrium

im - intermediate sclerite

is - internal sclerite(s)

isp - interspiracular process

ld - posteroventral lobe of distiphallus

$\mathrm{M}$ - media

ma-medandrium

$\mathrm{mh}$ - mouthhooks

$\mathrm{mp}$ - micropyle

MS - mesothoracic segment

$\mathrm{npl}$ - notopleural (seta)

oc - ocellar (seta)

or - oral ridges

ors - orbital (seta)

$\mathrm{pa}$ - postalar (seta)

$\mathrm{pb}$ - parastomal bar

$\mathrm{pg}$ - postgonite

pha - phallapodeme

$\mathrm{pp}$ - phallophore

ppl - propleural (= proepisternal) (seta)

$\mathrm{PR}$ - prothoracic segment

prg - pregonite

prs - presutural (seta)

psp - posterior spiracle (or spiracular process)

$\mathrm{pt}$ - peritreme

pvt - postvertical (seta)

$\mathrm{r}-\mathrm{rib}$

$\mathrm{R}_{1}, \mathrm{R}_{2+3}, \mathrm{R}_{4+5}-1 \mathrm{st}, 2 \mathrm{nd}$, 3rd branches of radius

$\mathrm{r}-\mathrm{m}$ - radial-medial (= anterior, $\mathrm{t}_{\mathrm{a}}$ ) cross-vein

$\mathrm{s}-$ saccus of distiphallus

S1-S10 - abdominal sterna

sa - supraalar (seta)

sc - scutellar (seta)

$\mathrm{Sc}-$ subcosta

$\mathrm{sp}$ - spermatheca

ss - spiracular slit

stpl - sternopleural (= katepisternal) (seta)

T1-T10 - abdominal terga

$\mathrm{T} 7+\mathrm{S} 7$ - tergosternum of 7 th abdominal segment

$t_{1}, t_{2}, t_{3}-$ fore, mid, hind tibia

ta - transandrium

ver - ventral cornu

vi - vibrissa 
vpr - ventral pharyngeal ridges

vr - ventral receptacle

vte - outer vertical (seta)

vti - inner vertical (seta)

\section{Genus Quametopia gen. n.}

Type species: Anthophilina terminalis Loew, 1863: 324 (herewith designated)

Etymology. The new genus is named Quametopia (= an abbreviated conjunction of Qua[m $+\mathrm{Mu}]$ metopia, gender feminine) because its type species was originally included in Mumetopia Melander, 1913, a similarly looking [Latin quam = like, as] genus of Anthomyzidae.

\section{Diagnosis}

(1) Head slightly higher than long. (2) Eye large, suboval, with longest diameter oblique. (3) Frons relatively wide; frontal triangle distinct, relatively large. (4) Frontal lunule very reduced but visible. (5) Occiput slightly concave, without silvery white microtomentum above foramen. (6) Antenna geniculate between pedicel and 1st flagellomere, the latter laterally compressed. (7) Arista long-ciliate, never pectinate. (8) Palpus yellow to brown, with 1 dark terminal (preapical) seta and several ventral setulae. Cephalic chaetotaxy: (9) pvt small, parallel, convergent to crossed; (10) vte, vti, oc long, vti and oc longest of cephalic setae; (11) 2 ors, anterior only onethird to half length of posterior ors, 1 microsetula in front of anterior ors; (12) a row of short but rather dense postocular setulae; (13) 1 long vi and 1 shorter and weaker but well-developed subvibrissa; (14) peristomal setulae small. (15) Palpus, face and sometimes also antenna sexually dichroic, pale in male (Figs 8, 11), dark (or partly darkened) in female (Figs 9, 12).

(16) Thorax slightly narrower than head. Thoracic chaetotaxy: (17) 1 fine but distinct hu, $2 \mathrm{npl}$ (anterior longer); (18) 1 well-developed prs (as long as or longer than hu); (19) 1 shorter sa, 1 longer pa; (20) 2 long postsutural dc (posterior longest of thoracic setae, also anterior relatively long); (21) ac microsetae in 4 rows on suture, in 2-4 between anterior dc; (22) 2 sc (apical long, basal short and weak); (23) 1 minute, pale hair-like ppl; (24) 2 stpl (posterior always longer) and 3-7 upcurved setulae near them. (25) Legs pale yellow, only apical segment of all tarsi (sometimes 2 apical segments of fore tarsus) dark brown; (26) $f_{1}$ with medium-long ctenidial spine inserted distinctly apicad of longest seta of posteroventral row of setae; (27) $t_{2}$ with distinct but relatively short ventroapical seta; (28) male $f_{3}$ with posteroventral row of shortened and thickened setae. (29) Wing (Figs 31-33) fully developed, long, never reduced; (30) wing membrane unicolourous. (31) $\mathrm{C}$ with distinct spinules between apices of $\mathrm{R}_{1}$ and $\mathrm{R}_{2+3}$; (32) $\mathrm{R}_{2+3}$ very long, parallel to $\mathrm{C}$, apically slightly upcurved to $C$; (33) $R_{4+5}$ subparallel or apically very slightly divergent from $\mathrm{M}$; (34) cell dm relatively long, tapered basally, wide distally; cross-vein r-m slightly oblique, situated in about middle of dm cell; (35) $\mathrm{CuA}_{1}$ almost reaching wing margin, $\mathrm{A}_{1}$ ending far from it; (36) alula small but distinct.

Male abdomen: (37) T1 separate from T2; (38) T2-T5 large and broad; (39) preabdominal sterna (S2-S5) nar- row, somewhat paler than associated terga, becoming slightly wider posteriorly. Male postabdomen (Fig. 106): (40) T6 reduced, bare, short, transverse, medially unpigmented; (41) S6 and S7 strongly asymmetrical, partly fused and situated laterally, each with 0-1 seta; (42) S8 relatively large, less asymmetrical, situated dorsally and setose.

Male genitalia (Figs 13-21): (43) Epandrium small compared to pregenital sclerites, always wider than high, with dorsal margin convex, with moderately dense setae, 1-2 pairs of which longer than others. (44) Medandrium $\mathrm{X}$-shaped because of projecting dorsolateral corners and strongly prolonged ventrolateral arms which bear 2-3 setulae each (cf. Fig. 14). (45) Cercus weakly sclerotized, shortly and finely setose; both cerci with apices approximating to attached medially. (46) Gonostylus bilobed, with anterior lobe longer, clavate and setose, and posterior lobe short, stump-like, wrinkled but lacking setosity. (47) Hypandrium simple, with internal lobes membranous, small, little or not projecting dorsally; (48) transandrium simple, transverse, without caudal process, weakly sclerotized except for thin dorsal ledge. (49) Pregonite reduced, fused to hypandrium and bent medially, forming 1-2 shallow lobes in lateral view, with 3-4 internal setae. (50) Postgonite medium-sized, slightly bent, with 1-2 setae on anterior margin and with apex fused to distal end of connecting sclerite. (51) Phallapodeme with deeply forked base and rather simple apex having, at most, small lateroventral corners. (52) Aedeagus with phallophore small, frame-shaped, but longer than high. (53) Distiphallus large, composed of voluminous membranous saccus and slender sclerotized filum. (54) Proximal part of distiphallus anterolaterally setulose and additionally provided basally with large, laterally flattened posteroventral lobe (Fig. 18, ld). (55) Saccus with only very fine spinules (more on right side), and sometimes with a few hyaline tubercle-like spines internally. (56) Filum formed by a pair of dark ribbon-shaped sclerites ending in membranous narrowly lanceolate apex provided with several denticles. (57) Aedeagal part of folding apparatus dark and strongly sclerotized in dorsal slender part and with pigmented tuberculiform excrescences on broader area more ventrally (Figs 18, 110); connecting sclerite well developed, long, darker proximally, paler and finely spinulose distally and apically firmly connected with apex of postgonite. (58) Basal membrane finely spinulose posteroventrally below transandrium (Fig. 21) and with finely granulose area laterally (Fig. 20). (59) Ejacapodeme relatively large, with digitiform projection distally somewhat widened.

(60) Female abdomen with broader terga and narrower sterna than in male. (61) Postabdomen (Figs 23-25) relatively broad, short but somewhat retractable from 7 th segment. (62) T6 and S6 normal, T6 large, more or less tapered posteriorly. (63) T7 and S7 fused to form annular tergosternum characterized by medially unpigmented (seemingly divided) dorsal part and by ventral part (original S7) partially separated by narrow ventrolateral incisions (see Fig. 24). (64) T8 plate-shaped, slightly 

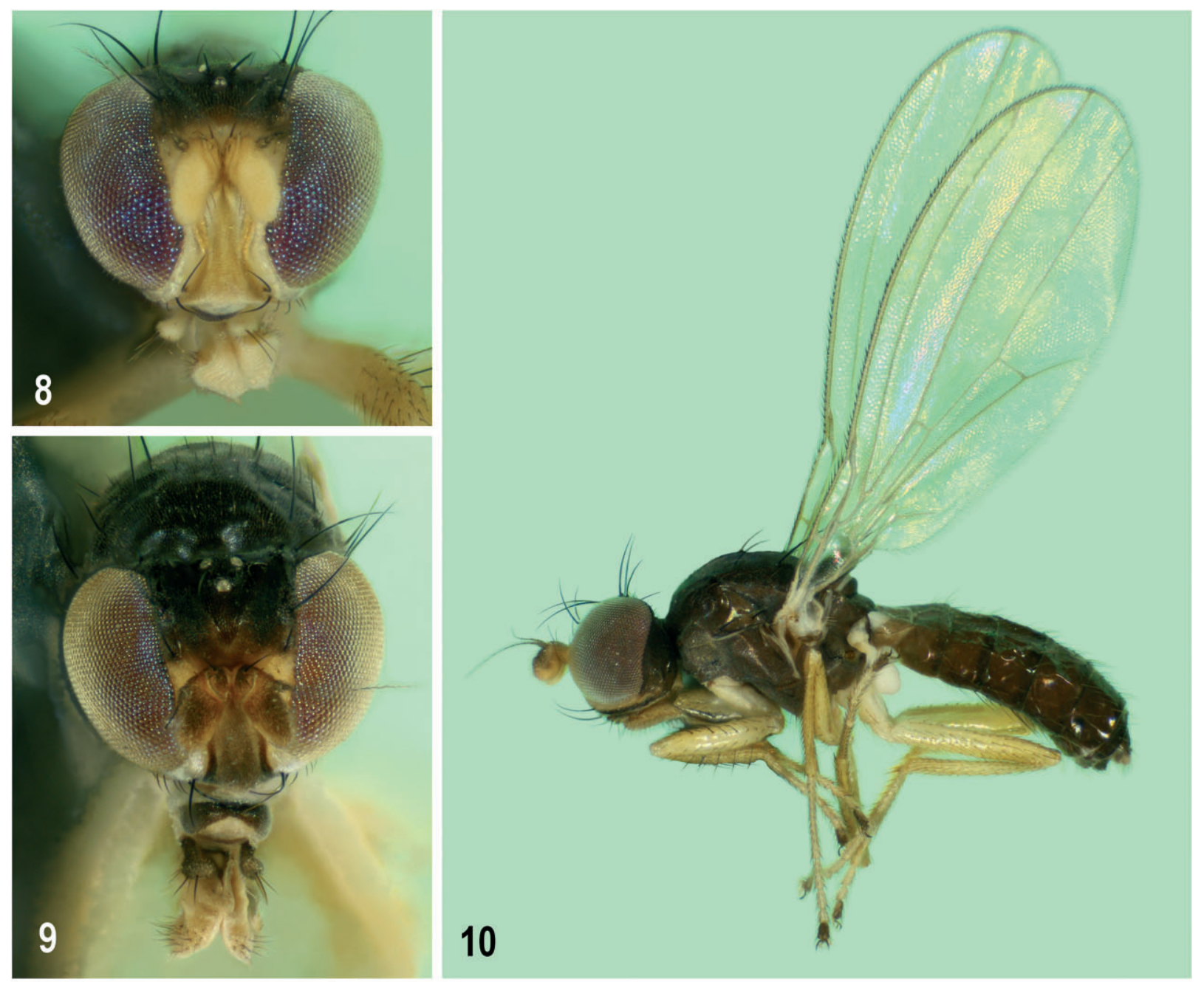

10
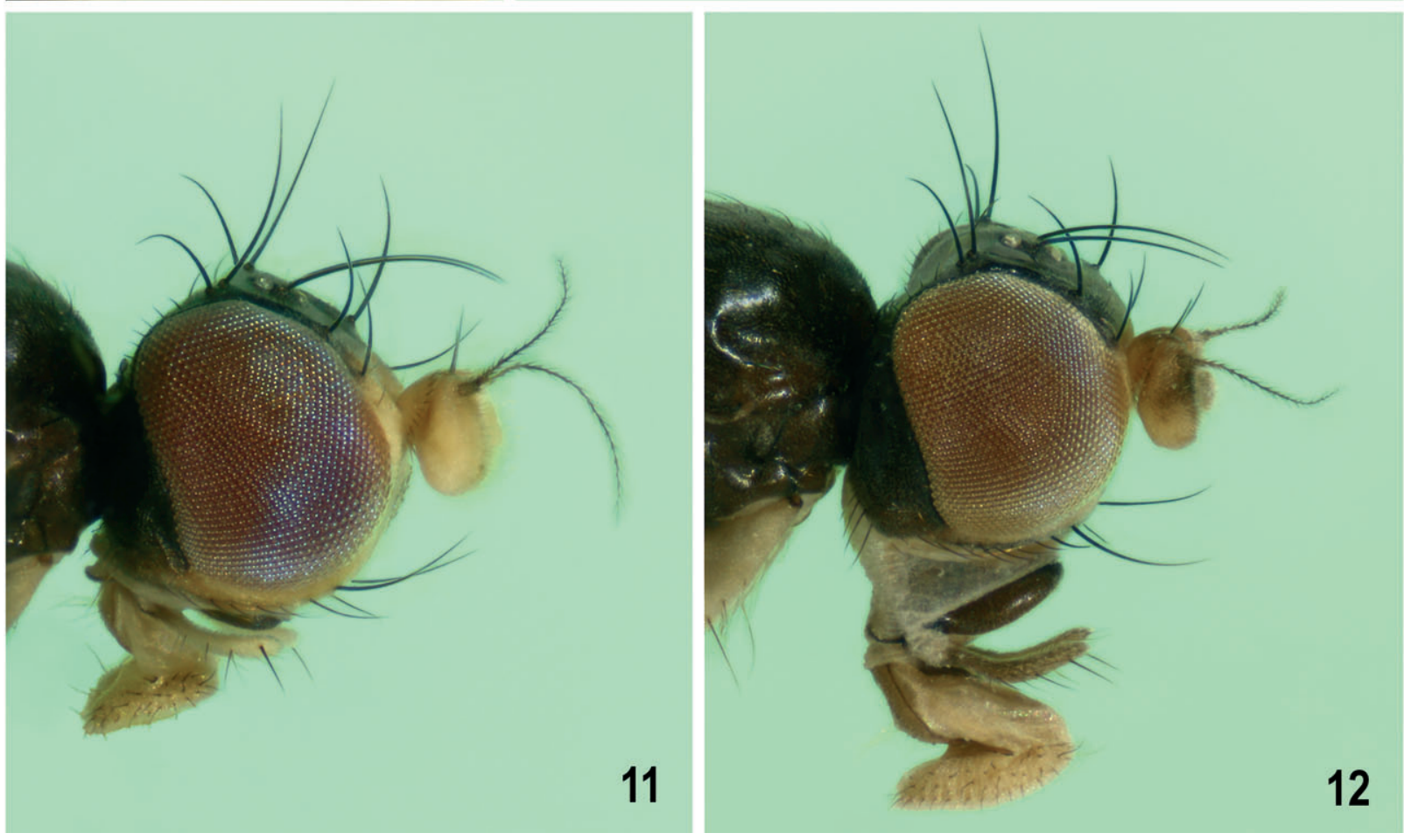

Figs 8-12. Quametopia terminalis (Loew), male, female (Canada: Ontario): 8 - male head, frontally; 9 - female head, frontally; 10 - female, habitus, laterally (body length $2.7 \mathrm{~mm}$ ); 11 - male head, laterally; 12 - female head, laterally. Photo: M. Deml. 
transverse with corners rounded, dark, sparsely setulose; (65) S8 short, transverse, posteromedially bulging and posterodorsomedially somewhat incised (Fig. 22). (66) Internal sclerotization (Figs 27, 28) of female genital chamber (uterus) formed by 3 pairs of flat, crooked and partly fused posterior sclerites (some may be secondarily desclerotized or unpigmented) and (67) 1 anterior slender, relatively long and broad annular sclerite. (68) Anterior part of uterus provided with a small, short, membranous, hyaline, bent, tube-like ventral receptacle with rounded apex (Fig. 30). (69) Accessory glands (Fig. 30) inconspicuously vesiculate, on ringed, terminally slightly to hardly dilated ducts. (70) Spermathecae $(1+1)$ elongately irregularly spindle-shaped, thus with both ends tapered; distal end often curved, rugged and provided with blunt processes, particularly on apex; proximal end subcylindrical, with a crown of blunt erect spine-like tubercles; spermathecal duct without sclerotized cervix (Fig. 26). (71) T10 small, short and transverse, with 1 pair of posteromedial dorsal setae; (72) S10 much larger than T10, about as long as wide, with anterior part bare, posterior part micropubescent (Fig. 29). (73) Cercus relatively short and with rich but rather short setae and very short micropubescence.

\section{Discussion}

The new genus Quametopia is established to accommodate a species formerly treated as Mumetopia terminalis plus two other closely allied species described below. Despite a striking external resemblance (e.g. shortened anterior ors, long frontal triangle, ctenidial spine on $f_{1}$, sparsely microtomentose and relatively shiny body, distinct prs) of Quametopia gen. n. to several other genera of Anthomyzidae including Mumetopia, but also Arganthomyza Roháček, 2009, Paranthomyza Czerny, 1902 and Carexomyza Roháček, 2009, we describe Quametopia as a separate genus because of its several distinctive apomorphies some being unique (U) within the entire family. These particularly include: (15) palpus, face and sometimes also antenna sexually dichroic; (41) male S6 and S7 each with only 0-1 seta; (44) medandrium with strongly prolonged ventrolateral arms bearing 2-3 setulae each (U); (45) male cerci with apices approximating to attached medially (U); (46) gonostylus bilobed (U); (54) proximal part of distiphallus basally with large, unpaired, laterally flattened posteroventral lobe (U); (57) connecting sclerite spinulose distally and firmly connected with apex of postgonite; (59) ejacapodeme relatively large; (63) female T7 and S7 forming annular tergosternum having medially unpigmented dorsal part and ventral part (original S7) partially separated by narrow ventrolateral incisions; (70) spermathecae $(1+1)$ elongately irregularly spindle-shaped, with distal end rugged, provided with blunt processes and often curved, and proximal end with a crown of spine-like tubercles (U).

The comparison of the characters listed in the above diagnosis of Quametopia with those known in all other described genera of Anthomyzidae, contrary to our expectations, resulted in finding that although Quametopia surely does not belong to the Chamaebosca clade, it is obviously more closely allied to it than Cercagnota Roháček \& Freidberg, 1993 (recognized as sister group to the Chamaebosca clade by Roháček \& Barber, 2009: 212-213), particularly because of the similarly formed female postabdomen. The following synapomorphies demonstrate this relationship: Female T7+S7 dorsomedially membranous or divided; female $\mathrm{S} 8$ short and posterodorsomedially (although not deeply) incised (however, in contrast to the members of the Chamaebosca clade, it is posteromedially protruding as in the unrelated genus Amygdalops Lamb, 1914 - cf. Roháček, 2004, 2008); posterior internal sclerites of female genital chamber well developed; spermathecae with surface spines (although different from those in representatives of the Chamaebosca group of genera). Also the formation of the female tergosternum $\mathrm{T} 7+\mathrm{S} 7$, where the original $\mathrm{S} 7$ is partly delimited, is more similar to that in some members (Stiphrosoma and Mumetopia nigrimana-group, see Roháček \& Barber, 2009) of the Chamaebosca group of genera than to that of Cercagnota where S7 is completely integrated into the tergosternal ring without traces of its original boundary. Considering the characters discussed above, Quametopia can be considered a sister group to the Chamaebosca group of genera instead of Cercagnota (but for differences in the male genitalia see below).

Only a few of the male genital characters may indicate affinity of Quametopia to the Chamaebosca clade, e.g. the sclerotized and dark-pigmented dorsal section of the aedeagal part of folding apparatus (occurring in several genera of the Chamaebosca clade but also in Cercagnota) or the prolonged dorsolateral corners of the medandrium (being, however, much longer in some genera of the Chamaebosca clade). However, generally, the synapomorphic features of the male genitalia of the Chamaebosca group of genera are lacking in Quametopia where only the most plesiomorphic condition can be found, viz. in postgonite (slender and simple, with only single seta), filum of distiphallus (bare and formed by 2 ribbon-shaped sclerites), saccus of distiphallus (at most with sparse microspinules and flat tubercles), male cercus (simple, not projecting), caudal process of transandrium (absent), gonostylus (disparate and micropubescent).

The genus Quametopia includes three species, all occurring in the Nearctic Region: Q. terminalis, Q. clintonia sp. n. and Q. amplistylus sp. n. Although their morphological differences are relatively small, some of them (mainly those in genitalic structures of both sexes) proved to be stable and enabled confident identification of these closely related species. Moreover, the recognized species (at least as regards $Q$. terminalis and $Q$. clintonia sp. n.) seem to differ significantly in their biology (habitat preference and host-plant association). Quametopia terminalis is most different from the remaining two species and apparently forms a sister-taxon to the $Q$. clintonia $+Q$. amplistylus pair which shares several synapomorphies, e.g. shortened posterior lobe of gonostylus, reduced anterior lobe of pregonite, elongate dorsal pair and reduced lateral pair of internal sclerites in female genital chamber. The species of Quametopia are keyed and treated in fur- 


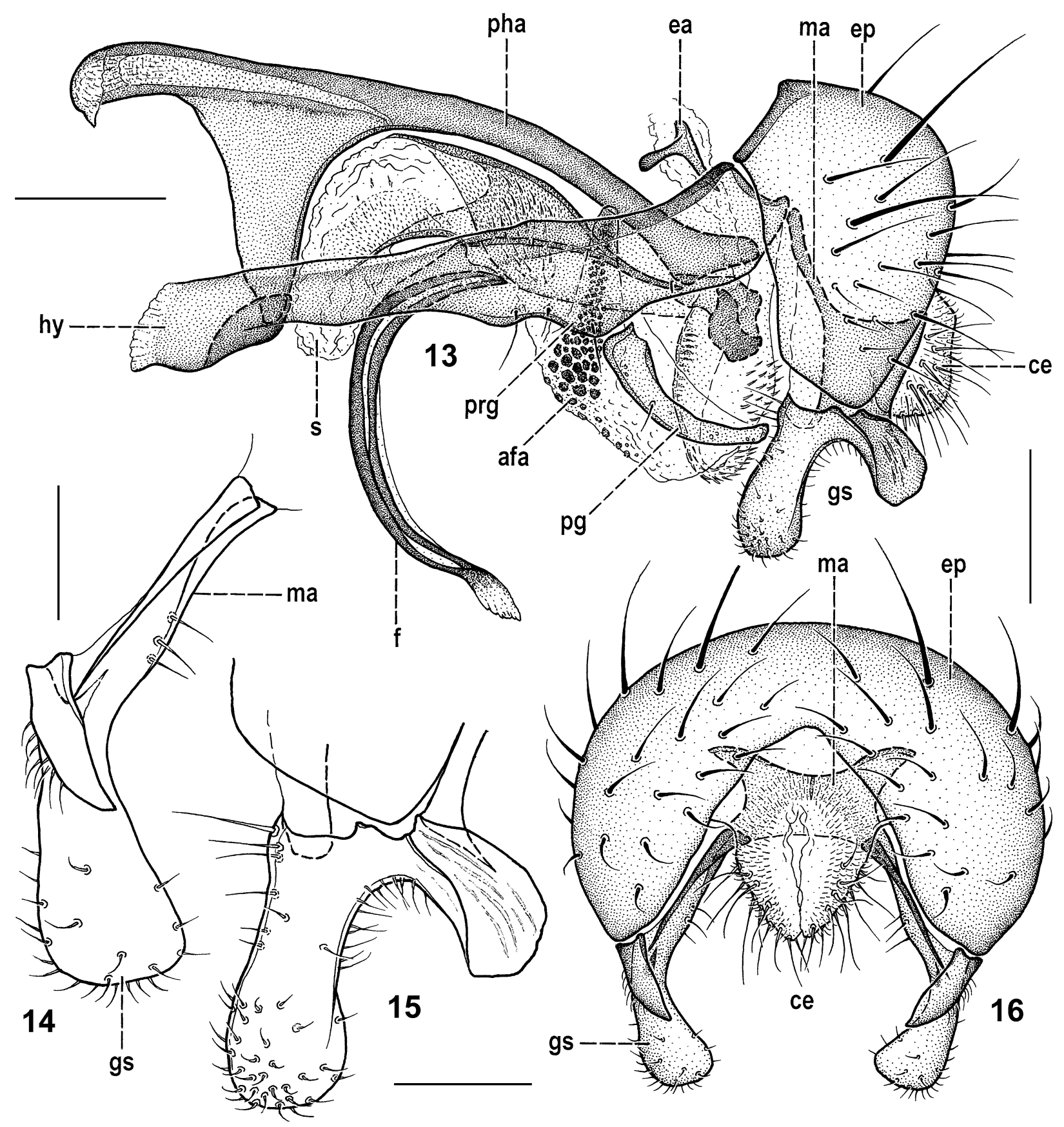

Figs 13-16. Quametopia terminalis (Loew), male (Canada: Ontario): 13 - genitalia, laterally; 14 - left gonostylus and left ventral part (lateral arm) of medandrium, posteriorly; 15 - left gonostylus, sublaterally (widest extension); 16 - external genitalia, caudally. Scales: Figs $14-15=0.05 \mathrm{~mm}$, others $=0.1 \mathrm{~mm}$. For abbreviations see text.

ther detail according to their presumed relationships below.

Discussion of pre-imaginal stages. Immature stages of Quametopia species (see below under Q. terminalis and Q. clintonia sp. n.) can be compared with only those few known in Anthomyzidae, viz. in the genera Anagnota (Roháček \& Freidberg, 1993, egg, 3rd-instar larva and puparium), Anthomyza (Roháček, 1986, egg; Roháček, 2009, 3rd-instar larva and puparium), Barbarista (Roháček, 1993, egg), Paranthomyza (de Meijere, 1944, 3rd-instar larva; Roháček, 2009, puparium), Santhomyza (Roháček \& Baez, 1988, egg), Stiphrosoma (Nye, 1958, 3rd-instar larva) and Typhamyza (Roháček, 1992, egg, 3rd-instar larva and puparium). Larvae of 1 st and 2 nd instars have not been previously known in the family Anthomyzidae and are here described for the first time in Quametopia. Consequently, only structures of the egg, 3rd-instar larva and puparium allow some comparison at the generic level.

Our study of the 1st-instar larva in $Q$. terminalis and $Q$. clintonia sp. n. revealed that it is metapneustic (possessing only posterior spiracles) and its cephalopharyngeal skeleton hardly sclerotized and pale-pigmented, with an unpaired medial mouthhook, a few oral ridges, and a 


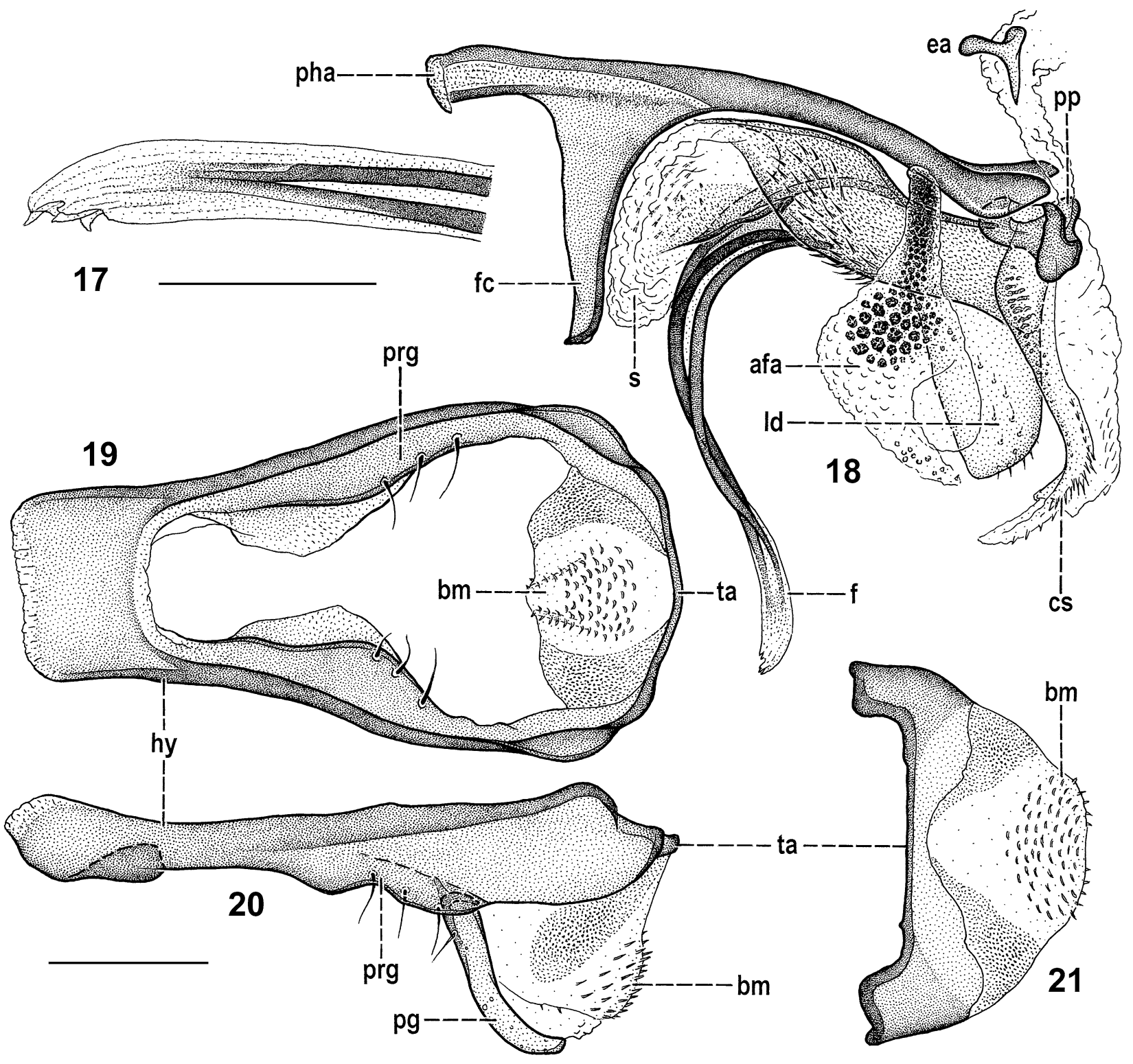

Figs 17-21. Quametopia terminalis (Loew), male (Canada: Ontario): 17 - apex of filum, subventrally (widest extension); 18 aedeagal complex, laterally; 19 - hypandrial complex, ventrally (postgonite omitted); 20 - ditto, laterally; 21 - transandrium, caudally. Scales: Fig. $17=0.05 \mathrm{~mm}$, others $=0.1 \mathrm{~mm}$. For abbreviations see text.

posterior spiracle lacking peritreme but having 2 spiracular slits. Interestingly, the unpaired median mouthhook has hitherto not been recorded in other families of Opomyzoidea but, following Ferrar (1987), the 1st-instar larvae were only described in three of its families, viz. in Agromyzidae, Aulacigastridae and Opomyzidae (the latter is considered to be the sister-group of Anthomyzidae, cf. Roháček, 1998) all of which have normally paired mouthhooks in this larval instar; the only exception is an extremely modified larva of Phytobia cambii (Hendel, 1931) (Agromyzidae), a cambium-miner, where all instars have an unpaired median mouthhook. The 2nd-instar larva, on the contrary, is already amphipneustic and its cephalopharyngeal skeleton (including paired mouthhooks) is similar to that of 3rd-instar larva but its anterior spiracle is simply clavate (with single slit) and the poste- rior spiracle has 2 spiracular slits as in that of the 1stinstar larva but with a well-developed peritreme.

Eggs of Quametopia species clearly have a surface structure different from those hitherto known in Anthomyzidae. Both the longitudinal elevated ribs (ridges, ledges) and the finely reticulate chorion surface have already been described in Anthomyza macra (cf. Roháček, 1986) but the number and position of these ribs is different (8 in Anthomyza macra, 4 in Quametopia spp.) as also is the extent of reticulation between them. The fine reticulate chorion surface structure on the ventral side of the egg also occurs in Anagnota coccinea (cf. Roháček \& Freidberg, 1993) while longitudinal ribs (laterodorsal and dorsal) are also developed in the afrotropical Barbarista guttata (see Roháček, 1993). However, eggs of Quametopia spp. differ from all above- 


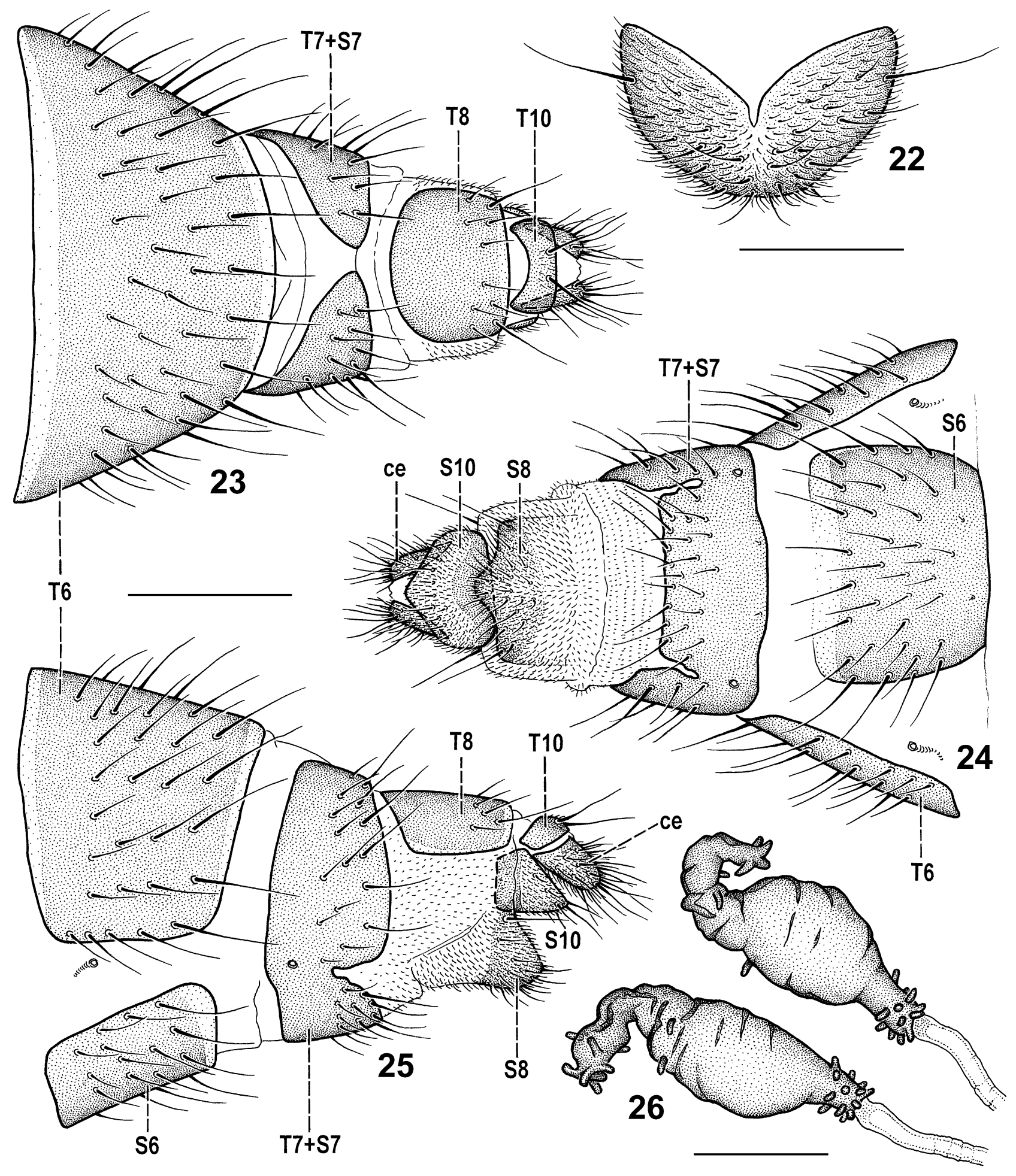

Figs 22-26. Quametopia terminalis (Loew), female (Canada: Ontario): 22 - S8 caudally; 23 - postabdomen, dorsally; 24 - ditto, ventrally; 25 - ditto, laterally; 26 - spermathecae. Scales: Fig. $22=0.1 \mathrm{~mm}$, Fig. $26=0.05 \mathrm{~mm}$, others $=0.2 \mathrm{~mm}$. For abbreviations see text.

mentioned taxa in having transverse reticulation between ribs also on the dorsal side and even laterally.

The 3rd-instar larva is known in several genera of Anthomyzidae but only structures of the cephalopharyngeal skeleton, anterior and posterior spiracles were described in sufficient detail to allow some comparison. The cephalopharyngeal skeleton in Quametopia spp. has mouthhooks most similar to those of Stiphrosoma sabulosum (Haliday, 1837) (see Nye, 1958), Paranthomyza nitida Meigen, 1838) (see Roháček, 2009) and Anagnota bicolor (Meigen, 1838) (see Roháček \& Freidberg, 1993) in having its middle part distinctly projecting ventrally; it differs, however, from these species by the posterior part being also extended ventrally so embracing the dental 
sclerite both anteriorly and posteriorly. Only the mouthhook of $A$. bicolor is posteriorly somewhat dilated but in this species this end is also deeply incised posteriorly (cf. Roháček \& Freidberg, 1993: Fig. 23). The intermediate sclerite (im) of Quametopia differs from those known in other genera in having the ventral connecting bridge divided into two parts, a short more sclerotized and darker posterior and a long and paler anterior. Only $P$. nitida (see Roháček, 2009) has this structure somewhat similar. The latter species and A. bicolor also have the most similar pharyngeal sclerite differing only in the larger dorsal apodeme on the ventral cornua. The anterior spiracular process of Quametopia spp. resembles most those of Anthomyza and Anagnota in having a palmate shape with 5-6 papillae. Note: $S$. sabulosum may also be similar in this structure having 3-5 (usually 4, but Nye, 1958 illustrated only 3 ) finger-like papillae. The posterior spiracle is most similar to that of $P$. nitida (cf. Roháček, 2009) but of the same general structure as in other Anthomyzidae. It is to be stressed that the dorsolateral bulges of the last abdominal segment (in front of posterior spiracles) could be an additional diagnostic character of Quametopia because it can also be recognised in the puparium (see below) and was hitherto not found in puparia (posterior part of 3rd-instar larva has only been known in Typhamyza, see Roháček \& Freidberg, 1993) of other genera (Anagnota, Anthomyza, Paranthomyza, Typhamyza).

Puparia of Quametopia species superficially most resemble that of $P$. nitida, because of the rugose surface structures (ribs), particularly on the anterior and posterior parts of the body. The other known puparia in Anthomyzidae either have a much finer surface structure (Anagnota bicolor, Anthomyza collini Andersson, 1976) or the puparium is strikingly dorsoventrally flattened [Typhamyza bifasciata (Wood, 1911)]. The shapes of the anterior and posterior spiracles of the puparium of Quametopia species are only slightly modified (i.e. sclerotized and somewhat shortened) from those of the 3rd-instar larva so it is unnecessary to repeat the features discussed above.

\section{Keys to identification of Quametopia species}

\section{Adults}

1 Male. Face and palpus brightly yellow. .......... 2

- Female. Face and palpus at least partly ochreous to brownish......................

2 Gonostylus (Figs 121-128) with posterior lobe longer, about half length of anterior lobe, with micropubescence reaching to about half of posterior side of anterior lobe (Fig. 15). Pregonite with distinct anterior lobe and postgonite more curved (Fig. 20). Ejacapodeme with digitiform projection shorter, at most as long as body of ejacapodeme (Fig. 18) and somewhat clavate. Apex of filum more acute and with larger denticles near tip (Fig. 17).... Q. terminalis (Loew) Gonostylus (Figs 129-137) with posterior lobe short, only about third length of anterior lobe, with micropubescence extended on outer side of anterior lobe (Figs 78, 109). Pregonite with anterior lobe reduced and postgonite straighter (Figs 77, 111). Ejacapodeme with digitiform projection more slender and longer than body of ejacapodeme (Figs 79, 110). Apex of filum not acute or truncate, with minute denticles on tip (Figs 80,112). . . . . . . . . . . 3
3 Anterior lobe of gonostylus (Fig. 78) shorter and its distal end slightly clavate (Figs 129-133); micropubescence on outer side of anterior lobe of gonostylus almost reaching apex (Fig. 78). Epandrium narrower in caudal view (Fig. 74). Saccus with only fine spinules (Fig. 79). Apex of filum hardly widened; dark ribbon-like sclerites of filum only meeting subterminally (Fig. 80)...... Q. clintonia sp. n.

- Anterior lobe of gonostylus (Fig. 109) longer and its distal end expanded posteriorly (Figs 134-137); micropubescence of anterior lobe of gonostylus restricted to posterior part of outer side and not reaching to apical third (Fig. 109). Epandrium broader in caudal view (Fig. 107). Saccus with several internal tuberculiform spines in addition to external spinules (Fig. 110). Apex of filum somewhat widened, lanceolate or truncate; dark sclerites of filum crossed subterminally (Fig. 112)............. Q. amplistylus sp. n.

4 Antenna with 1st flagellomere brownish on inner side and below insertion of arista on outer side (see Figs 9, 12). Internal sclerotization of genital chamber with 3 pairs (dorsal, lateral and ventrocaudal) of short and partly fused sclerites (Fig. 28). Spermathecae (Fig. 26) usually with more or less strongly curved distal end...... Q. terminalis (Loew) - Antenna (Fig. 104) with 1st flagellomere entirely yellow or orange-yellow (as in male). Only 2 pairs (lateral sclerite reduced) of internal sclerites in genital chamber; dorsal sclerites distinctly longer (Figs 86, 120). Spermathecae (or one of them) usually with distal end straighter (Figs 85, 119)

........

5 S6 narrower and less densely setose (Fig. 84). S10 with anterior bare area larger (Fig. 82) and less abruptly separated from short posterior micropubescent part. Genital chamber with internal dorsal sclerite longer (Fig. 86). Spermathecae more slender (Fig. 85)...... Q. clintonia sp. n.

- S6 wider and more densely setose (Fig. 118). S10 with anterior bare area smaller and shorter (Fig. 115) and strongly abruptly separated from posterior micropubescent part (Fig. 120). Genital chamber with internal dorsal sclerite shorter (Fig. 120). Spermathecae more robust, with larger maximum diameter (Fig. 119) . . . . . . . . Q. amplistylus sp. n.

Eggs (unknown for Q. amplistylus sp. n.)

1 Body of egg usually more slender (Figs 35-37). Chorion with ventral reticulate area with 3 rows of transverse meshes margined (separated from a narrow row of meshes and lateral rib) by only an inconspicuous line (Fig. 37). . . . . . .

Q. terminalis (Loew) Body of egg usually more robust, wider (Figs 38-40). Ventral reticulate area with 3 rows of transverse meshes margined by a distinctly elevated ledge (Fig. 40) . . . . . . . . ........................ Q. clintonia sp. n.

Larvae (unknown for $Q$. amplistylus sp. n.)

1 Small, body length $0.9-1.6 \mathrm{~mm}$. No anterior spiracle. Cephalopharyngeal skeleton weakly sclerotized, unpigmented and with unpaired medial mouthhook (Figs 48-49). 1st-instar larva. . . . . . . . . . . . . . . . . . . . . . 2

- Larger, body length 1.6-5.0 mm. Anterior spiracle present, at least as simply clavate projection (Fig. 58) or palmate with 5-6 papillae (Fig. 62). Cephalopharyngeal skeleton at least partly sclerotized and pigmented, with paired mouthhooks (Fig. 61) . . . . . . . . . . . . . . . . . 3

2 Ventral spinules at posterior margin of cephalic segment in 5-6, partly incomplete, rows (Fig. 50). Dorsal cornu of cephalopharyngeal skeleton more robust and only slightly shorter than ventral cornu (Fig. 47); mouthhook longer and more acute; parastomal bar more slender (Fig. 48). . . . . . . . $\ldots \ldots \ldots \ldots \ldots \ldots \ldots$. . . terminalis (Loew) 
- Ventral spinules at posterior margin of cephalic segment in only 3-4, partly incomplete, rows (Fig. 89). Dorsal cornu of cephalopharyngeal skeleton more slender and markedly shorter than ventral cornu (Fig. 87); mouthhook shorter and less acute; parastomal bar thicker (Fig. 88).

Smaller, body length $1.6-2.9 \mathrm{~mm}$. Anterior spiracle simply clavate with single slit (Fig. 58). Posterior spiracle smaller, with only 2 spiracular slits (Fig. 57). 2nd-instar larva. . . . . 4

- Larger, body length $3.0-5.0 \mathrm{~mm}$. Anterior spiracle palmate, with 5-6 terminal papillae (Fig. 62). Posterior spiracle larger, with 3 spiracular slits (Fig. 63). 3rd-instar larva. . . . 5

4 Anterior clavate spiracle more robust, broad (Fig. 58) Mouthhooks with distinct additional ventral tooth in concavity between apex and ventral middle process (Fig. 55). Dorsal cornu of cephalopharyngeal skeleton almost as long as ventral cornu (Fig. 54).......... Q. terminalis (Loew)

- Anterior clavate spiracle more slender, narrow (Fig. 91). Mouthhooks with a minute spine-like denticle in concavity between apex and ventral middle process (Fig. 92). Dorsal cornu of cephalopharyngeal skeleton distinctly shorter than ventral cornu (Fig. 90). . . . . . . . . Q. clintonia $\mathrm{sp.} \mathrm{n.}$

5 Mouthhooks with middle projection shorter and less projecting laterally (Fig. 61); dental sclerite smaller and shorter (Fig. 60); intermediate sclerite with ventral connecting bridge anteriorly pale-pigmented and its short posterior protruded part rounded and simply dark-pigmented (Fig. 61). Dorsal cornu of cephalopharyngeal skeleton almost as long as ventral cornu (Fig. 60)......... Q. terminalis (Loew) Mouthhooks with middle projection longer and more projecting laterally (Fig. 94); dental sclerite larger and longer (Fig. 93); intermediate sclerite with ventral connecting bridge anteriorly dark-pigmented and its short posterior protruded part anteriorly more acute and darkened only medially (Fig. 94). Dorsal cornu of cephalopharyngeal skeleton distinctly shorter than ventral cornu (Fig. 93).

. clintonia $\mathrm{sp} . \mathrm{n}$

Puparia (unknown for Q. amplistylus sp. n.)

1 Body slightly narrower and more parallel-sided (Figs 68-70). First (= cephalic + prothoracic) segment dorsally anteromedially with or without shallow emargination (Fig. 99), ventrally with dark palmately branched ornamentation having solid black base narrower (Fig. 100). Mesothoracic and metathoracic (2nd and 3rd) segments dorsally with dense coarsely ribbed sculpture in the middle (Fig. 99). Posterior end with dense transverse ribs on precaudal segment and area behind anus with a pair of elongate tubercle-like swellings (Fig. 101). Posterior stump-like spiracular processes situated on broadened subconical bases (Fig. 101). . . . Q. terminalis (Loew) Body slightly wider in the middle and hence more convex laterally (Figs 102-103). First segment dorsally anteromedially with distinct emargination (Fig. 96), ventrally with dark palmately branched ornamentation having solid black base broader, subcircular (Fig. 97). Meso- and metathoracic (2nd and 3rd) segments dorsally with sparse ribbed sculpture in the middle (Fig. 96). Posterior end with sparse ribs on precaudal segment and area behind anus with several ribshaped tubercles (Fig. 98). Posterior stump-like spiracular processes without subconical bases (Fig. 98). . . . . . . . .

$\ldots \ldots \ldots \ldots \ldots \ldots \ldots \ldots$. clintonia $\mathrm{sp} . \mathrm{n}$.

Quametopia terminalis (Loew, 1863) comb. $\mathrm{n}$.

(Figs 8-31, 35-37, 41-43, 46-71, 99-101, 121-128)

Anthophilina terminalis Loew, 1863: 324.
Anthomyza terminalis: Czerny, 1902: 252 (generic combination).

Mumetopia terminalis: Melander, 1913: 294 (key, generic combination); Sabrosky, 1965: 820 (catalogue); Roháček, 1998: 174 (checklist).

Mumetopia nitens Melander, 1913: 294; Sabrosky, 1965: 820 (catalogue, synonymy); Roháček, 1998: 174 (checklist, synonymy)

\section{Redescription}

Male. Total body length $1.68-2.79 \mathrm{~mm}$; dark to blackish brown, relatively shiny; only extremities and fore head largely yellow (as in Fig. 10). Head slightly higher than long, subquadrate in profile but anteriorly somewhat rounded, bicolourous, yellow and dark brown. Frons dark brown posteriorly, yellow anteriorly; its yellow anterior third to almost half reaching at least to anterior (shorter) ors but usually distinctly behind it on orbit and yet more so medially and is darker (ochreous) posteriorly but bright to light yellow anteriorly (around bases of antennae). Frontal triangle large, reaching to level of anterior ors, brown or with paler brown anterior corner, sparsely greyish brown microtomentose anteriorly up to anterior ocellus and more densely so on ocellar triangle, but with bare shiny spots in posterior corners on both sides of ocellar triangle; narrow areas (stripes) between frontal triangle and orbits more densely grey microtomentose, duller and, consequently, seemingly lighter than adjacent areas. Frontal lunule reduced but visible, light yellow. Orbit posteriorly and around insertion of ors narrowly bare and shining, otherwise microtomentose, yellow anteriorly, brown posteriorly. Occiput slightly concave, dark to blackish brown, distinctly (but not densely) dark grey microtomentose except for bare and hence shining medial spot above foramen. Face yellow (sometimes darker yellow medially) and whitish microtomentose, dull (Fig. 8). Parafacialia and gena yellow and densely silvery white microtomentose; parafacialia internally and gena ventrally orange ochreous to pale-brown margined. Postgena and adjacent ventrolateral part of occiput pale brown. Mouthparts yellow to whitish yellow including palpus but clypeus brown or dark brown and some sclerites (anterior in particular) of proboscis also darkened (Figs 8, 11). Cephalic chaetotaxy: pvt small and weak, strongly convergent; all macrosetae on frons very long but relatively thin; vti and oc distinctly longest of cephalic setae, at least as long as frons; vte and posterior ors subequal, long but shorter than vti or oc; 2 ors, posterior long, anterior ors variable in length but always markedly shorter (one-third to slightly more than half length) than posterior; 1 microsetula in front of anterior ors; 1-2 (rarely 3 ) pairs of minute medial microsetulae in front of frontal triangle; vi about as long as posterior ors but finer; subvibrissa well developed, up to three-quarters of vi length but markedly weaker; usually 6-9 short peristomal setae; about 3 small (one longer) setae on postgena with adjacent ventrolateral part of occiput finely setulose; postocular setulae (about 10) short, in single, relatively dense row. Eye very shortly and sparsely pilose, suboval; its longest (oblique) diameter about 1.4 times as long as shortest; smallest genal height 0.09 times as long as 


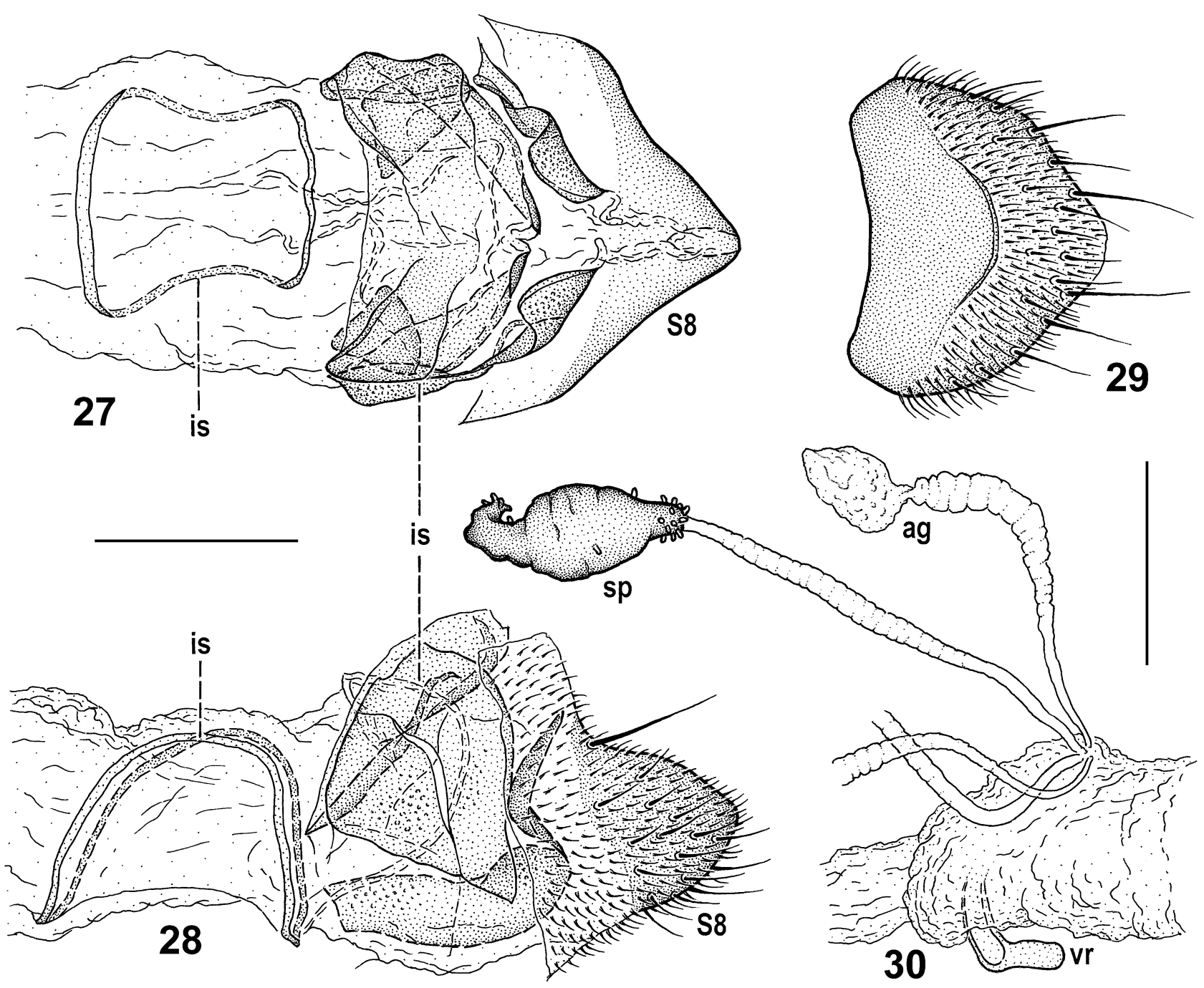

Figs 27-30. Quametopia terminalis (Loew), female (Canada: Ontario): 27 - sclerites of the female genital chamber and S8 (setosity omitted), ventrally; 28 - ditto, laterally; 29 -S10, ventrally; 30 - distal end of genital chamber and associated structures, laterally. Scales: $0.1 \mathrm{~mm}$. For abbreviations see text.

shortest eye diameter. Palpus whitish yellow only very basally brownish darkened, with 3-4 ventral setulae in addition to usual preapical seta. Antenna geniculate, yellow to whitish yellow (Fig. 11); 1st flagellomere lightest, with whitish cilia on anteroventral side about as long as those of arista. Arista about 1.9 times as long as antenna, brown with paler (ochreous or pale brown) two basal segments and distinctly long-ciliate.

Thorax slightly narrower than head. Mesonotum with scutum blackish brown, pleural sclerites especially ventrally, and sometimes humerus (= postpronotum) and notopleural area, brown. Mesonotum sparsely brownish grey microtomentose and shining; pleural part of thorax with somewhat denser microtomentum and rather subshiny. Subscutellum more densely microtomentose and duller than scutellum or metanotum. Thoracic chaetotaxy: 1 distinct but fine hu (as long as or longer than posterior $\mathrm{npl}$ ); $2 \mathrm{npl}$, anterior long (almost as long as anterior $\mathrm{dc}$ but finer), posterior short; 1 prs well developed although thin, subequal or slightly shorter than hu; $1 \mathrm{sa}$, as long as prs; 1 pa ranging from slightly shorter than anterior npl to slightly shorter than posterior npl; 2 strong postsutural dc, anterior dc long (slightly longer and thicker than anterior $\mathrm{npl}$ ), posterior dc very long, longest of thoracic setae (slightly longer than apical sc); a long row of 5-7 dc microsetae in front of anterior dc; ac microsetae sparse, in 4 rows on suture but lateral rows reduced, represented by only 1-2 (rarely 3 ) microsetae, so only medial rows longer and reaching beyond anterior dc; $2 \mathrm{sc}$, basal short and weak, apical sc long but slightly shorter and weaker than posterior dc; ppl reduced to pale hair-like microseta; 2 long stpl (posterior longer and thicker) plus several (3-7) upcurved setulae close (between, in front and below) to them in addition to several downcurved setae in ventralmost corner of sternopleuron. Scutellum moderately long, rounded triangular, with distinctly convex disc. Legs pale yellow to yellowish white (coxae in particular), only terminal segment of all tarsi dark brown. $f_{1}$ with ctenidial spine as long as to distinctly longer than maximum width of $t_{1}$ and inserted distinctly apicad of longest seta of posteroventral row; long setae in both posterodorsal and posteroventral rows relatively fine; fore 

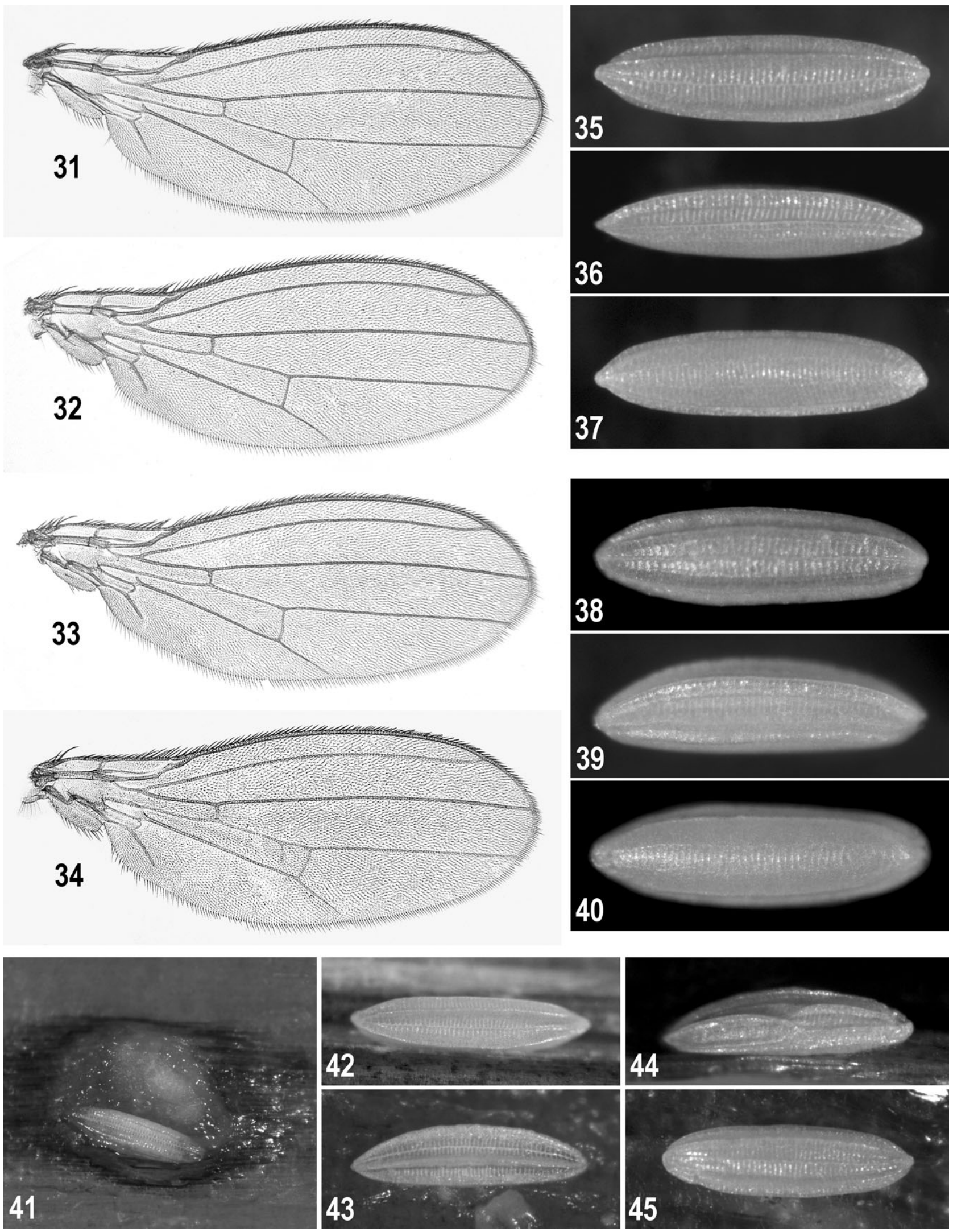

Figs 31-45. 31-34: Wings of Quametopia species (males, Canada): 31 - Q. terminalis (Loew) (Ontario, wing length $2.55 \mathrm{~mm}$ ); 32 - Q. clintonia sp. n., paratype (Ontario, length $2.53 \mathrm{~mm}$ ); 33 - Q. amplistylus sp. n., paratype (Nova Scotia, length $2.69 \mathrm{~mm}$ ); $34-$ same, paratype (Nova Scotia, length $2.78 \mathrm{~mm}$ ) with aberrant venation. 35-45: Eggs of Quametopia species: 35-37 - Q. terminalis (Loew), dorsally, laterally and ventrally (egg length $0.72 \mathrm{~mm}$ ); 38-40-Q. clintonia sp. n., dorsally, laterally and ventrally (length $0.67 \mathrm{~mm}) ; 41-Q$. terminalis, egg found on field-collected Impatiens stem in small (insect?)-damaged area; 42, 43 - Q. terminalis, eggs on natural substrate, dorsally (42) and laterally (43), length $0.76-0.80 \mathrm{~mm} ; 44,45-Q$. clintonia sp. n., eggs on natural substrate, aberrant laterally (44), normal dorsally (45), length 0.69 mm. Photo: K.N. Barber. 

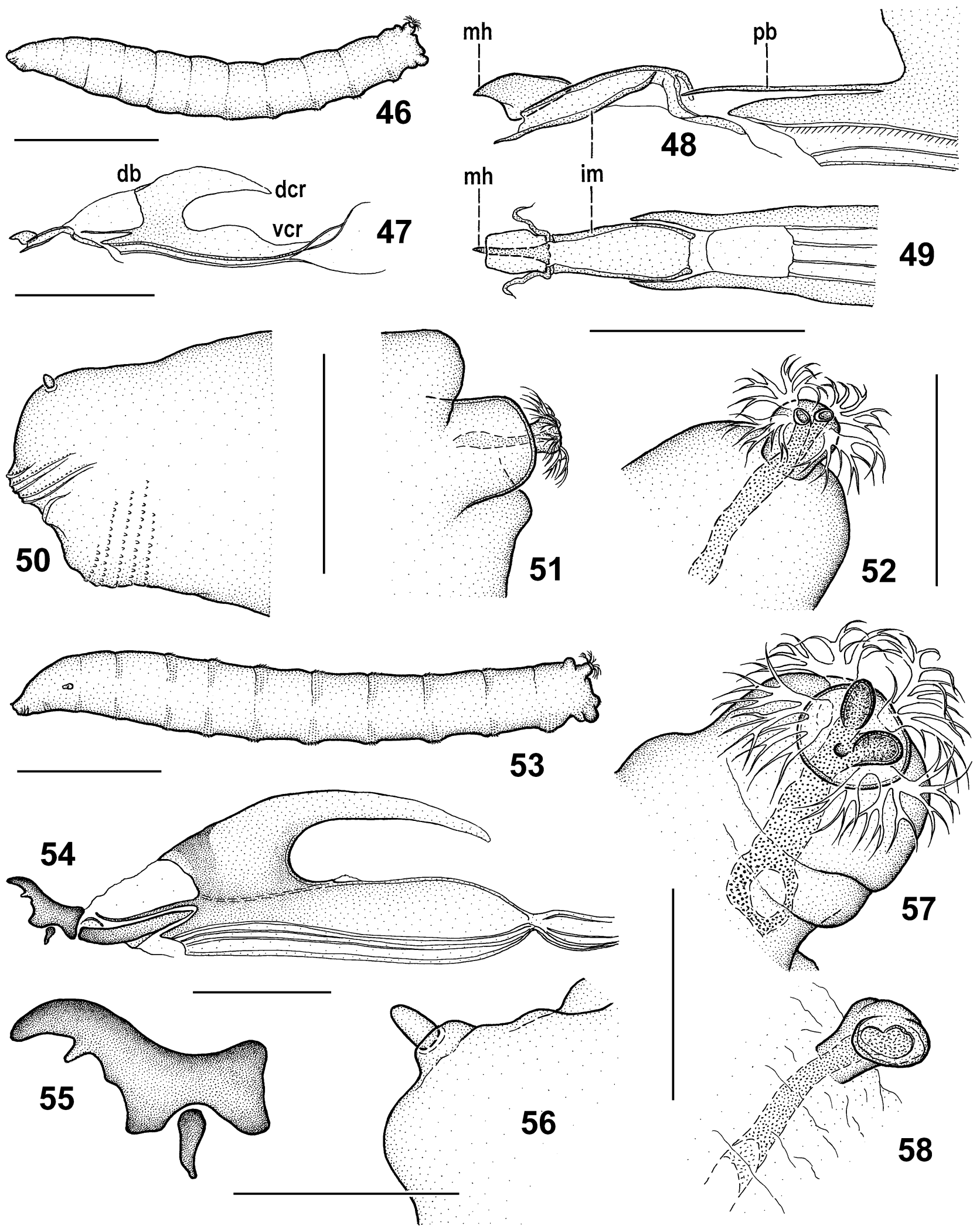

Figs 46-58. Quametopia terminalis (Loew), larvae (Canada: Ontario): 46 - 1st instar, habitus, laterally; 47 - same, cephalopharyngeal skeleton (CPS), laterally; 48, 49 - same, anterior part of CPS, laterally (48) and ventrally (49); 50 - same, head laterally; 51, 52 - same, left posterior spiracular process, laterally (51) and dorsocaudally (52); 53 - 2nd instar, habitus, laterally; 54 - same, CPS, laterally; 55 - same, mouthhook, laterally; 56 - same, antenna, laterally; 57 - same, left posterior spiracular process, dorsocaudally; 58 - left anterior spiracular process, widest extension. Scales: Figs 46, $53=0.5 \mathrm{~mm}$, Figs 47, 50-51, $54=0.1 \mathrm{~mm}$, others $=0.05$ $\mathrm{mm}$. For abbreviations see text. 

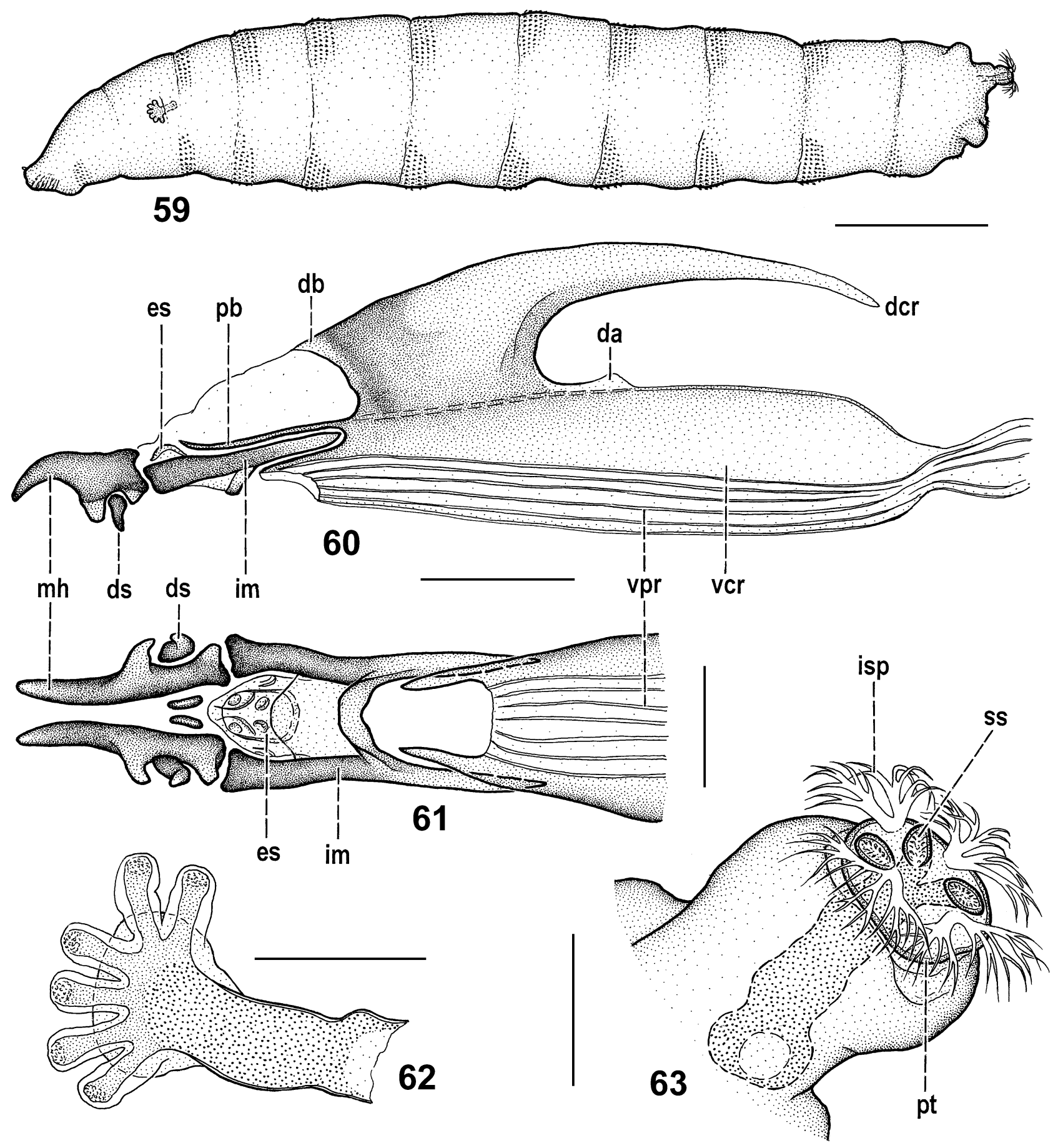

Figs 59-63. Quametopia terminalis (Loew), 3rd-instar larva (Canada: Ontario): 59 - habitus, laterally; 60 - cephalopharyngeal skeleton (CPS), laterally; 61 - anterior part of CPS, ventrally; 62 - left anterior spiracular process, sublaterally (widest extension); $63-$ left posterior spiracular process, dorsocaudally. Scales: Fig. $59=0.5 \mathrm{~mm}$, Fig. $60=0.1 \mathrm{~mm}$, others $=0.05 \mathrm{~mm}$. For abbreviations see text.

basitarsus with 2-3 longer and slightly thicker setulae ventrobasally. $t_{2}$ with relatively short ventroapical seta. $f_{3}$ in distal half to two-thirds with posteroventral row of 8-10 erect but only indistinctly thickened setae; hind basitarsus with slightly longer but not thickened ventrobasal setulae. Mid and hind basitarsus and claws of all tarsi relatively long. Wing (Fig. 31) fully developed, relatively long and narrow, of Anthomyza-type. Wing membrane hyaline, pale brownish ochreous-tinged, veins yellowish brown. $\mathrm{C}$ reaching to apex of $\mathrm{M}$, in $\mathrm{Cs}_{2}$ with sparse but distinct spinules in addition to usual setulae. Sc apically coalesced with $\mathrm{R}_{1}$ forming a distinct preapical kink. $\mathrm{R}_{2+3}$ very long, bent parallel to $\mathrm{C}$ and apically slightly upcurved to it. $\mathrm{R}_{4+5}$ long, very slightly bent or indistinctly sinuate, ending nearer to apex of wing than vein $\mathrm{M}$; $\mathrm{M}$ subparallel to $\mathrm{R}_{4+5}$, almost straight. Cross-vein $\mathrm{r}-\mathrm{m}$ slightly oblique, situated in about middle of discal (dm) cell; dm cell tapered basally, wide distally; cross- 

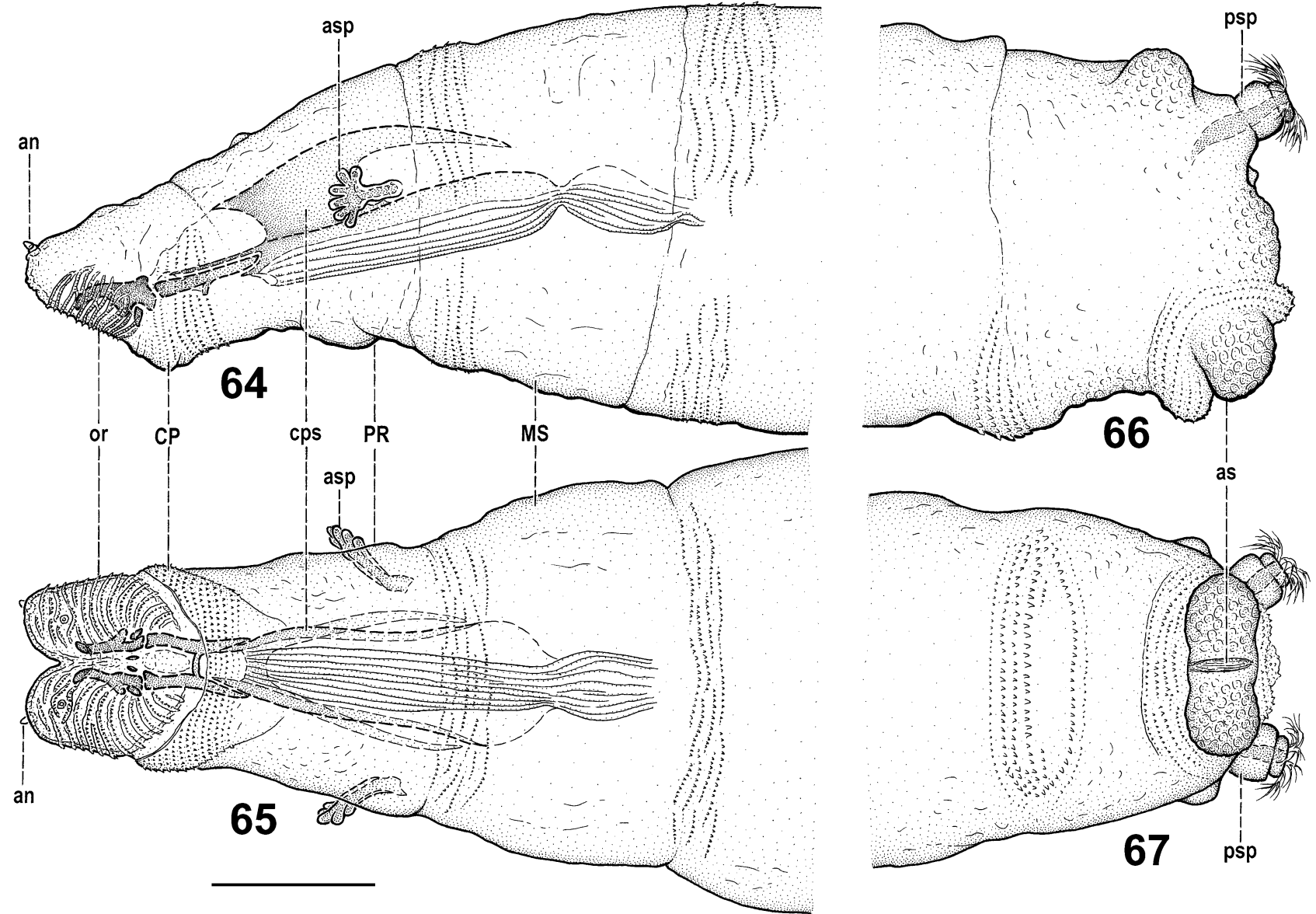

Figs 64-67. Quametopia terminalis (Loew), 3rd-instar larva (Canada: Ontario): 64 - anterior part (cephalic and thoracic segments), laterally; 65 - ditto, ventrally; 66 - posterior part (caudal segment), laterally; 67 - ditto, ventrally. Scale: $0.2 \mathrm{~mm}$. For abbreviations see text.

vein $\mathrm{dm}$-cu slightly to distinctly shorter than apical portion of $\mathrm{CuA}_{1}$, the latter almost reaching wing margin; basal medial (bm) and posterior cubital (cup) cells closed; $\mathrm{A}_{1}$ short, not reaching wing margin; anal lobe and alula well developed. Wing measurements: length $1.77-2.78$ $\mathrm{mm}$, maximum width $0.63-0.96 \mathrm{~mm} ; \mathrm{Cs}_{3}: \mathrm{Cs}_{4}=$ $1.16-1.72 ; \mathrm{r}-\mathrm{m} \backslash \mathrm{dm}-\mathrm{cu}: \mathrm{dm}-\mathrm{cu}=2.18-3.20$. Haltere with large whitish knob and yellowish stem.

Abdomen. Preabdominal terga T2-T5 completely dark brown (rarely T2 with anterolateral corners paler), all large and broad, reaching onto lateral sides of abdomen, with well-developed setosity, particularly on lateral and posterior margins. T1 often paler (pale or ochreous brown) than remaining terga. T1 and T2 distinctly shorter (T1 shortest) than subsequent terga (T3-T5). T3-T5 subequal in length. T1-T5 with very fine transverse microsculpture. T1 completely, T2 largely (except for posteroventral corners) greyish microtomentose; T3 (more) and T4 (less) microtomentose only anteromedially and T5 with microtomentum restricted to narrow stripe along anterior margin; large bare areas of terga lacking microtomentum lustrous and hence abdomen of more shiny appearance than thorax. Preabdominal sterna becoming wider (S5 widest) and darker posteriorly, ranging from ochreous yellow (S1, S2) to pale brown (S5); S1 reduced to a small, transverse and bare remnant;
S2 slightly wider than long and somewhat tapered posteriorly; S3 and S4 suboblong, usually longer than broad; S5 largest, as long as broad; S2-S5 finely densely setose. T6 reduced, bare, short, strongly transverse, having medial part membranous and unpigmented; lateral parts pale brown and weakly sclerotized (left part usually smaller than the right part). S6-S8 asymmetrical, partly (dorsally) coalesced, dark brown, S6 and S7 grey microtomentose, S8 without microtomentum and shiny; S6 shorter and more transverse (about half length of S7), with strongly sclerotized and blackish brown anterior marginal ledge; S7 longer but also anteriorly (very narrowly) dark-margined; S6 with $0-1$ (usually 0 ) seta and S7 with 0-1 (usually 1) seta; S8 large, with numerous setae.

Genitalia. Epandrium (Figs 13, 16) relatively small compared to pregenital sclerites or internal genitalia, medium-long but broad, distinctly wider than high, with moderately dense and rather fine setae, 1 dorsolateral (more) and 1 sublateral (less) enlarged; dorsal margin of epandrium convex; anal fissure relatively small, rounded subtriangular. Cercus almost as long as gonostylus, shortly and finely setose, both cerci with apices attached medially. Medandrium (Fig. 16) roughly X-shaped with distinctly projecting dorsolateral corners and strongly prolonged ventrolateral arms; the latter with 2-3 (usually 

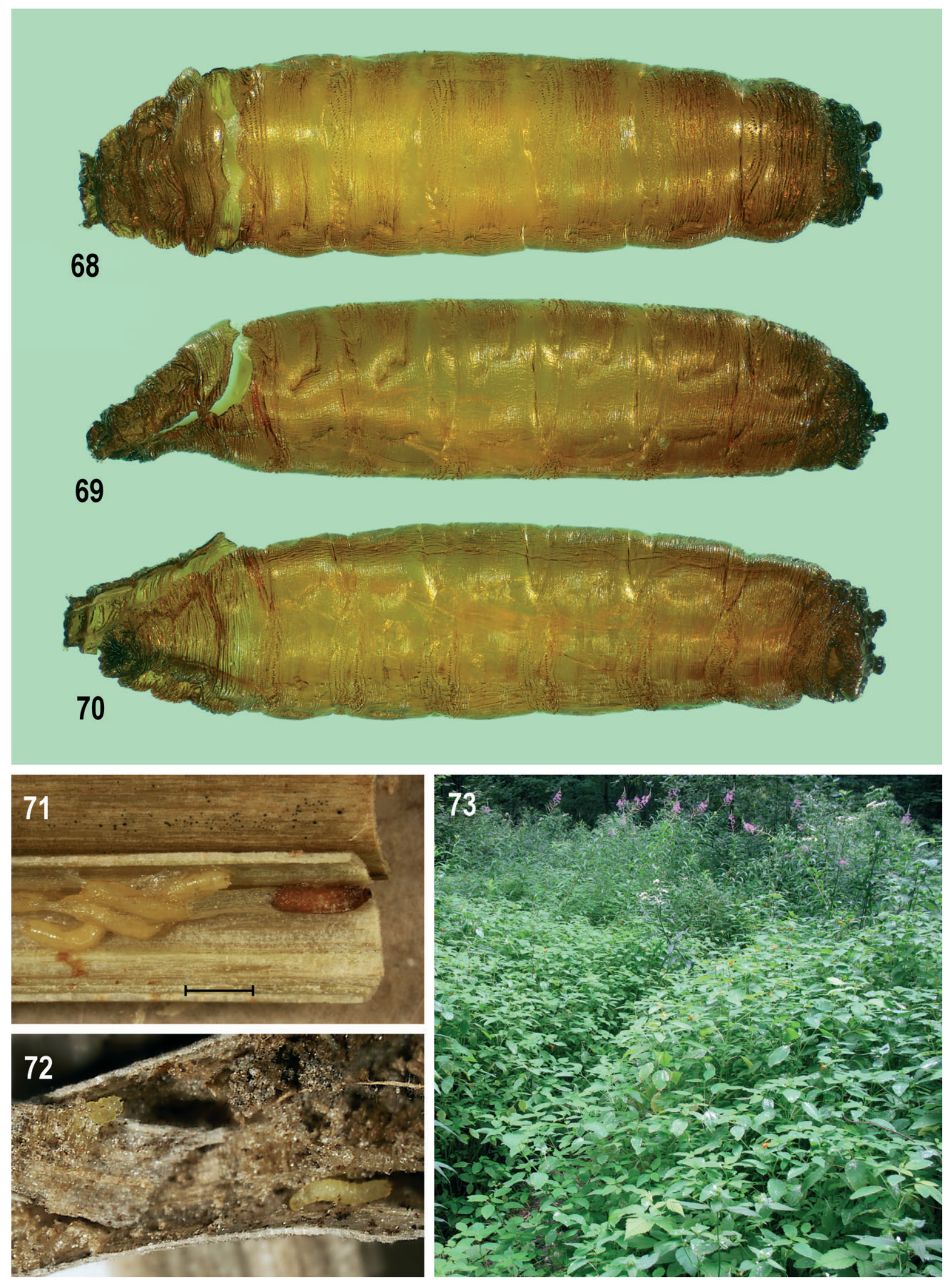

Figs 68-73. Quametopia terminalis (Loew), puparium and habitat of adults and immatures (Canada: Ontario): 68 - empty puparium (length $3.1 \mathrm{~mm}$ ), dorsally; 69 - ditto, laterally; 70 - ditto, ventrally; 71 - artificially reared larvae and puparium inside stem of Impatiens capensis; 72 - microhabitat of overwintering larvae, hollow root of I. capensis; 73 - typical habitat of $Q$. terminalis, growth of I. capensis in birch-maple forest (Ontario: Sault Ste Marie). Photo: M. Deml (Figs 68-70), K.N. Barber (Figs 71-73). 
3) distinct setulae (see Fig. 14) and apically firmly fused with posterior lobe of gonostylus. Gonostylus (Figs 15, 121-128) bilobed, with anterior lobe longer, slightly clavate, finely setulose in distal half and with longer but fine setae anterodorsally; posterior lobe about half length of anterior lobe (thus longer than in both congeners), usually bare (rarely with 2-3 microsetulae) but somewhat wrinkled; only ventral incision between both lobes with "long" micropubescence reaching to about half of anterior lobe (Fig. 15). Internal genitalia comparatively large. Hypandrium (Figs 19-20) moderate, rather straight in lateral view; internal hypandrial lobes (Fig. 19) largely membranous and pale-pigmented, slightly to hardly projecting dorsally. Transandrium relatively broad (Fig. 21) and weakly sclerotized except for dorsal ledge, without medial caudal process; basal membrane armed with fine spinules posteroventrally (Figs 20,21), and provided with finely granulose lanceolate area laterally (Fig. 20). Pregonite (Figs 19, 20) reduced, bent medially, in lateral view forming distinct though very weak lobes (Fig. 20), having 3 or (more rarely) 4 internal setae. Postgonite (Fig. 20) moderately sized, simply bent but having apex fused to distal end of connecting sclerite, and its somewhat darker proximal part provided with 1 fine seta inserted on anterior side. Aedeagal complex (Fig. 18). Phallapodeme robust, with deeply forked proximal end, rather simple apical part with small lateroventral corners and variable fulcrum (cf. Figs 13 and 18). Aedeagal part of folding apparatus (afa) strongly sclerotized and dark-pigmented in dorsal slender third and its external side with dark tubercles becoming larger and covering broader area more ventrally; connecting sclerite slender, long, darker proximally, paler and finely spinulose distally, apically connected with apex of postgonite. Phallophore small, but longer than high, compact, frame-shaped (Fig. 18). Distiphallus large, with basal part distinctly sclerotized and provided with distinctive, large, laterally flattened, but relatively weakly sclerotized posteroventral lobe overgrown by several short setulae (Fig. 19, ld). Middle part of distiphallus laterally finely spinulose. Saccus of distiphallus medium-sized, largely membranous and provided with fine spinules, sparse on left side, more numerous on right side (Fig. 18). Filum of distiphallus simple, slender, formed by a pair of ribbon-shaped sclerites ending in membranous narrowly lanceolate (hardly widened) apex having some teeth at tip (Figs 17, 18). Ejacapodeme relatively large, with digitiform projection distally somewhat widened and about as long as body of ejacapodeme (Fig. 18).

Female (Fig. 10). Similar to male unless mentioned otherwise. Total body length 1.89-3.06 mm. Head colouring markedly different from that of the male (see Figs 9, 12). Frons largely dark brown, with yellow area restricted to anterior fourth, posteriorly maximally reaching to anterior ors, usually ending just above lunule. Face ochreous brown to brown, dull; bordering stripe of parafacialia and gena dark brown and sharply contrasting with yellow, silvery microtomentose remainder of gena and parafacialia. Mouthparts with dark brown clypeus and brownish palpus and proboscis, only labellae pale ochreous to whitish yellow. Also antenna distinctly darkened, with brownish inner side of pedicel (usually) and 1st flagellomere, the latter also brownish darkened on outer side below insertion of arista, otherwise orangeyellow. Lateral rows of ac microsetae usually longer, composed of up to 5 microsetae. Ctenidial spine on $f_{1}$ strong, generally longer than in male, much longer than maximum width of $t_{1} ; f_{3}$ without posteroventral row of erect setae. Wing measurements: length 2.06-3.20 mm, maximum width $0.65-1.15 \mathrm{~mm} ; \mathrm{Cs}_{3}: \mathrm{Cs}_{4}=1.20-1.45$; $\mathrm{r}-\mathrm{m} \backslash \mathrm{dm}-\mathrm{cu}: \mathrm{dm}-\mathrm{cu}=2.17-3.00$.

Abdomen somewhat broader and preabdominal terga more transverse and shorter than in male; T2-T5 similarly coloured in male. T2 distinctly shorter than T3 but less so than that of male. T3-T4 subequal in length, T5 usually slightly longer. T1-T2 microsculptured as in male but T3-T6 with fine transverse microsculpture reduced, almost glabrous. T3-T4 less densely though similarly microtomentose; T5 without microtomentum, bare. S1 reduced to form transverse bare strip-like sclerite having 3 darker pigmented parts (laterally and medially). S2-S5 light brown, each usually with paler anterior part, S2-S4 of subequal width, S2 sometimes and S5 regularly somewhat wider than S3-S4. S2 slightly wider than long, S3-S4 slightly longer than broad or as long as broad, S5 widest and slightly transverse but narrower (and paler) than S6. Setosity of preabdominal terga and sterna similar to that of male.

Postabdomen (Figs 23-25). T6 dark brown except for narrow anterior and posterior marginal stripe, comparatively long and strongly tapered posteriorly, relatively densely but finely setose (Fig. 23). S6 trapezoidal to suboblong with rounded corners, wider posteriorly, slightly lighter brown and with setae finer than those on T6. T7 and S7 fused to form tergosternum $\mathrm{T} 7+\mathrm{S} 7$ but with narrow (ventrolateral) incisions indicating the boundary between orginal T7 and S7 (see Figs 24, 25). $\mathrm{T} 7+\mathrm{S} 7$ dorsomedially seemingly divided (with unpigmented membranous part wider anteriorly and narrowed posteriorly - see Fig. 23), laterally longest, darkest and with longest setae, ventrally (original S7) finely setose only in posterior paler-pigmented half (Fig. 24). 7th spiracle embedded in tergosternum $\mathrm{T} 7+\mathrm{S} 7$ near anterior margin ventrolaterally (Fig. 25). T8 (Fig. 23) brown, slightly transverse, with strongly rounded anterior corners and posterior margin narrowly pale-pigmented, with fine sparse setae in posterior corners. S8 (Fig. 24) short, with poorly defined anterior margin, posteromedially more or less bulging and posterodorsomedially incised (visible in caudal view - Fig. 22), finely setose and entirely micropubescent (see also Figs 24, 28). Internal structures of genital chamber (Figs 27, 28) distinct, formed by complex of 3 pairs (dorsal, lateral and ventrocaudal) of relatively short and partly fused sclerites and by 1 anterior, slender, relatively long and broad, dorsally bent annular sclerite. Ventral receptacle forming (Fig. 30) membranous, hyaline (and poorly visible), short, anteriorly strongly bent tube. Accessory gland inconspicuous (Fig. 
30 ), vesiculate with some grains in surface, set on subterminally slightly dilated and ringed duct. Spermathecae $(1+1)$ elongately irregularly pyriform to spindle-shaped, thus with both ends tapered; distal end of spermatheca more or less strongly curved, rugged and provided with several blunt processes, particularly on apex; proximal end subcylindrical, with a crown of blunt erect spine-like tubercles (Figs 26, 30); duct without sclerotized cervix on its insertion in spermatheca. T10 (Fig. 23) short and transverse, bent and dark-pigmented, with 2 very long posteromedial setae and reduced micropubescence concentrated around bases of the latter. S10 much larger than T10, rounded pentagonal (Figs 24, 29), with anterior part (about as long as posterior part) bare, posteromedially somewhat bulging; posterior half of S10 densely micropubescent and with relatively long but fine setae at posterior margin. Cerci short, narrow in dorsal view but broad in lateral view, with rich but rather short setae (the longest apical with lateral setae subequal in length) and very short micropubescence (Figs 23-25).

Type material. Anthophilina terminalis Loew. Lectotype $\delta$ (designated here) labelled: "Loew Coll.", "terminalis m." (Loew's handwriting), "Type 14558" (red label), "Lectotypus đิ, Anthophilina terminalis Loew, 1863, J. Roháček \& K.N. Barber des. 2010" (red label) and "Quametopia terminalis (Loew) đ, J. Roháček \& K.N. Barber det. 2010”. The specimen is in relatively good condition, with only 1 st flagellomere of right antenna missing and its genitalia somewhat damaged (apical part of filum of distiphallus broken off and missing) but both gonostyli well preserved (MCZC, genit. prep.). Note: There are 3 other specimens labelled as types in MCZC (with the same red label "Type 14558" as the lectotype) but these do not belong to the type series because all are (1) females, (2) originate from New Hampshire (labelled "N.H.") while the type locality is "Carolina" (see Loew 1863: 324) and (3) do not agree with the original description because they belong to the genera Anthomyza and Arganthomyza.

Mumetopia nitens Melander. Lectotype $\&$ (designated here) labelled: "Woods Hole, 7-16-2 Mass" (printed, only date handwritten), “TYPE, Mumetopia nitens Mel.” (red label), "ALMelander Collection 1961", "Mumetopia nitens Mel., TYP." (? Melander's handwriting), "Lectotypus $\$$, Mumetopia nitens Melander, 1913, J. Roháček \& K.N. Barber des. 2010" (red label) and "Quametopia terminalis (Loew) ९, J. Roháček \& K.N. Barber det. 2010". The specimen is somewhat damaged, with 1st flagellomeres of both antennae, left wing and some parts of legs missing (USNM, genit. prep.). Paralectotypes: 1 ㅇ labelled: "Woods Hole, 7-16-2 Mass" (completely handwritten), "PARATYPE, Mumetopia nitens Mel." (red label), "ALMelander Collection 1961" and "Paralectotypus + , Mumetopia nitens Melander, 1913, J. Roháček \& K.N. Barber des. 2010" (yellow label) - intact specimen in good condition (USNM); 1 우 labelled: "Woods Hole, VII-17-2 Mass" (handwritten), "PARATYPE, Mumetopia nitens Mel.” (red label), “ALMelander Collection 1961" and "Paralectotypus \%, Mumetopia nitens Melander, 1913, J. Roháček \& K.N. Barber des. 2010” (yellow label) - headless specimen (USNM, genit. prep.).

Other material examined. CANADA: Alberta (1\%): McMurray (B1, CNCI). Ontario (528 $0^{2}, 706$ ) ): Algonquin Provincial Park, Scott Lake env. (Ro, SMOC); same, Swan Lake (Ma, DEBU); Ancaster (Mr, Pe, CNCI); Caledon E. (Be, DEBU); Dundas (Ca, DEBU); Spencer Gorge near Dundas (Ro, SMOC); Fergus, Grand River (Ma, Ro, DEBU, SMOC); Guelph
(Ba, De, DEBU); Guelph, Arboretum (Ba, DEBU); Hamilton (Be, DEBU); Hamilton, Royal Botanical Gardens (Ba, Sc, DEBU); Lancaster, Cooper Marsh Conservation Area $(\mathrm{Br}$, LEMQ); Midland (Ch, CNCI); One Sided Lake (Ke \& Wh, CNCI); Ottawa (Vo, Sh, CNCI), Ottawa, Black Rapids (Vo, CNCI); Ottawa, Dow's swamp (Mo, CNCI); Outlet Beach, Prince Edward Co. (Vo, CNCI); Pancake Bay Provincial Park (Ba, DEBU); Rockport (Vo, CNCI); Rockwood (Be, Cu, DEBU); 14 km W Rutherglen, Highway \#17 (Ba, DEBU); St. Lawrence Islands National Park, Thwartway Is. (Re, CNCI); Sault Sainte Marie, S. of Algoma University College (Ba, DEBU); same locality, Baseline Rd. at Allen's Side Road (Ba, DEBU); same locality, Birchwood Park (Ba, DEBU, SMOC); same locality, Bristol Place Park (Ba, AMNH, BYUC, CASC, CNCI, CSCA, DEBU, EMUS, INHS, MCZC, SEMC, SMOC, ZSMC); same locality, Centennial Drive Park (Ba, DEBU); same locality, Finn Hill (Ba, DEBU); same locality, Fish Hatchery Road near Coldwater Creek (Ro, SMOC); same locality, Florwin Drive greenbelt (Ba, DEBU); same locality, Sault College Outdoor Lab. (Ba, DEBU, SMOC); Short Hills Provincial Park, Terrace Creek Trail (Ba, DEBU); Toronto (Pa, Vo, CNCI, USNM); Waterloo Region, Blair, Cruickston Creek (Ce, $\mathrm{Bg} \& \mathrm{Ma}, \mathrm{DEBU})$; Waupoos (Bc, CNCI); Windsor (Ma \& He, DEBU). Quebec (430ิ, 45 + ): Abbotsford (Sh, CNCI); Beech Grove (Mc, CNCI); Gatineau Park (Ik, LEMQ); Knowlton Lodge (Vo, CNCI); Mont St.-Hilaire Reserve, Pain de Sucre Trail (Br, Cn, Po, LEMQ); Old Chelsea (Vo, CNCI); same locality, King Mt. (Ch, CNCI); same locality, Summit King Mt. (Vo, CNCI); same locality, Meach Brook (Ba, DEBU); Terrasse-Vaudreuil Molson Nature Reserve (Bo, Cc, We, LEMQ); Trois Rivières (Ts, ZSMC); Wakefield (Sh, CNCI). UNITED STATES OF AMERICA: Connecticut $(1 \hat{\sigma}, 2 q)$ : Canaan (St, USNM). District of Columbia $(1 \hat{\delta}, 10 \%)$ : Washington (Me, USNM); Rock Creek Pk. (Ml, BYUC, SMOC, USNM); Washington, Deanwood (Bt, MBP, SMOC); Illinois (11 $\hat{0}, 5 q)$ : Champaign Co. (Sm, CNCI); Kankakee Co., Kankakee State Park, Altorf (Wb \& Mn, INHS); Macomb (Wi, USNM); McLean Co., Downs (Wb \& Mn, INHS); Ottawa (Wn, MCZC); Union Co., Shawnee National Forest, Pine Hills Campground (As, DEBU); Woodford Co., $4 \mathrm{mi} \mathrm{W}$ Cazenovia (Wb \&

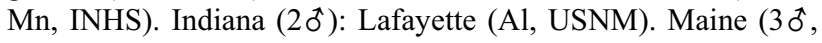
$3 \uparrow)$ : Seal Harbor (Me, USNM). Maryland (7ई̃, $7 \uparrow)$ : Montgomery Co., Bethesda (Sy, USNM); Montgomery Co., Carderock Pk. (Kn, USNM); Plummers Island (Mt, Sn, Sy, Hg \&

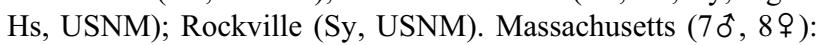
Auburndale (Jo, MCZC); Catoctin, Mt. Park, Owen's Creek (Bt, MBP, SMOC); Concord (Wi, USNM); Franklin Co., $\sim 0.5 \mathrm{~km} \mathrm{E}$ Farley (Ba, DEBU); Middlesex Co., Lincoln (Ar, USNM); Petersham (Me, USNM); Woods Hole (Me, USNM). Michigan (2 9$)$ : Ionia Co.; Newaygo Co. (Dr, USNM). New Hampshire (3 +): Pinkham Notch (Me, USNM); Grafton Co., Rumney, Quincy Bog (Ga \& Gs, CSCA); [no locality] (Os, MCZC). New Jersey (2 $\%$ ): Morris Plains (Su, USNM); Pemberton (no collector, USNM). New York $(3 \delta, 11 \%)$ : Buffalo (Vd, USNM, CASC); Chittenango (Ph, USNM); East Aurora (Vd, CASC); Ithaca (Me, Bn, USNM, SEMC); same locality, Six Mile (Bn, SEMC); Niagara Falls (Jo, MCZC); Peekskill, (Me, USNM); Portage (Vd, CASC); Poughkeepsie (To, USNM); Tompkins Co., Mud Creek (no collector, AMNH); Salmon Creek (Bk,

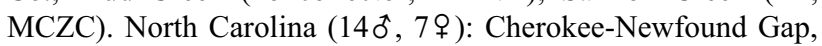
Great Smoky Mountains N.P. (Vo, CNCI); Graham Co., Robbinsville (Bh, EMUS). Pennsylvania $(2 \hat{\jmath}, 4$ 우): Centre Co., Pine Grove Mills (Wl, CASC); Philadelphia (Jo, MCZC); Roxborough (no collector, USNM); Swarthmore (Cr, USNM). Virginia (12 0 , 19 + ): Alexandria (Wi, USNM); Alexandria Co., Maywood (Mt, SMOC, USNM); Big Meadows (Me, USNM); 
Fairfax Co., Deer Run (Sn, USNM); Giles Co., Jefferson National Forest, Cascades Recreation Area (Ma, DEBU). West Virginia $(2 \hat{\jmath}, 1 \%)$ : Franklin (Wi, USNM); Grafton (Sy, USNM); Pocahantas Co., Hills Creek Falls (Fl \& Mh, USNM).

Preimaginal stages

Egg rather slender, elongate (Figs 35-37, 41-43), 0.71-0.83 mm long, 0.16-0.19 $\mathrm{mm}$ wide (maximum width), with both ends tapered, with dorsal side (dorsal side determined by position of freshly laid egg on substrate, anterior end by position of neonate larva before hatching) more convex than ventral side in lateral view. Colour whitish but chorion hyaline, with relatively simple sculpture, formed by 4 (2 lateral and 2 laterodorsal) pronounced longitudinal ribs of finely granulose structure and by very fine and tenuous transverse reticulation between them, forming 3 rows of meshes ventrally (Fig. 37), 2 dorsally (Figs 35, 42) and 1 laterally (Figs 36, 43). Ventral egg area (Fig. 37) with 3 rows of strongly transverse meshes $(1: 3.5$ to $1: 5.5)$ is margined by finely granulose but hardly elevated line; between this line and lateral rib there is an additional narrow row of subquadrate to square-shaped meshes (1:1 to $1: 1.5)$. Laterodorsal and/or lateral ribs can relatively often be malformed (interrupted, connected or split), similar to that in $Q$. clintonia on Fig. 44. Micropylar area lies on ventral side of anterior (more acute) end of egg with poorly differentiated micropyle situated in a subterminal depression. Note: The previous descriptions of eggs in Anthomyzidae (for references see above in the Discussion of pre-imaginal stages) incorrectly recognized dorsal side of egg as that in which micropyle is situated, i.e. the less convex side of the egg.

Larva. 1st-instar larva. Body whitish hyaline, slender, maggot-like (Fig. 46), very variable in length (smallest = larva immediately after hatching). Measurements: length 0.91-1.55 mm, maximum width $0.14-0.23 \mathrm{~mm}$. Segmentation of body relatively distinct, same as in 3rd-instar larva (see below). Creeping welts developed only ventrally on mesothoracic, metathoracic and all abdominal segments, each composed of several (3-5) transverse rows of very minute spinules. 1st-instar larva is metapneustic, i.e. with only posterior pair of spiracles developed.

Cephalic segment simplified compared to those of 2nd and 3rd instars and only indistinctly anteroventromedially furrowed so cephalic lobes less distinct; facial mask with a few (3 complete) denticulate oral ridges (Fig. 50). "Antenna" (= sensory organ) on dorsal side of cephalic lobe two-segmented as in later instars but basal segment reduced to a short ring. Oral atrium developed but the unpaired mouthhook (see below) is not projecting through it. Posterior part of cephalic segment ventrally ornamented by only some 5-6 transverse rows of minute spinules. Prothoracic segment simple, lacking anterior spiracles. Cephalopharyngeal skeleton situated inside the cephalic and all thoracic segments.

Cephalopharyngeal skeleton (Figs 47-49) weakly sclerotized and pale-pigmented, with reduced structures: mouthhook (mh) unpaired, best sclerotized of all parts of skeleton, laterally flattened, relatively high and anteriorly pointed, roughly rhomboid in profile (Fig. 48). No dental sclerite. Intermediate (= hypostomal) sclerite (Figs 48, 49, im), integrating probably also epistomal plate, situated between (and below) mouthhook and pharyngeal sclerite, weakly sclerotized and unpigmented, of poorly defined form, anteriorly plate-shaped and with slender lateral curved projections (Fig. 49). Pharyngeal sclerite (Fig. 47) relatively large and bearing distinctly developed parastomal bars and robust paired dorsal cornua being as high as ventral cornua, but both dorsal and ventral cornua hyaline and weakly sclerotized. Dorsal cornua anterodorsally connected by simple, short and hardly sclerotized dorsal bridge. Ventral cornua somewhat longer than dorsal cornua, ventrally with shallow and weakly sclerotized downward-curving trough having reduced number (only 4) of fine longitudinal ridges (Fig. 49). No window or apodeme in either dorsal or ventral cornua.

Last abdominal segment (Figs 46, 51) with dorsolateral bulges in front of posterior spiracles and protruding anal area similar to those of later instars. Posterior spiracles (Figs 51, 52) formed as a button-like projection on protruding stump-like process, lacking distinct peritreme, perforated by only 2 oval spiracular slits in subradial position and bearing 4 finely palmately branched (less than in later instars) interspiracular processes.

2nd-instar larva. Body whitish hyaline to dirty white, of the same shape as in 3rd-instar larva but smaller and more slender (Fig. 53). Measurements: length 1.57-2.78 mm, maximum width $0.22-0.38 \mathrm{~mm}$. Two thoracic and all abdominal segments with creeping welts as in 3rd-instar larva but arranged in only 3-6 rows. Both anterior and posterior spiracles developed.

Cephalic segment similarly formed as in 3rd-instar larva, including "antenna" (Fig. 56), cephalic lobes and oral atrium but facial mask with fewer oral ridges and transverse rows of minute spinules (only 5-7) on posteroventral part of cephalic segment. Prothoracic segment laterally with retractable anterior spiracles being simply clavate, with single spiracular slit on tip (Fig. 58).

Cephalopharyngeal skeleton (Figs 54-55) generally similar to that of 3rd-instar larva but differing (except for size) as follows: paired mouthhooks with distal hook less pointed but basally bearing distinct, slender and acute tooth (see Fig. 55) and less projecting ventrally in the middle and posteriorly. Dental sclerites more slender. Intermediate sclerite (Fig. 54) as in 3rd instar but its ventral connecting bridge with posterior part indistinctly separate and pale-pigmented as is anterior part. Epistomal plate hyaline and its structure poorly visible. Pharyngeal sclerite (Fig. 54) with more sinuate parastomal bars, otherwise closely resembling that of 3rd instar but with slightly shorter dorsal cornua and ventral trough with fewer longitudinal ridges.

Last abdominal segment (Fig. 53) with similarly formed dorsolateral bulges in front of posterior spiracles and bulging anal area as in 3rd instar. Posterior spiracles (Fig. 57) with only 2 oval spiracular slits (as in 1st-instar larva) but with distinctly developed spiracular plate surrounded by peritreme set on protruding stump-like process (as in 
3rd-instar larva); also 4 multiply branched interspiracular processes resembling more those of the latter.

3rd-instar larva. Body whitish hyaline to pale dirty ochreous, of elongate, maggot-like form (Fig. 59); length $3.02-4.77 \mathrm{~mm}$, maximum width $0.35-0.56 \mathrm{~mm}$, when extended. Body more or less distinctly segmented, composed of cephalic, 3 thoracic (pro-, meso-, and metathoracic) and 8 abdominal segments. Abdominal segments usually more convex (bulging) laterally than dorsally and ventrally. Mesothoracic, metathoracic and all abdominal segments provided with both dorsal and ventral (last abdominal segment with only ventral) creeping welts composed of minute spinules arranged in 5-9, usually several times interrupted, transverse rows. Third-instar larva is amphipneustic, with a pair of anterior and posterior spiracles.

Cephalic segment (Figs 64, 65) rather simple, weakly sclerotized, divided by anteroventromedial furrow into left and right cephalic lobes. Facial mask (Fig. 65) with numerous fine oral ridges composed of small cuticular thornlets. Each cephalic lobe dorsally with very minute two-segmented sensory organ, the so-called "antenna". Ventrally, between cephalic lobes, is the oral atrium (Fig. $65)$ with projecting apices of mouthhooks. Posterior part of cephalic segment ventrally ornamented with about 10 transverse rows of minute spinules. Prothoracic segment (Figs 64, 65) laterally with partly retractable anterior spiracles being terminally palmate and terminating regularly in 6, relatively short and thick, finger-like projections (for detailed structure see Fig. 62). Inside the cephalic and all thoracic segments there is the cephalopharyngeal skeleton (Fig. 64, cps).

Cephalopharyngeal skeleton (Figs 60-61) generally structured as in other saprophagous acalyptrate larvae. The paired mouthhooks ( $\mathrm{mh}$ ) of moderate size, laterally flattened, with simple, slightly bent distal hook, in the middle and posteriorly distinctly projecting ventrally to lateroventrally (Fig. 61). Dental sclerites (ds) below mouthhooks well developed, canine-shaped, projecting ventrally and lying between processes of mouthhooks. In addition, there is a pair of minute, closely attached sclerites $(=$ ? accessory oral sclerites) between proximal parts of mouthhooks (see Fig. 61). Intermediate (= hypostomal) sclerite (Figs 60, 61, im) situated between mouthhooks and pharyngeal sclerite and separate from both of them, H-shaped in ventral view (Fig. 61), with connecting part between lateral rods bipartite, with anterior part longer and pale, posterior part short-transverse and darkpigmented. Epistomal plate rounded subtriangular, palepigmented to hyaline, situated anteriorly to anterodorsally between anterior arms of intermediate sclerite, of rather complex structure with small rounded ?perforations (see Fig. 61). Pharyngeal sclerite (Fig. 60) forming the largest part of cephalopharyngeal skeleton. Its paired anterior projections (parastomal bars) very slender and lying closely above intermediate sclerite. Its paired dorsal (dcr) and ventral (vcr) cornua well developed, dark-pigmented only anteriorly (Fig. 60). Dorsal cornua anterodorsally connected by simple (non-perforated), rather short dorsal bridge $(\mathrm{db})$; more posteriorly free and becoming attenuated and hyaline. Ventral cornua somewhat longer than dorsal cornua, connected by weakly sclerotized ventral, downward-curving trough which is provided with fine longitudinal ridges (Figs 60, 61) serving as filter for concentration of larval food. No window in either dorsal or ventral cornua but each of the latter provided with indistinct, small and unpigmented dorsal apodeme (da).

Last abdominal segment of larva (Figs 66, 67) characterised by dorsolateral bulges in front of posterior spiracles and by lateroventrally protruding anal area embedding slot-like anus in the middle and being surrounded by fine rows of spinules both anteriorly and posteriorly (Fig. 67). Paired posterior spiracles (Fig. 66, psp) formed by sclerotized plate on shortly protruding stump-like process (Fig. 63). Spiracular plate surrounded by more sclerotized rim (peritreme) and perforated by 3 oval or ovoid spiracular slits (ss) in irregularly radial pattern and provided with 4 finely palmately (multiply) branched interspiracular processes (isp) arising among spiracular slits.

Puparium (Figs 68-70) elongately barrel-shaped, only slightly wider than high, with more tapered anterior end, less tapered and rather rounded posteriorly. Measurements: length $2.42-3.26 \mathrm{~mm}$, maximum width $0.58-0.89$ $\mathrm{mm}$, maximum height $0.55-0.83 \mathrm{~mm}$. Integument of (empty) puparium ochreous yellow (in the middle, lightest ventrally) to brown (anteriorly and posteriorly), intensively finely transversely wrinkled and ribbed in most of abdominal segments while roughly, densely and rather irregularly ribbed anteriorly (cephalic and thoracic segments) and posteriorly (caudal abdominal segment). Larval features mostly visible on puparium but modified by sclerotization process of puparium, usually somewhat reduced. Segmentation of body generally visible. Abdominal segments (except for last one) with shallow but distinct dorsolateral and ventrolateral crescent-shaped impressions (Figs 68-70).

Anterior end of puparium strongly tapered and distinctly dorsoventrally compressed and equal to thoracic (plus integrated cephalic) segments of larva. First visible segment (= prothoracic + cephalic) dorsolaterally with sclerotized (larval) anterior spiracles each forming a short, palmately branched projection with 6 short papillae; segment proper characteristically sculptured, anteromedially hardly or very shallowly emarginate, dorsally (Fig. 99) with a group of coarse twisted ridges medially and wrinkled margins (with rest relatively smooth), ventrally (Fig. 100) with distinctive blackish, palmately branched ornamentation having its (darkest) base relatively narrow and sharply demarcated. Also 2nd and 3rd (meso- and metathoracic) segments dorsally with distinctly coarser sculpture than on following (i.e. abdominal) segments, the former with dense twisted and partly net-like connected ridges, the latter with ridges more transverse and anteriorly with several rows of very fine spinules. Cephalopharyngeal skeleton of 3rd-instar larva situated inside of anterior part of puparium, affixed to its ventral wall. 
Posterior end of puparium less narrowed, convex and densely ribbed (Figs 68-70, 101), ventrally with characteristic sculpture surrounding larval anus (Fig. 101) including rows of very fine spinules, posteriorly behind anus relatively smooth but strongly sloping, with pair of elongate tubercle-like swellings, and dorsolaterally with still visible bulges (though reduced against those of larva). Posterior spiracles on short stump-like processes (Fig. 101) being set on relatively broadened subconical protrusions of posterior abdominal segment. Larval adornment (transverse bands $=$ creeping welts of fine spinules) of cuticle well preserved both on dorsal and ventral sides of abdominal segments.

Material examined (pre-imaginal stages): 154 eggs +23 egg chorions, 1001 st-instar larvae, 172 2nd-instar larvae, 187 3rdinstar larvae, 23 puparia +68 empty puparia: all lab-reared on Impatiens capensis using adults from CANADA: Ontario: Sault Ste. Marie, Bristol Place Park and Sault Ste. Marie, Birchwood Park (Ba, all DEBU, only 8 empty puparia SMOC).

Discussion. Quametopia terminalis is the most distinct of the Quametopia species. Apart from structures in the male and female genitalia, it can be confidently recognized in the female sex by the darkened 1st antennal flagellomere (see Figs 9, 12). Differences in other external features are small and often overlapping (for details see descriptions of $Q$. clintonia sp. n. and $Q$. amplistylus sp. n.) and, therefore, it is suggested to identify the males of Quametopia species using characters of gonostylus and internal genitalia (aedeagal complex) as listed in the above key. Also the pre-imaginal stages of $Q$. terminalis differ from those of $Q$. clintonia sp. n. in lacking the pronounced ledge defining the ventral perimeter of the egg, in the formation of the cephalopharyngeal skeleton of the 1st-instar larva, anterior spiracles and cephalopharyngeal skeleton of both the 2nd- and 3rd-instar larvae, and in the surface structures of the anterior and posterior segments of the puparium (see key). Moreover, Q. terminalis also differs from $Q$. clintonia sp. n. in its biology, being strictly associated with I. capensis (see below) in undergrowths of moist forests and their edges or openings.

Mumetopia nitens Melander, 1913 was synonymized with $Q$. [Mumetopia at that time] terminalis by Sabrosky (1965). Melander (1913) did not recognize that some parts of the head of $Q$. terminalis are sexually dichroic and described its female with darkened antennae, face and mouthparts as a different species, $M$. nitens. It is, however, peculiar that he was mistaken in this case because, in fact (see other material examined) there are both males and females of $Q$. terminalis in his material collected in the same locality and on the same date as the (female) type specimens.

Biology. Adults of $Q$. terminalis are commonly found in stands of $I$. capensis in Ontario (Canada) where they can be seen sitting on leaves, and hovering amongst stems or above the plants when disturbed. Most collections by the authors were made in shaded or semi-shaded habitats (Fig. 73), usually on moist soil (at least in the spring), where $I$. capensis occurred or occasionally where it may have been overlooked as a minor component. Where $I$. capensis stands are strong and dominant, this fly can be very abundant and its choice of host plant quite evident. However, no observation of oviposition was ever made in the field so finer details of life history remain unknown (but see note below of egg on damaged stem).

Adults of $Q$. terminalis have been caught as early as 16 May (Plummers Island, MD) and as late as 18 September (Sault Ste. Marie, ON; 2 October, Middlesex Co., MA but Malaise trap start date not recorded) which suggests two generations. The majority of specimens have been taken with sweep nets with two records from Malaise traps.

Field collections of litter and soil, and stems of $\boldsymbol{I}$. capensis. Of the five rectangular samples from 1999 ( $\sim 1170 \mathrm{~cm}^{2}$ of substrate), three yielded a total of five $Q$. terminalis adults. Two males emerged 17 days and three females emerged 18, 19, and 23 days after collection at $20^{\circ} \mathrm{C}$. Of the 14 cylindrical cores from $2002\left(\sim 370 \mathrm{~cm}^{2}\right.$ of substrate), four yielded a total of five adults of $Q$. terminalis. The one male and four females emerged between 13 and 16 days later (all found the same day after a 3-day interruption of observation, all but one dead) at $25^{\circ} \mathrm{C}$. These preliminary observations indicated that $Q$. terminalis was resident in these sites and overwinters in the litter and/or soil below I. capensis.

Table 1 summarizes the acalyptrate Diptera and associated parasites (only those emerging from isolated immature flies) emerging from the field-collected stems. The first sample maintained at $20^{\circ} \mathrm{C}$ beginning 1 May 2010 yielded a single adult female $Q$. terminalis (17 May) but also eight adults of the chloropid Tricimba trisulcata (Adams, 1905) (40, 4 + , 4-24 June) which had not been recognized until eclosion. An additional eight mature or nearly mature maggots and two puparia found on the floor of the boxes produced two female $Q$. terminalis, six T. trisulcata $(2 \hat{\delta}, 4$ ㅇ), and one eucoiline parasite (Figitidae: Trybliographa sp.) of a Q. terminalis puparium (one unidentified maggot died). The sample of 17 May 2010 yielded larger numbers with 22 adult $Q$. terminalis $(9 \hat{\sigma}$,

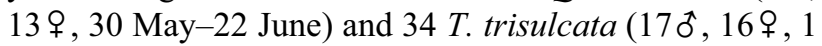
escaped, 4 June-11 July) emerging. Mature maggots and puparia found on the floor of the boxes (17 and 3, respectively) or from the 62 dissected stems ( 31 and 10, respectively) totaling 61 , yielded 50 puparia (11 dead larvae). Of these 50 puparia, 11 were $Q$. terminalis $(3 \hat{\sigma}, 5 q, 2$ eucoiline parasites, 1 dead parasitized puparium) and 39 were $T$. trisulcata (18ठ, $15 q, 6$ dead puparia). Adults of Q. terminalis emerged 14-15 days after pupariation $(\mathrm{n}=$ 3 ) while those of $T$. trisulcata emerged 15-18 days after pupariation $($ mean $=16.17$, s.d. $=0.71, \mathrm{n}=35)$. A single specimen of Trybliographa sp. required 37 days to emerge from a $Q$. terminalis puparium while two others, from puparia with a questionable start date, required at least 33 and 35 days.

Thirty-six of the 38 immature specimens of $Q$. terminalis and T. trisulcata dissected from the stems were found in the lower $3 \mathrm{~cm}$ of the plant and mostly in the hollow lateral roots (Figs 7, 72). From Table 1, it can be seen that 26 flies emerged from the dissected stems and thus represent immatures overlooked during the initial 
TABLE 1. Quametopia terminalis and Tricimba trisulcata and associated parasites from intact overwintered stems and a dissected subsample of stems of Impatiens capensis, May-June 2010.

\begin{tabular}{|c|c|c|c|c|c|c|c|c|c|c|c|}
\hline \multirow{3}{*}{ Sample date } & \multirow{3}{*}{ Stage } & \multirow{3}{*}{ Totals } & \multicolumn{9}{|c|}{ Components } \\
\hline & & & \multirow[b]{2}{*}{ Dead } & \multicolumn{4}{|c|}{ Q. terminalis } & \multicolumn{4}{|c|}{ T. trisulcata } \\
\hline & & & & 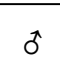 & 우 & $\begin{array}{c}\text { live } \\
\text { parasites }^{1}\end{array}$ & $\begin{array}{c}\text { dead } \\
\text { puparia }^{2}\end{array}$ & o & $q$ & lost & $\begin{array}{c}\text { dead } \\
\text { puparia }^{3}\end{array}$ \\
\hline \multirow[t]{3}{*}{1 May } & Adults & 9 & & & 1 & & & 4 & 4 & & \\
\hline & Larvae & 8 & 1 & & 1 & 1 & & 1 & 4 & & \\
\hline & Puparia & 2 & & & 1 & & & 1 & & & \\
\hline \multirow[t]{3}{*}{17 May } & Adults & 30 & & 7 & 9 & & & 7 & 7 & & \\
\hline & Larvae & 17 & 2 & & 1 & & & 8 & 4 & & 2 \\
\hline & Puparia & 3 & & 2 & & & & 1 & & & \\
\hline \multicolumn{12}{|c|}{ 62-stem subsample } \\
\hline & Adults ${ }^{4}$ & 26 & & 2 & 4 & & & 10 & 9 & 1 & \\
\hline & Larvae & 31 & 8 & & 3 & & & 8 & 9 & & 3 \\
\hline & Puparia & $10^{5}$ & 1 & 1 & 1 & 2 & 1 & 1 & 2 & & 1 \\
\hline & & 136 & 12 & 12 & 21 & 3 & 1 & 41 & 39 & 1 & 6 \\
\hline
\end{tabular}

${ }^{1}$ Figitidae: Eucoilinae: Trybliographa sp.; ${ }^{2}$ parasitized by unidentified Hymenoptera; ${ }^{3}$ no parasites recognized; ${ }^{4}$ emerged from stems after dissection thus representing immatures that had been overlooked; ${ }^{5}$ includes three puparia found loose in box containing dissection residue.

dissection. A second search of a portion of this material (one box with 19 of the 26 adults) uncovered 11 empty puparia and four additional desiccated larvae. These 11 puparia were comprised of three $Q$. terminalis (one in a lateral root, and two loose) and eight T. trisulcata (one in the main root, one in a lateral root, five in a stem internode, and one loose).

The dissected stems of $I$. capensis also yielded small numbers of Cecidomyiidae, Sciaridae, and a community that appears to be based on the stem-boring Pristerognatha agilana (Clemens, 1860) (Tortricidae) (MacKay, 1959; Gilligan et al., 2008). A total of 82 adult P. agilana emerged and more larvae and pupae were encountered in the dissections. Parasites associated with the caterpillars or pupae included Braconidae, Ichneumonidae, and Chalcidoidea. A single platygastrid also emerged but its host is not known.

A single, serendipitous observation of a field-collected egg was made when preparing for rearings. A section of $I$. capensis stem collected 29 July 2010 was removed from the freezer in early September and a flattened (empty or damaged) egg was found attached to the outer wall of what appeared to be insect feeding damage (Fig. 41). This shallow injury did not penetrate to the hollow interior of the stem but fluid from the freeze-damaged tissues readily leaked into the depression indicating a possible entry point for a hatching larva - no such larva was found in the section of stem.

The association of $Q$. terminalis with its putative host plant is based on several observations: repeated collections of adults from pure and mixed stands; laboratory rearing from adult to adult upon presentation of the stems of I. capensis; and rearing of adults from litter/soil and stem samples. Dissection of maggots from overwintered stems, and particularly roots, coupled with a single observation of an egg on a damaged stem, provides a finer degree of detail and certainty.

Collectively, these data indicate that at least some $Q$. terminalis larvae overwinter within the roots (and pos- sibly stems) of $I$. capensis, primarily or exclusively as third instars. The relationship with $T$. trisulcata is not known but their combined life history may include the use of younger plants earlier in the season. Self-thinning is known to occur in dense stands of the annual I. capensis (see Schmitt et al., 1987) which would provide a ready source of decomposing plant tissue for ovipositing flies. Alternatively or additionally, mechanical damage caused by vertebrates, wind, or the larval tortricid moths, in particular, could provide access to the plant tissues or hollow stem interior - the frass of the latter also could be an important resource for the maggots.

Rearing of $\boldsymbol{Q}$. terminalis. Egg production in the flight cages was not enumerated but the last $4 \hat{0}$ and 69 transferred to the cup cage yielded 200 eggs from 18 August until 13 September 2002 whereupon the 5 surviving adults were killed, 112 days after their collection from the field. This suggests a capacity for a protracted flight period on the level of the individual flies.

The first puparium was observed on 4 August 2002, 41 days after initial setup of adults and about one month after the first observation of eggs. Puparia that were produced from 5 August to 31 October in 2002 yielded 18 adults $(7 \delta, 11 \%), 12$ days $(\hat{\delta}, \mathrm{n}=4)$ or approximately 11 days $(\$$, range $=9-12, \mathrm{n}=10$ ) after pupariation when held at $20^{\circ} \mathrm{C}$. These adults were generally undersized measuring $\sim 84 \%$ (males) of the body length of wildcaught adults from Bristol Place Park. Of the puparia resulting from overwintered larvae, 29 adults (19 $0,10 \%$ ) were produced from 12-25 April and these required about 14 days (range $=13-15$ for both sexes) at $20^{\circ} \mathrm{C}$ to eclose. These adults were also undersized measuring $\sim 90 \%$ of wild-caught adults (males $\mathrm{n}=7$ ).

The smaller rearing from 2009 provided some additional information. Eggs required 6 days to hatch at $20^{\circ} \mathrm{C}$. Of the 35 eggs laid between 24 and 27 August, 10 puparia were produced between 14 November and 24 January (other larvae died, were lost, or were preserved). There could have been some delays in development as a 
result of the late season despite the laboratory holding conditions. Since all adults (7ठ, $3 q$ ) emerged 15-16 days later, there was no obligatory puparial diapause which supports the stem-dissection results that suggest this species overwinters as mature larvae. The 10 adults produced in 2009 (at least 89-161 days after egg hatch) were not undersized but slightly larger than the wildcaught adults used to compare with the 2002-2003 rearings and this length of time suggests no more than two generations would be possible. Immediate and exclusive use of split stems of I. capensis in a moisture-controlled (no wet sand) Petri plate is thus recommended for this species (Fig. 71).

Oviposition choices. Table 2 summarizes the results of the oviposition choice trial. Females of $Q$. terminalis showed a strong preference for I. capensis by laying 43 eggs on the stems compared to a single egg on the petiole of C. borealis.

Distribution. The distribution of this species (as Mumetopia terminalis) was summarized by Sabrosky (1965): New Hampshire, Michigan to Quebec, south to Virginia. Actually, there are very few original records of this species: Loew (1863) described it from "Carolina" [this was for unknown reasons changed to "New Hampshire" by Melander (1913) and this correction, as an error made by Loew, was also accepted in Sabrosky (1965)], Melander (1913) described it as M. nitens from Massachusetts, Johnson (1925) recorded it from Maine, New Hampshire and Massachusetts (but at least his record from Maine: Mt. Desert is based on misidentification of $Q$. clintonia sp. n., see below), Procter (1946) probably only repeated the misidentified record from Mt. Desert, Winn \& Beaulieu (1932) reported it from Quebec and Marshall et al. (2001) from Ontario. Other parts of the distribution range presented by Sabrosky (1965) were apparently based on unpublished records known to him. Although most of the above records obviously refer to $Q$. terminalis, some may be partly based on misidentifications of the other two species described below. The general distribution of the species is detailed here on the basis of material examined: Canada $(\mathrm{AB}$, ON, QC) and USA (CT, DC, IL, IN, MA, MD, ME, MI, NC, NH, NJ, NY, PA, VA, WV). This is the most commonly collected species of Quametopia and it is glaringly absent from the maritime provinces of Canada. The single specimen from Alberta is quite baffling as is the absence of records through Manitoba and Saskatchewan. The host plant, I. capensis, is very broadly distributed in North America with notable absence only in Montana, Wyoming, the southwest USA, California and the far north of Canada and Alaska (United States Department of Agriculture, 2010) (present in Labrador, S.J. Meades, pers. comm.). This would seem to be a case of insufficient collection effort directed at $I$. capensis as $Q$. terminalis is very easily collected if it is present (in contrast to $Q$. clintonia $\mathrm{sp}$. $\mathrm{n}$. that can be much more difficult to sweep out of $C$. borealis).

\section{Quametopia clintonia sp. n.}

(Figs 32, 38-40, 44-45, 74-98, 102-104, 129-133)

Etymology. The species is named "clintonia" (a noun in nominative singular, standing in apposition to the generic name) owing to its distinct association with the plant Clintonia borealis.

\section{Description}

Male. Total body length $1.94-2.58 \mathrm{~mm}$; body shape and colouration closely resembling that of $Q$. terminalis,
TABLE 2. Number of eggs laid by Quametopia terminalis and Q. clintonia sp. n. in a choice trial comparing leaf and petiole of Clintonia borealis and stem of Impatiens capensis, 24-30 August 2009.

\begin{tabular}{|c|c|c|c|}
\hline \multirow{2}{*}{ Substrate } & \multirow{2}{*}{$\begin{array}{c}\text { Q. terminalis } \\
2 \lesssim 2 q\end{array}$} & \multicolumn{2}{|c|}{ Q. clintonia sp. n. } \\
\hline & & 2029 & 19 \\
\hline Clintonia borealis leaf & 0 & 14 & 9 \\
\hline Clintonia borealis petiole & 1 & 25 & 11 \\
\hline Impatiens capensis stem & 43 & 0 & 2 \\
\hline Totals & 44 & 39 & 22 \\
\hline
\end{tabular}

${ }^{1}$ Excludes 9 eggs laid by Q. clintonia sp. n. on the Petri plate or the sand.

thus blackish brown, relatively shiny, with legs and fore head largely yellow. Head similarly formed and coloured as in Q. terminalis. Frons with anterior yellow area (being somewhat darker ochreous posteriorly) usually reaching up to level of posterior ors but only more medially, in dull narrow areas between frontal triangle and orbits. Frontal triangle large, slightly longer than wide, not reaching to level of anterior ors (thus slightly shorter than in $Q$. terminalis), brown, sparsely greyish brown microtomentose only in anterior corner and on ocellar triangle, otherwise glabrous and shiny; narrow areas between frontal triangle and orbits dull and grey microtomentose as in Q. terminalis. Orbit narrowly bare, shining and brown posteriorly (up to anterior ors), yellow and microtomentose in front of the latter. Occiput as in Q. terminalis but less densely microtomentose and more shiny (besides bare medial spot above foramen) also laterally. Face pale to dark yellow and dull as in Q. terminalis. Parafacialia and gena light yellow and silvery white microtomentose; parafacialia (internally) with narrower and paler, gena (ventrally) with wider and darker brown marginal stripe. Mouthparts whitish yellow including palpus and proboscis but clypeus (small and often hidden) brownish. Cephalic chaetotaxy as in Q. terminalis but pvt sometimes crossed, anterior ors usually about half length of posterior and postocular setulae dorsally (behind vte) longer. Eye with longest (oblique) diameter about 1.5 times as long as shortest; smallest genal height 0.10 times as long as shortest eye diameter. Palpus entirely whitish yellow, with same chaetotaxy as that of $Q$. terminalis. Antenna as in $Q$. terminalis but 1 st flagellomere with whitish cilia on anteroventral side longer than those of arista.

Thorax closely resembling that of $Q$. terminalis in shape, colour, microtomentose pattern and even chaetotaxy. Legs as in Q. terminalis, yellow, only apical (terminal) segment of all tarsi dark brown, more rarely also preapical segment of fore tarsus brown. $f_{1}$ with ctenidial spine longer than maximum width of $t_{1}$; long setae in both posterodorsal and posteroventral rows fine but longest posteroventral seta (near ctenidial spine) often markedly thicker than others. $t_{2}$ with ventroapical seta yet shorter (usually only as long as maximum width of $t_{2}$ ) and slightly curved. $\mathrm{f}_{3}$ in distal two-thirds with denser posteroventral row of 12-15 erect and more distinctly thickened setae. Wing (Fig. 32) very similar to that of $Q$. terminalis including colour of membrane and veins. $\mathrm{R}_{4+5}$ long, usually slightly bent; $M$ subparallel to $R_{4+5}$, very 

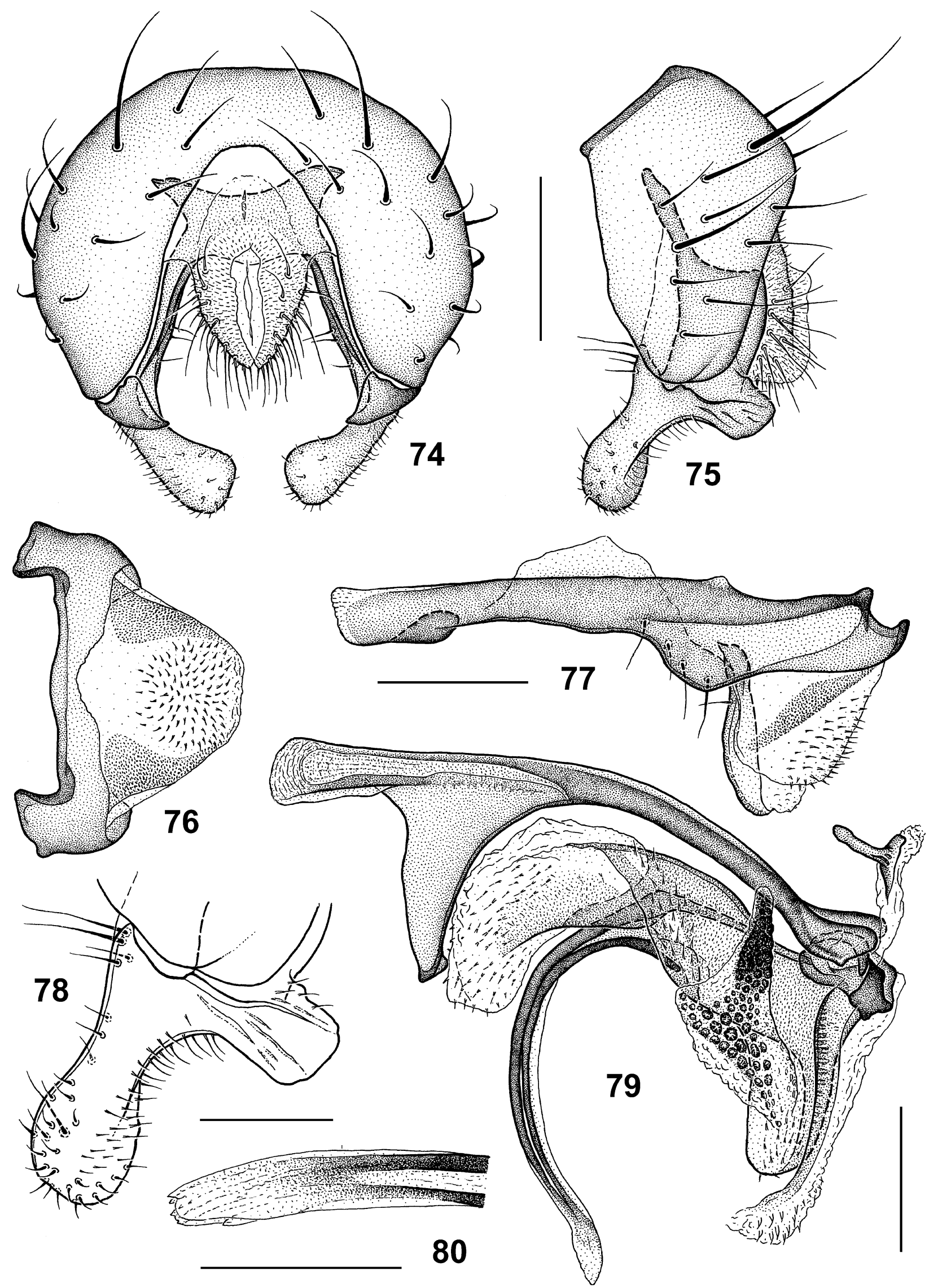

Figs 74-80. Quametopia clintonia sp. n., male paratype (Canada: Ontario): 74 - external genitalia caudally; 75 - ditto, laterally; 76 - transandrium, caudally; 77 - hypandrial complex, laterally; 78 - left gonostylus, sublaterally (widest extension); 79 - aedeagal complex, laterally; 80 - apex of filum, lateroventrally (widest extension). Scales: Figs 78, $80=0.05 \mathrm{~mm}$, others $=0.1 \mathrm{~mm}$. 
slightly bent or indistinctly sinuate, apically slightly divergent from $\mathrm{R}_{4+5}$. Cross-vein $\mathrm{r}-\mathrm{m}$ situated slightly to distinctly in front of discal ( $\mathrm{dm})$ cell; $\mathrm{dm}$ cell elongate and formed as in $Q$. terminalis; cross-vein dm-cu usually distinctly shorter than apical portion of $\mathrm{CuA}_{1}$; all other veins and cells as in $Q$. terminalis. Wing measurements: length 2.22-2.70 mm, maximum width 0.71-0.89 mm; $\mathrm{Cs}_{3}: \mathrm{Cs}_{4}$ $=1.29-1.55 ; \mathrm{r}-\mathrm{m} \backslash \mathrm{dm}-\mathrm{cu}: \mathrm{dm}-\mathrm{cu}=2.38-3.29$. Haltere of the same colour and form as that of $Q$. terminalis.

Abdomen. Preabdominal terga T2-T5 as in Q. terminalis, completely dark brown, $\mathrm{T} 1$ paler brown than remaining terga, at least anterolaterally. T1-T5 with very fine transverse microsculpture and similarly greyish microtomentose as those of $Q$. terminalis but this microtomentum usually denser and covering larger medial area on T3 and T4 in both reaching or almost reaching to posterior margin (hardly so in T4 of $Q$. terminalis); also T5 with wider microtomentose stripe along anterior margin; consequently, bare areas of terga smaller and hence abdomen generally less shiny than in $Q$. terminalis. Preabdominal sterna becoming very slightly wider (S5 widest) and darker posteriorly; $\mathrm{S} 1$ as in $Q$. terminalis; $\mathrm{S} 2$ slightly wider than long; S3 and S4 subquadrate, usually as long as broad or S4 slightly wider than long; S5 largest, distinctly wider than long (thus transverse), with anterior corners more or less rounded. T6 similarly reduced and with bipartite pigmentation as in Q. terminalis. S6-S8 resembling those of $Q$. terminalis in shape, pigmentation and microtomentose pattern. S6 with $0-1$ (usually 0) and S7 without setae; S8 large, with numerous setae.

Genitalia. Epandrium (Figs 74, 75) similar to that of $Q$. terminalis but with setae more sparse and anal fissure narrower and more rounded dorsally. Cerci as in Q. terminalis, shortly setose and with apices attached medially. Medandrium (Fig. 74) with dorsolateral corners less projecting and ventrolateral arms less divergent; the latter with 3 setulae, 1 usually distant from 2 others. Gonostylus (Figs 78, 129-133) bilobed, with longer anterior clavate lobe similarly setose to that of $Q$. terminalis but with micropubescence reaching in distal part of its outer side; posterior lobe markedly shorter than that of $Q$. terminalis, always shorter than half length of anterior lobe, and regularly with some microsetulae at dorsal margin; ventral incision between both lobes shallow (Fig. 78). Internal genitalia very similar to those of $Q$. terminalis but differing as follows. Hypandrium (Fig. 77) slightly more robust and with internal membranous hypandrial lobes more projecting dorsally. Transandrium with somewhat thicker dorsal ledge; basal membrane similarly armed with fine spinules (Fig. 76) but lateral finely granulose area narrower (Fig. 77). Pregonite (Fig. 77) yet more reduced than in $Q$. terminalis, with anterior lobe almost indistinct in lateral view; 3 (usually) to 4 setae present on internal side of pregonite. Postgonite (Fig. 77) usually straighter, regularly with 1 fine proximal seta as in $Q$. terminalis, rarely with a similar seta in distal third of anterior margin. Aedeagal complex (Fig. 79). Phallapodeme similar to that of $Q$. terminalis but its apical part with lateroventral corners reduced. Aedeagal part of folding apparatus similarly sclerotized and armed but dark tubercles often covering larger area ventrally; connecting sclerite with thicker spinules distally. Phallophore with somewhat larger (expanded) anterior part. Distiphallus with flat posteroventral lobe setulose mainly in distal third (Fig. 79). Middle part of distiphallus as in Q. terminalis. Saccus of distiphallus somewhat larger and with more spinules, particularly on right side (Fig. 79). Filum similarly formed to that in $Q$. terminalis but its membranous apex with only very fine denticles at tip (Fig. 80). Ejacapodeme somewhat larger than that of Q. terminalis, with digitiform projection longer than body of ejacapodeme (Fig. 79).

Female (Fig. 104). Similar to male unless mentioned otherwise. Total body length $1.98-2.88 \mathrm{~mm}$. Head colouring different from that of the male but less distinctly than in $Q$. terminalis. Frons with anterior yellow area similar to that of male. Face ochreous to pale brown, greyish microtomentose and dull; bordering stripe pale brown on parafacialia, darker brown on gena. Mouthparts with blackish brown clypeus; palpus with brownish outer side (darkest basally) and ochreous yellow inner side and apex; proboscis ochreous to pale brown, only labellae dirty whitish yellow. Antenna not darkened, entirely yellow or orange-yellow (Fig. 104) as in male. Lateral rows of ac microsetae usually longer, also prs seta longer than in male. Ctenidial spine on $f_{1}$ distinctly longer than maximum width of $t_{1} ; t_{2}$ with ventroapical seta longer than maximum width of tibia but usually slightly bent (as in male); $\mathrm{f}_{3}$ without posteroventral row of erect setae. Wing measurements: length 2.26-2.96 mm, maximum width $0.75-1.03 \mathrm{~mm} ; \mathrm{Cs}_{3}: \mathrm{Cs}_{4}=1.19-1.65 ; \mathrm{r}-\mathrm{m} \backslash \mathrm{dm}-\mathrm{cu}$ : $\mathrm{dm}-\mathrm{cu}=2.61-3.66$.

Abdomen somewhat broader and preabdominal terga more transverse and shorter than in male (as in Q. terminalis); T1-T6 with fine transverse microsculpture reduced, less distinct than in male. Microtomentose pattern of T1-T4 similar to that of male, T5 and T6 almost without microtomentum. S1 reduced to transverse bare strip-like sclerite, similar to that of $Q$. terminalis but with less distinct tripartite pigmentation pattern. S3-S4 of subequal width, S2 and S5 usually slightly wider than S3-S4. S2 somewhat wider than long, S3-S4 as long as broad (or S4 slightly wider than long), S5 somewhat wider than S4 and slightly transverse, usually narrower than S6.

Postabdomen (Figs 81, 84) generally similar to that of Q. terminalis. T6 usually less tapering posteriorly and with less dense setae only covering posterior two-thirds of T6 (Fig. 81); also S6 with sparser setae and lightened both posteriorly and anteriorly. Tergosternum $\mathrm{T} 7+\mathrm{S} 7$ similarly formed to that in $Q$. terminalis but usually somewhat less transverse (longer particularly ventrally) and less densely setose on original S7. T8 slightly larger, suboblong to anteromedially prolonged and hence somewhat rounded pentagonal (see Fig. 81). S8 (Fig. 84) as in Q. terminalis, posteromedially bulging and posterodorsomedially incised. Internal structures of genital chamber 


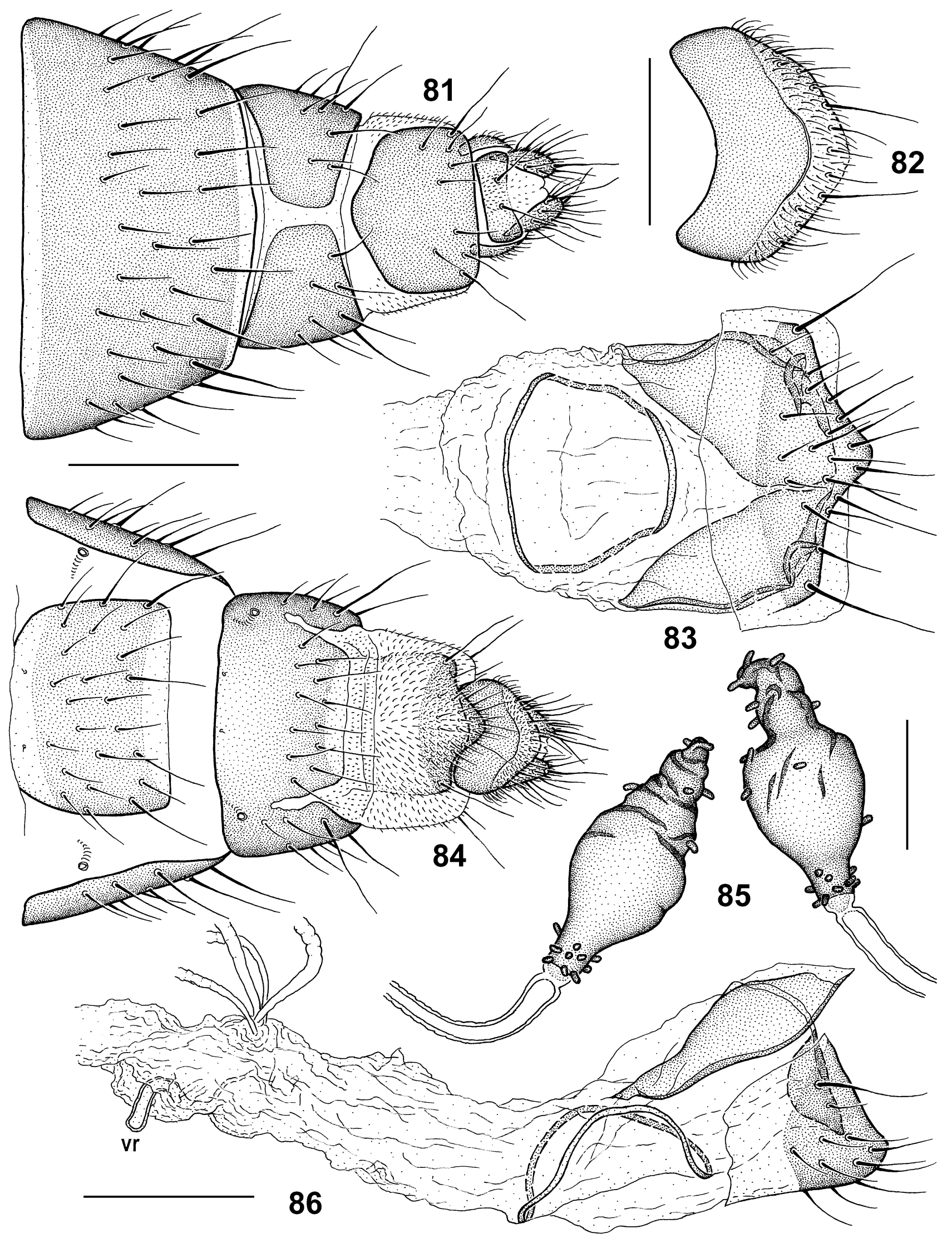

Figs 81-86. Quametopia clintonia sp. n., female paratype (Canada: Ontario): 81 - postabdomen, dorsally; 82 - S10, ventrally; 83 - sclerites of the female genital chamber and S8 (micropubescence omitted), ventrally; 84 - postabdomen, ventrally; 85 - spermathecae; 86 - genital chamber and S8 (micropubescence omitted), laterally. Scales: Figs $81,84=0.2 \mathrm{~mm}$, Fig. $85=0.05 \mathrm{~mm}$, others $=0.1 \mathrm{~mm}$. For abbreviation see text. 

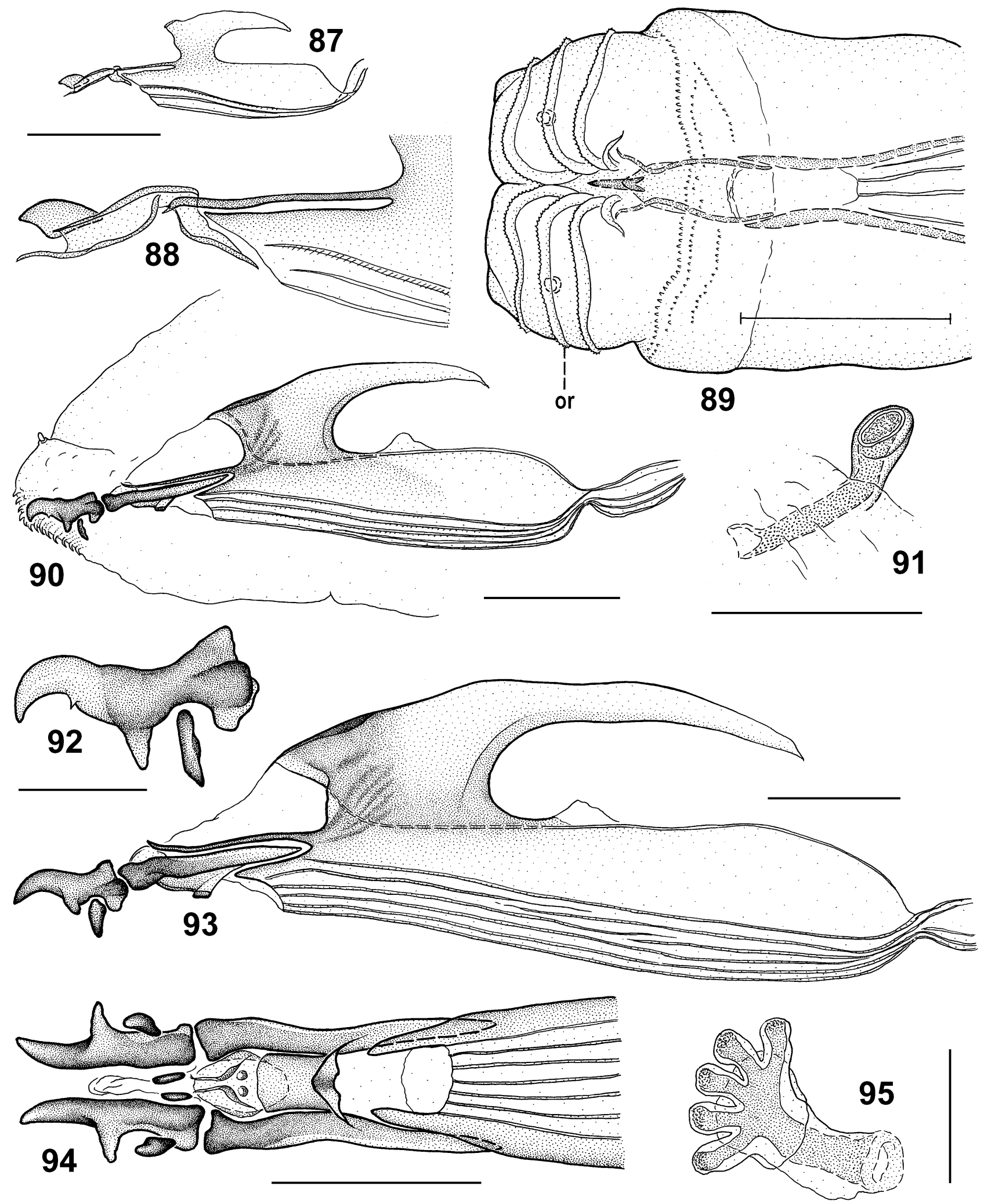

Figs 87-95. Quametopia clintonia sp. n., larvae (Canada: Ontario): 87 - 1st instar, cephalopharyngeal skeleton (CPS), laterally; 88 - same, anterior part of CPS, laterally; 89 - same, cephalic segment, ventrally; 90 - 2nd instar, CPS (in situ), laterally; 91 - same, left anterior spiracular process, widest extension; 92 - same, mouthhook, laterally; 93 - 3rd instar, CPS, laterally; 94 - same, anterior part of CPS, ventrally; 95 - same, left anterior spiracular process, sublaterally (widest extension). Scales: Fig. $92=0.03 \mathrm{~mm}$, Figs $87,90,93,94=0.1 \mathrm{~mm}$, others $=0.05 \mathrm{~mm}$. For abbreviation see text.

(Figs 83, 86) different from those of Q. terminalis, having lateral pair of sclerites reduced (or membranous) but dorsal pair (longer than in Q. terminalis) and caudal pair (short) well developed; anterior annular sclerite dorsally usually less bent. Ventral receptacle (Fig. 86) formed as a membranous, hyaline, short, ventrally curved and apically 

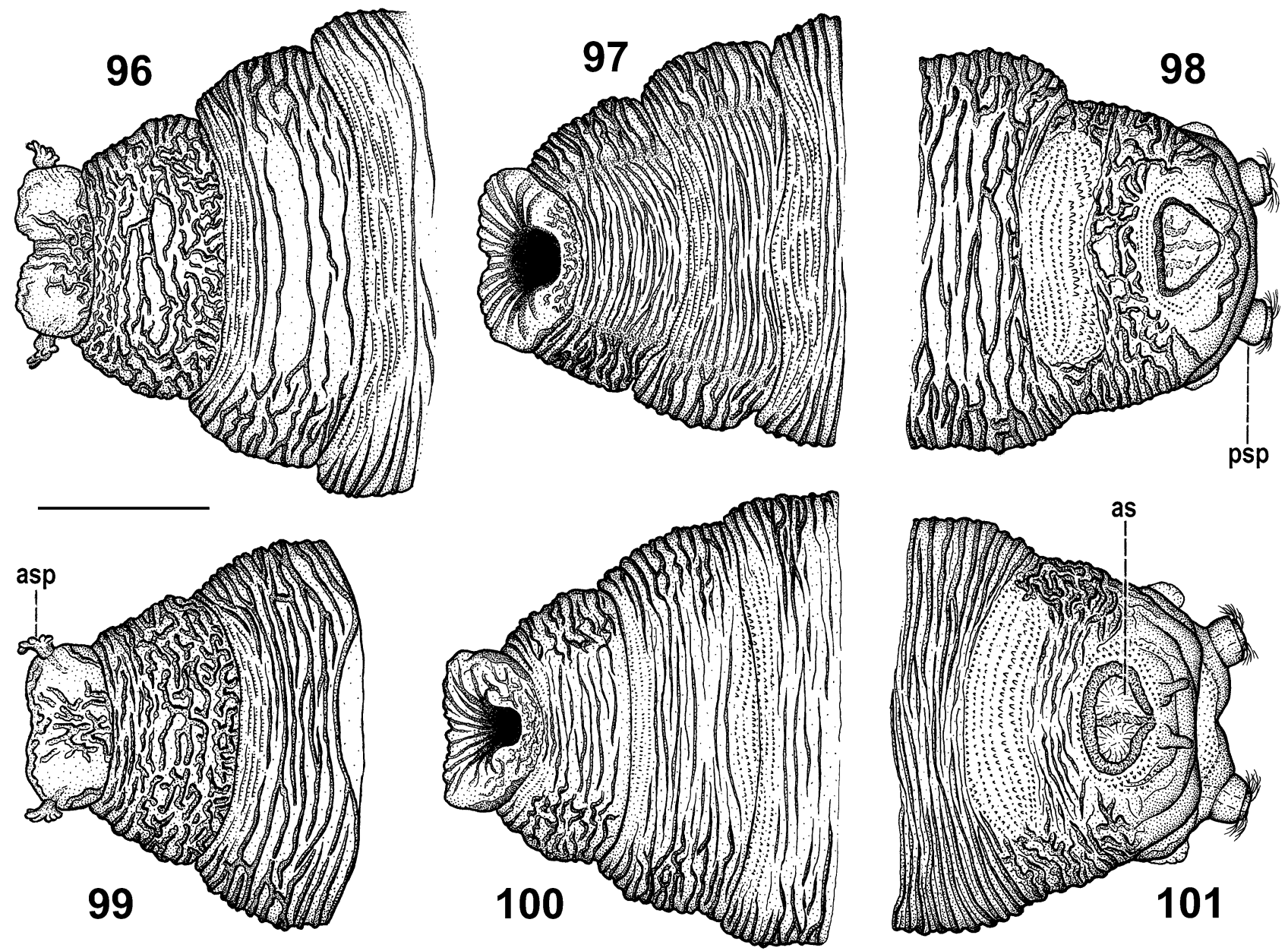

Figs 96-101. 96-98: Quametopia clintonia sp. n., puparium (male paratype, Canada: Ontario): 96 - anterior part, dorsally; 97 ditto, ventrally; 98 - posterior part, ventrally. 99-101: Quametopia terminalis (Loew), puparium (male, Canada: Ontario): 99 - anterior part, dorsally; 100 - ditto, ventrally; 101 - posterior part, ventrally. Scale: $0.3 \mathrm{~mm}$. For abbreviations see text.

rounded tube. Accessory gland inconspicuous as in $Q$. terminalis. Spermathecae $(1+1)$ closely resembling those of $Q$. terminalis but usually distal tapered end of spermatheca less or hardly curved (often one spermatheca with curved end, other with straighter end, see Fig. 85). T10 (Fig. 81) often yet more transverse than that of $Q$. terminalis and with more micropubescence medially. S10 differing from that of $Q$. terminalis in having anterior bare part larger and less abruptly separated from much shorter posterior micropubescent part (Fig. 82). Cerci short, very similar to those of $Q$. terminalis, both in shape and chaetotaxy (Figs 81, 84).

Type material. Holotype ơ labelled: “CAN: ON: Greenwater PPk, Green Trail, 21.vii.2009, KNBarber, sweeps, Eurybia, Cornus, Clintonia, Diervilla, Aralia under Populus, $49^{\circ} 11.74^{\prime} \mathrm{N} 81^{\circ} 16.82^{\prime} \mathrm{W}$ ", "debu 01502195 " and "Holotypus ơ, Quametopia clintonia sp.n., J. Roháček \& K.N. Barber det. 2010" (red label) (DEBU, genit. prep.). Paratypes: CANADA: Newfoundland and Labrador (1 9 ): Terra Nova National Park, (Ax, USNM). Nova Scotia (9 $\hat{0}, 9$ 우): Cape Breton Highlands Nat. Pk., North Mt. (Ms, Vo, Sr, LEMQ, CNCI, DEBU); same locality, Fishing Cove Trail (Te, CNCI); Halifax (Kr, USNM); Lockeport (Vo, CNCI). Ontario (1310, 119 $)$ ): Aubrey Falls Provincial Park (Ba, Ro, DEBU, SMOC); Batchawana Provincial Park; Chutes Provincial Park, Twin Bridges Trail; $\sim 14$ km
W Dubreuilville, Highway 519 (all Ba, DEBU); Dubreuilville [some labels misspelled as Dubreilville] (Ba, Ro, DEBU, SMOC); $8 \mathrm{~km}$ NE Echo Bay, Echo Lake; Fairbank Provincial Park, Wa-shai-ga-mog Trail; Greenwater Provincial Park, Sandbar Lake Trail; same locality, Green Trail; North of Hurkett, km 46.3 Black Sturgeon Rd., (all Ba, DEBU); Iroquois Falls (Vo, CNCI); Kettle Lakes Provincial Park, Tamarack Trail; same locality, Kettle Trail, (both Ba, DEBU); Killarney Provincial Park (At, DEBU); Lake Superior Provincial Park, Fenton-Treeby trail (Ba, DEBU); same locality, Crescent Lake campground; same locality, Crescent Lake Trail (all Ba, Ro, DEBU, SMOC); Mississagi Provincial Park, Flack Lake Trail (Ba, DEBU); Neys Provincial Park (Bu, DEBU); $20 \mathrm{~km} \mathrm{E}$ Nipigon, Highway \#17, rest area (Ba, DEBU); Ottawa (Vo, CNCI); Pancake Bay Provincial Park (Ba, Ro, DEBU, SMOC); Pukaskwa National Park, Coastal Trail, Hattie Cove - Playter Harbour; same but Thunder Bay District, Playter Harbour White River (both Bu, DEBU); Sault Sainte Marie, Birchwood Park; same locality, Fort Creek Conservation Area; same locality, Hiawatha Highlands Conservation Area; same locality, Old Goulais Bay Rd., Voyageur Trail; same locality, Sault College Woodlot (all Ba, DEBU); Icewater Creek watershed (Ba, DEBU, SMOC); $\sim 14.7 \mathrm{~km} \mathrm{~N}$ Searchmont, Icewater Creek watershed; $\sim 13 \mathrm{~km}$ NNE Searchmont, Whitman Dam Road, km 17.2; 4 km SE Searchmont, Ranger Lake Road; Lab-reared on Clintonia borealis, from $2 \hat{0}, 3 \hat{q}$ collected near Searchmont, Whitman Dam \& Ranger Lake Roads (all Ba, DEBU); Serpent 

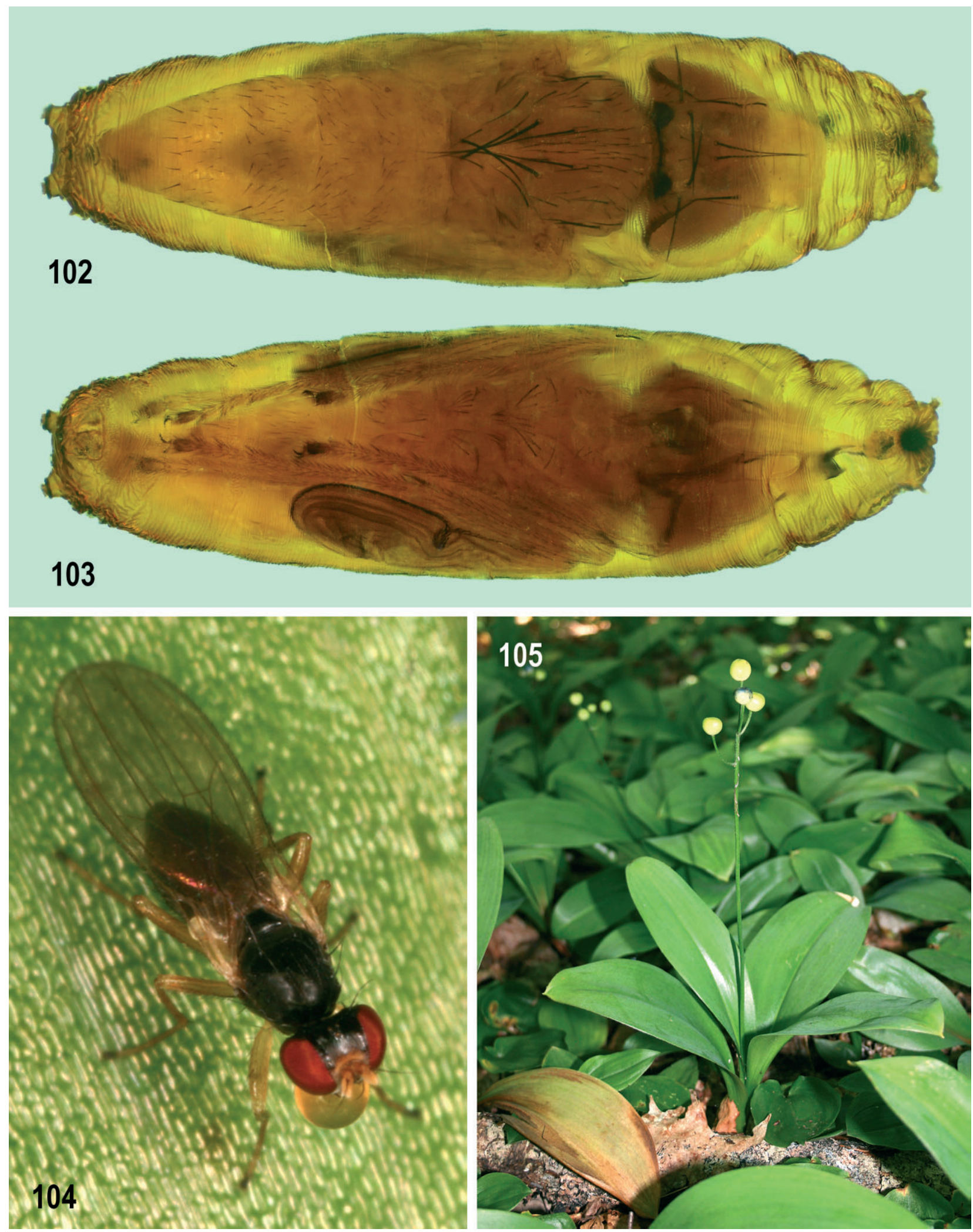

Figs 102-105. Quametopia clintonia sp. n., puparium, adult (female paratype, Canada: Ontario) and host plant: 102 - female puparium (length $3.0 \mathrm{~mm}$ ) with mature adult inside, dorsally; 103 - ditto, ventrally; 104 - bubbling female (body length cca $2.3 \mathrm{~mm}$ ) on leaf of host plant; 105 - Clintonia borealis, host plant of $Q$. clintonia sp. n., with dead leaf (a presumed breeding substrate of larvae) in foreground. Photo: M. Deml (Figs 102-103), J. Roháček (Figs 104-105).

River, Hwy. 17 picnic area (Ba, Ro, DEBU, SMOC); Shakwa Lake, Ouelette Township (Ap, DEBU); 92 km NNE Thessalon, Mountain Ash Lake; 16 km N Wawa, Hwy. 17 pulloff (both Ba, DEBU); 27 km SSW White River; 37 km SSW White River (Ho, DEBU); $40 \mathrm{~km}$ SSW White River (Ba, DEBU). Quebec $(1 \hat{\delta}, 2$ ) : Duncan Lake near Rupert (Mc, CNCI); 
Gatineau Co., Masham Township; Gatineau Park (both Ik, LEMQ). UNITED STATES OF AMERICA: Indiana (1 $q$ ): Turkey Run (Me, USNM). Maine (1 9 ): Echo Lake, Mt. Desert (Jo, USNM). New Hampshire (1 $\widehat{\jmath}, 4 \%)$ : Graham; Mt. Washington, Auto Road 5800 (both Vo, CNCI); Coos Co., White Mts. National Forest, Dolly Copp (We, LEMQ); White Mts. Nat. For., Kancamagus Hwy, East Pond Trail (Fo \& We, LEMQ). New York $(3 \delta, 1 \%$ ): Lake Placid; Whiteface Mtn. (both Vo, CNCI); Whiteface Mtn., summit (Ch, CNCI). Vermont (1 + ): 12 km SW Waterbury, Camel's Hump Trail (Br, LEMQ).

\section{Preimaginal stages}

Egg similar to that of $Q$. terminalis, $0.75-0.84 \mathrm{~mm}$ long, $0.20-0.22 \mathrm{~mm}$ wide (maximum width), thus slightly thicker on the average (Figs 38-40). Both ends tapered but usually less acutely than in $Q$. terminalis. Colour whitish, chorion hyaline with very similar sculpture as in latter species, thus formed by 4 (2 lateral and 2 laterodorsal) pronounced longitudinal ribs and by very fine and tenuous transverse reticulation between them, forming 3 rows of meshes ventrally (Fig. 40), 2 dorsally (Figs 38, 45) and 1 laterally (Fig. 39). However, in contrast to $Q$. terminalis, ventral reticulated area with 3 rows of transverse meshes is margined by a distinctly elevated ledge (visible in Fig. 40) almost forming a low additional rib, being separated from lateral rib by a narrow row of subquadrate (almost square-shaped) meshes. In contrast, the row of meshes between lateral and laterodorsal rib is distinctly wider and meshes are transverse (1:2 to $1: 3)$. Sometimes eggs with abnormal formation of ribs (Fig. 44) occur among normal eggs. The anomalies (split or interrupted ribs) can affect both lateral and laterodorsal ribs and can be relatively frequent. Micropylar area poorly visible, forming ventral subterminal depression on anterior (more acute) end of egg.

Larva. 1st-instar larva. Body shape, colour and structures closely resembling those of $Q$. terminalis but differing as follows. Measurements: length $0.87-1.59 \mathrm{~mm}$, maximum width $0.14-0.22 \mathrm{~mm}$. Cephalic segment (Fig. 89) with only 3 complete oral ridges as in $Q$. terminalis but ventral transverse rows of minute spinules at posterior margin of cephalic segment more reduced (3-4, some incomplete). Posterior end (last abdominal segment) hardly different from that of $Q$. terminalis including shape, structure and armature of posterior spiracles. Cephalopharyngeal skeleton (Figs 87, 88) also similar to that of the latter species but dorsal cornua more slender and shorter than ventral cornua, unpaired mouthhook shorter and less acute, parastomal bar thicker (particularly anteriorly) and intermediate sclerite with ventral plate anteriorly acute-angled (subtriangular).

2nd-instar larva. Similar to that of $Q$. terminalis, only differing in some detail of the anterior spiracle and cephalopharyngeal skeleton. Measurements: length 1.60-2.94 $\mathrm{mm}$, maximum width $0.22-0.42 \mathrm{~mm}$. Anterior spiracle (Fig. 91) simply clavate as in Q. terminalis but somewhat narrower, with ellipsoid slit. Cephalopharyngeal skeleton (Fig. 90). Mouthhooks differing from those of Q. terminalis in having more robust distal hook, reduced but sharply pointed denticle on its base (Fig. 92), and longer and more projecting middle and posterior processes.
Dental sclerite longer and more slender (Fig. 92). Intermediate sclerite (Fig. 90) similarly formed to that of 3rd instar, hence differing from that of $Q$. terminalis in having anterior part of ventral connecting bridge darkpigmented. Dorsal cornua distinctly shorter than ventral cornua and its anterior part (below dorsal bridge) with somewhat darker striped pigmentation. Ventral cornua with larger (although unpigmented) dorsal apodeme, thus more similar to that of 3rd-instar larva.

3rd-instar larva. Very similar to that of $Q$. terminalis including shape, colouring and armature but differing as follows. Measurements: length 3.17-4.92 mm, maximum width $0.49-0.76 \mathrm{~mm}$, when extended. Anterior spiracles terminally palmate as in $Q$. terminalis but usually with only 5 (less frequently with 6) finger-like projections (see Fig. 95). Posterior spiracles hardly different from those of Q. terminalis. Cephalopharyngeal skeleton (Figs 93, 94) generally similar to that of $Q$. terminalis but mouthhooks with middle projection longer and projecting more laterally (cf. Fig. 94), dental sclerite longer and more robust, intermediate sclerite (Figs 93, 94) thicker and with connecting ventral bridge with anterior part dark-pigmented and posterior short-transverse protruded part anteriorly more acute and darkened only medially. Epistomal plate weakly sclerotized and pale-pigmented, of about rhomboid shape and of different (though poorly defined) structure (see Fig. 94). Pharyngeal sclerite (Fig. 93) differing from that of $Q$. terminalis in pigmentation (having darker stripes in anterior part), dorsal cornua distinctly shorter than ventral cornua and the latter provided with larger unpigmented dorsal apodeme.

Puparium (Figs 102, 103, with mature adult inside) of similar shape to that of $Q$. terminalis (slightly wider on the average) differing only in some detail in structures of anterior and posterior ends (not to mention larval cephalopharyngeal skeleton preserved inside). Measurements: length $2.86-3.26 \mathrm{~mm}$, maximum width $0.77-0.91 \mathrm{~mm}$, maximum height $0.66-0.83 \mathrm{~mm}$. Anterior end of puparium with somewhat deeper incisions between segments. First segment (= prothoracic + cephalic) dorsolaterally with anterior palmately branched spiracular processes, each with 5-6 short papillae; segment proper anteromedially usually with distinct (often deep) emargination, dorsally (Fig. 96) with somewhat finer sculpture in the middle, ventrally (Fig. 97) with dark palmately branched ornamentation having its blackish base broader. 2nd and 3rd (meso- and metathoracic) segments dorsally (in large central area) with coarse ribbed structure usually less dense than in $Q$. terminalis, ventrally, on the contrary, more dense than in the latter species. Posterior end of puparium (Fig. 98) ventrally with fewer ribs on precaudal segment and area posterior to anus differently ribbed, with several rib-shaped tubercles. Posterior spiracles on short stump-like processes (Figs 98, 102-103) without broadened subconical bases. Larval adornment (creeping welts) on ventral side of caudal abdominal segment with somewhat larger spinules.

Material examined (pre-imaginal stages): 62 eggs +50 egg chorions, 19 1st-instar larvae, 13 2nd-instar larvae, 9 3rd-instar 
larvae, 6 puparia +7 empty puparia: all lab-reared on Clintonia borealis, using adults from CANADA: Ontario: nr. Searchmont, Whitman Dam \& Ranger Lake Roads; Batchawana Provincial Park; Lake Superior Provincial Park, Crescent Lake (Ba, DEBU)

Discussion. Quametopia clintonia sp. n. is most closely allied to $Q$. amplistylus sp. n. as demonstrated by the similarly abbreviated posterior lobe of gonostylus, reduced anterior lobe of pregonite, finely denticulate apex of filum of distiphallus and very similar internal sclerotization of the female genital chamber (reduced lateral sclerites, prolonged dorsal sclerite). Moreover, females of both species have yellow antennae, concolourous with those of males, in contrast to sexually dichroic antennae in $Q$. terminalis. While males of $Q$. clintonia $\mathrm{sp}$. n. can be easily distinguished from those of $Q$. amplistylus sp. n. by the shape of the anterior lobe of gonostylus and some additional details in the aedeagal complex (see the key above), the females of both species are so similar that sometimes it is difficult to separate them confidently (particularly when internal sclerites in the female genital chamber are in unusual, i.e. other than rest, position).

Based on the material examined, it was found that sometimes both $Q$. clintonia sp. n. and $Q$. amplistylus sp. n. can occur syntopically. Quametopia clintonia sp. n. proved to be strictly associated with $C$. borealis in Ontario (for detail see below) but the host plant(s) of $Q$. amplistylus sp. n. remain(s) unknown. As mentioned above, $Q$. clintonia sp. n. differs from $Q$. terminalis in some structures of all pre-imaginal stages (see the key and in the above description) as well as in the host-plant and habitat association. This can supposedly be also true for $Q$. amplistylus sp. n. as it is more closely related to $Q$. clintonia sp. n. than $Q$. terminalis.

Biology. Compared to $Q$. terminalis, it was more difficult to typify and predict suitable habitat for $Q$. clintonia sp. $\mathrm{n}$. as adults were never found in numbers sufficient to localize microsites in 2009. Once collections in Greenwater Provincial Park (2009) suggested the presence of this second species in Ontario, dominant understory plant species were recorded in subsequent specimen label data. Subsequently, C. borealis (Fig. 105) surfaced as the only species that was consistently present at capture sites of this fly. Some sites included virtual monoculture stands of the clonal $C$. borealis but, paradoxically, these proved not to be the most productive sources of adults when compared to the heterogeneous sites at Greenwater Provincial Park and Dubreuilville. While most adults were swept from mixed vegetation under canopy, single records implicating rotting mushrooms and a bleeding maple stump were located in forest habitat harbouring $C$. borealis. Records mentioning sedges and ferns have likely overlooked the $C$. borealis component. However, the large collection from Lake Superior Provincial Park (Crescent Lake, 2010) represents the strongest field evidence for this host association where the dominance of $C$. borealis was clear. Individual rotting leaves of this plant were frequently observed at this site (Fig. 105) and are presumed to be the oviposition and developmental sites.
Adults of Q. clintonia sp. n. (Fig. 104) have been collected as early as 13 June (Lake Superior Provincial Park, $\mathrm{ON}$ ) and as late as 20 September (Batchawana Provincial Park, ON). Compared to Q. terminalis, this species is under-collected but might also manage two generations per year. Adults have been taken on sticky traps in mixed forest, by flight interception, pan, and pitfall traps, but mostly by sweeping in various forested areas with a range of ground cover including $C$. borealis (where records were made).

Rearing of $\boldsymbol{Q}$. clintonia sp. n. Adults in the cup cages were presented with choices of plant parts (see next section below and Table 2) or, later, with only petioles of $C$. borealis. Most eggs hatched 6 days after oviposition but some as late as 13 days. Most larvae died during early stages within the petioles but surviving larvae transferred to leaf material (Fig. 4) survived and developed quite well. The first two puparia were produced on 30 October and 1 November but then died. Of the 13 puparia formed, 7 produced adults $(3 \hat{\delta}, 4 \%)$ from 8 November to 1 December, a range of at least 65-88 days after egg hatch. Pupariation times ranged $15-19(17.4 \pm 1.72$ s.d., $\mathrm{n}=7)$ days at $20^{\circ} \mathrm{C}$. The resultant adults were not measured but were not noticeably undersized. The last larva was quite lethargic and was killed 21 December, more than 100 days after hatching. It is recommended that leaf material be used as a larval substrate for rearing this species.

Oviposition choices (Table 2). The two females of $Q$. clintonia sp. $\mathrm{n}$. in one cage laid 39 eggs (excludes nine eggs laid on the Petri plate or the sand) exclusively on $C$. borealis surfaces, 25 on the petiole and 14 on the leaf. The single female of $Q$. clintonia sp. n. was less discriminating with 11 eggs laid on the petiole and 9 on the leaf of $C$. borealis but also 2 eggs laid on the split stem of $I$. capensis. This is strong behavioural evidence of an ecological separation of $Q$. clintonia sp. n. and $Q$. terminalis which is congruent with field observations of habitat selection.

Distribution. Of the former records of "Mumetopia" terminalis, only the one by Johnson (1925) from Maine (Mt. Desert) proved to be based on misidentified $Q$. clintonia sp. n. (see type material). Based on material examined, this species is known from Canada (NL, NS, ON, QC) and USA (IN, ME, NH, NY, VT). This is a slightly more northern distribution than that of $Q$. amplistylus $\mathrm{sp}$. $\mathrm{n}$. with which it sometimes co-occurs (NS, NH, see below). The known distribution of the presumed host plant, C. borealis, extends broadly from southern Labrador west to Minnesota and south to Pennsylvania, then further south only at higher elevations to Georgia (Utech, 2002). With a directed sampling from the host plant, it is most likely that $Q$. clintonia sp. n. will be found in a larger area within the range of $C$. borealis especially since the current records in the USA seem to be restricted to the northern tier (as in $Q$. terminalis). It is tempting to speculate that $Q$. clintonia sp. n. and $Q$. amplistylus sp. n. share the same host plant as their combined distributions are suggestive of that of $C$. borealis and, as previously mentioned, they have been found in the same traps in Nova Scotia. Quametopia terminalis can occur within $50 \mathrm{~m}$ of $Q$. clintonia sp. n. in Ontario (Sault Ste. Marie, Pancake Bay Provincial Park) but is separated by host plant. 
Quametopia amplistylus sp. $\mathbf{n}$.

(Figs 33-34, 106-120, 134-137)

Etymology. The name "amplistylus" (from Latin, with enlarged stylus, a noun in nominative singular, standing in apposition to the generic name) refers to the strikingly expanded fore part of the gonostylus of the new species.

\section{Description}

Male. Total body length 2.22-2.75 mm (2.69-3.02 mm when dried from specimens preserved many years in alcohol); body shape and colouration similar to those of both relatives, thus blackish brown (brown to reddish brown in some type specimens originally preserved in alcohol), relatively shiny, with legs and fore head largely yellow. Head formed, coloured and bristled as in Q. clintonia sp. n. unless mentioned otherwise. Frons with anterior yellow area often medially reaching up to level of posterior ors and sometimes also covering anterior (microtomentose) corner of frontal triangle. Frontal triangle longer than wide, usually not reaching to level of anterior ors, coloured and microtomentose as that of $Q$. clintonia sp. n. Orbit with narrow shiny areas as in allies but its brown posterior part reaching slightly in front of posterior ors, thus yellow anterior part larger. Face often darker (dirty yellow to ochreous) than in relatives (not visible in faded specimens originally preserved in alcohol). Parafacialia and gena as in $Q$. clintonia sp. n. but lighter margined (dark yellow on parafacialia; pale brown on gena). Mouthparts yellow including palpus (lighter) and proboscis (darker) but clypeus brown. Cephalic chaetotaxy as in relatives but pvt often longer and only slightly convergent to almost parallel; anterior ors variable in length, ranging from one-third to three-fifths of length of posterior ors; postocular setulae dorsally longer as in $Q$. clintonia sp. n. Eye with longest (oblique) diameter 1.3-1.4 times as long as shortest; smallest genal height 0.10 times as long as shortest eye diameter. Palpus pale to bright yellow. Antenna with whitish cilia on anteroventral side of 1st flagellomere not longer than those of arista.

Thorax resembling that of both relatives in shape, colour, microtomentose pattern and chaetotaxy but ac microsetae more numerous, in 4 rows reaching posteriorly to level of anterior dc. Legs as in $Q$. clintonia sp. n., yellow, with apical (terminal) segment of all tarsi dark brown and usually also preapical segment of fore tarsus brown. $f_{1}$ with ctenidial spine longer than maximum width of $t_{1} ; t_{2}$ with ventroapical seta slightly longer than maximum width of $t_{2}$ and slightly curved. $\mathrm{f}_{3}$ in distal two-thirds with posteroventral row of $12-14$ erect (as in Q. clintonia sp. n.) setae but they are longer and finer (resembling more those of $Q$. terminalis). Wing (Fig. 33; Fig. 34 with an aberrant venation having surplus cross-vein in $\mathrm{dm}$ cell) closely resembling those of both congeners including colour of membrane and veins. $\mathrm{R}_{4+5}$ long, slightly bent as in $Q$. clintonia sp. n.; $\mathrm{M}$ subparallel to $\mathrm{R}_{4+5}$, very slightly bent, apically parallel or very slightly convergent to $\mathrm{R}_{4+5}$. Cross-vein $\mathrm{r}-\mathrm{m}$ situated around middle of $\mathrm{dm}$ cell (ranging from slightly in front of it to slightly behind it); $\mathrm{dm}$ cell formed as in congeners; cross-vein dm-cu shorter than apical portion of $\mathrm{CuA}_{1}$; all other veins and cells as in
Q. terminalis. Wing measurements: length $2.38-3.00 \mathrm{~mm}$, maximum width 0.81-1.11 mm; $\mathrm{Cs}_{3}: \mathrm{Cs}_{4}=1.30-1.85$; $\mathrm{r}-\mathrm{m} \backslash \mathrm{dm}-\mathrm{cu}: \mathrm{dm}-\mathrm{cu}=2.24-3.33$. Haltere as in Q. terminalis.

Abdomen. Preabdominal terga T2-T5 similar to those of both allies, dark brown, only T1 with anterolateral corners paler. T1-T5 with fine transverse microsculpture and similarly greyish microtomentose to those of $Q$. terminalis thus with microtomentum covering smaller area on T4 only reaching to one-third or half its length medially; T5 with narrow microtomentose stripe at anterior margin; thus, bare areas of terga larger and abdomen as shiny as that of $Q$. terminalis. Preabdominal sterna S2-S5 becoming slightly wider (S5 widest and usually darkest) posteriorly; $\mathrm{S} 1$ as in $Q$. terminalis; $\mathrm{S} 2$ slightly wider than long; S3 and S4 subquadrate as in Q. clintonia sp. n.; S5 largest, widest, distinctly transverse. Postabdomen (Fig. 106): T6 similarly reduced (but sometimes longer), bare and with bipartite pigmentation as in $Q$. terminalis. S6-S8 resembling those of both congeners in shape, pigmentation and microtomentose pattern. Both S6 and S7 without setae; S8 large, with numerous setae.

Genitalia. Epandrium (Figs 107, 108) broader than those of $Q$. terminalis and Q. clintonia sp. n., but with setae more dense than in latter species and anal fissure usually narrower and more triangular than in both these relatives. Cerci resembling those of $Q$. terminalis, shortly setose and with apices attached medially (less distinct in Fig. 107 because of everted anus in this specimen). Medandrium (Fig. 107) more similar to that of Q. clintonia sp. $\mathrm{n}$. in having shorter dorsolateral corners but with ventrolateral arms as divergent as in $Q$. terminalis; the latter with 2-3 setulae. Gonostylus (Figs 109, 134-137) bilobed, differing from those of relatives in having anterior clavate lobe longer and posteriorly strongly dilated; its posterior lobe of only half width of the anterior lobe and as short as that of $Q$. clintonia sp. n., usually without microsetulae at dorsal margin. Internal genitalia resembling those of congeners but differing in some detail as follows. Hypandrium (Fig. 111) more similar to that of $Q$. clintonia sp. n., with internal membranous hypandrial lobes more projecting dorsally. Transandrium medially more narrowed, with thin dorsal ledge; basal membrane similarly armed with fine spinules (Fig. 113) but lateral finely granulose area larger than in both relatives (Fig. 111). Pregonite (Fig. 111) with anterior lobe reduced and with 3 to 4 setae as in $Q$. clintonia sp. n. Postgonite (Figs 110,111 ) also very similar to that of $Q$. clintonia sp. n., but slightly longer and, hence, relatively more slender, with 1 fine proximal seta. Aedeagal complex (Fig. 110). Phallapodeme generally more robust than those of both congeners, and its apical part with small acute lateroventral corners. Aedeagal part of folding apparatus with dorsal narrow blackish part usually more robust and dark tubercle-like armature more dense ventrally; connecting sclerite well developed, pigmented and distally provided with both fine and thicker spinules. Phallophore more similar to that of Q. terminalis. Distiphallus with flat posteroventral lobe somewhat more triangular (Fig. 110) in 

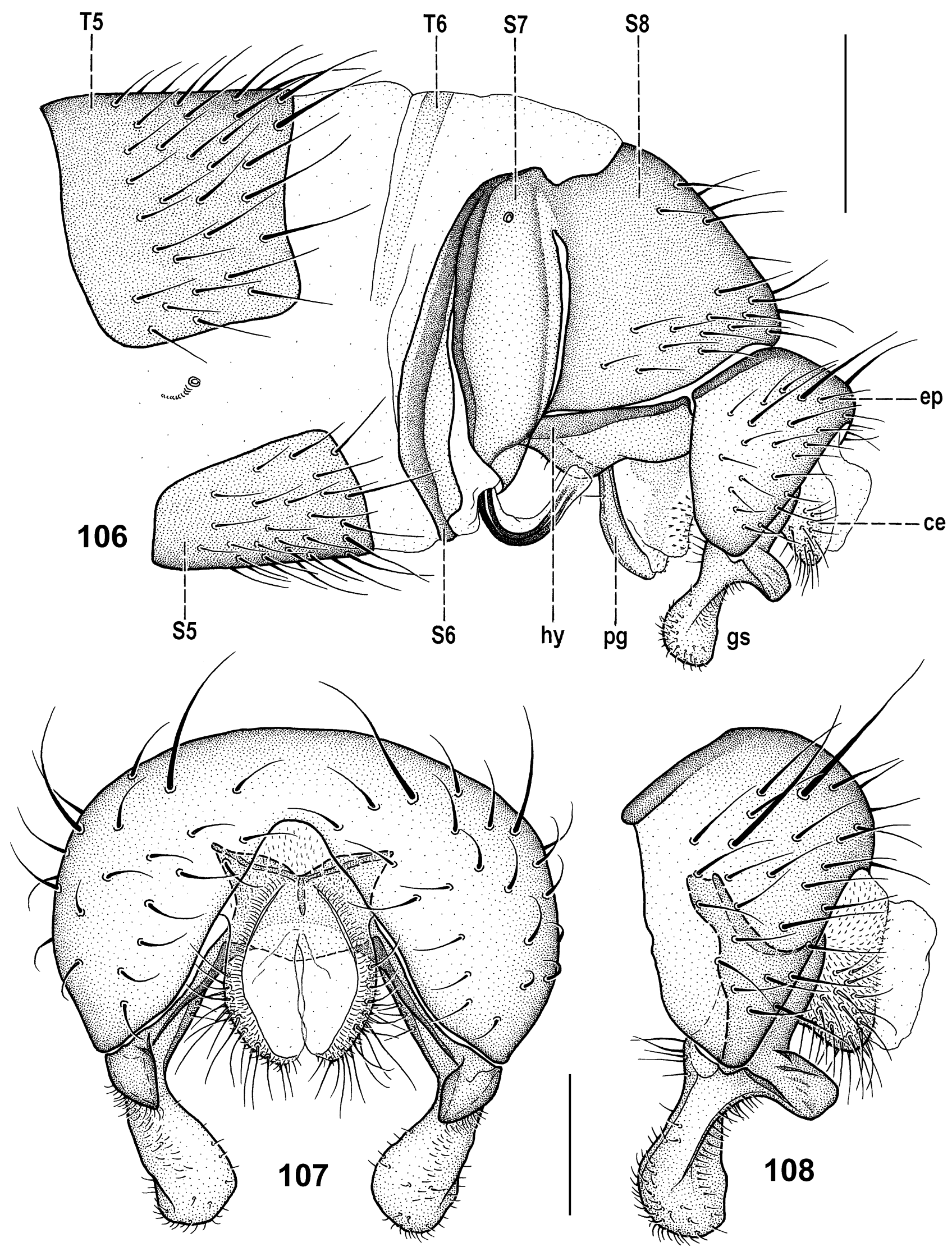

Figs 106-108. Quametopia amplistylus sp. n., male paratype (Canada: Nova Scotia): 106 - postabdomen (in situ), laterally; 107 external genitalia, caudally; 108 - ditto, laterally. Scales: Fig. $106=0.2 \mathrm{~mm}$, others $=0.1 \mathrm{~mm}$. For abbreviations see text. 


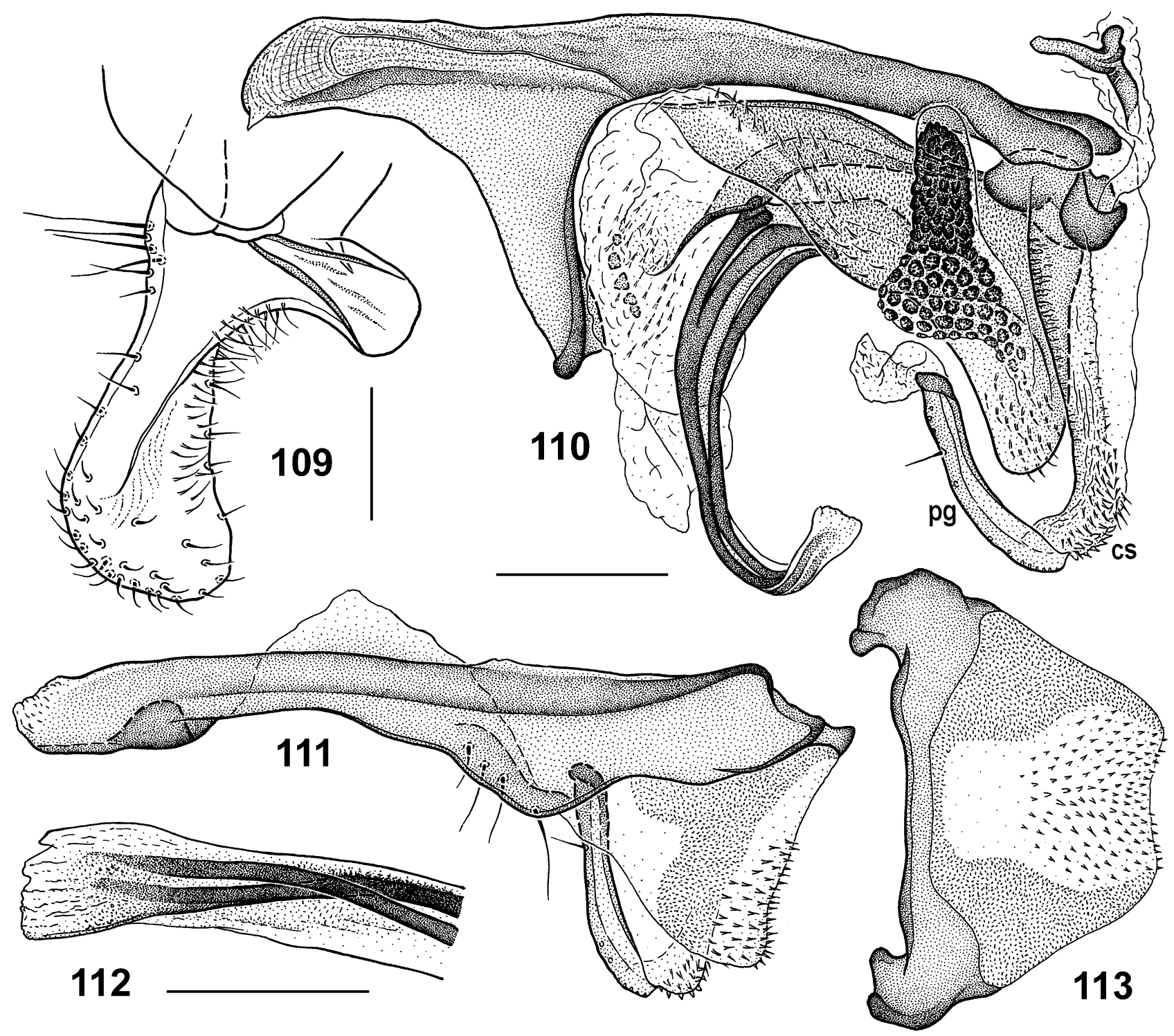

Figs 109-113. Quametopia amplistylus sp. n., male paratype (Canada: Nova Scotia): 109 - left gonostylus, sublaterally (widest extension); 110 - aedeagal complex, laterally; 111 - hypandrial complex, laterally; 112 - apex of filum, lateroventrally (widest extension); 113 - transandrium, caudally. Scales: Figs $109,112=0.05 \mathrm{~mm}$, others $=0.1 \mathrm{~mm}$. For abbreviations see text.

lateral view, distinctly setulose. Middle part of distiphallus as in relatives. Saccus of distiphallus yet larger than in $Q$. clintonia $\mathrm{sp}$. n. and internally provided with a few (4-6) small pale-pigmented tubercle-like spines in addition to fine spinules on surface (Fig. 110). Filum composed of usual pair of dark ribbon-shaped sclerites but dorsal (anterior) of them dilated and basally split; both these sclerites seem to cross below membranous apex which is distinctly dilated (lanceolate to somewhat truncate, see Fig. 112) with a few flat denticles at tip. Ejacapodeme well developed, with body as long as digitiform projection being hardly dilated terminally (Fig. 110).

Female. Similar to male unless mentioned otherwise. Total body length $2.38-2.65 \mathrm{~mm}$ (2.81-3.26 mm when dried from alcohol-preserved specimens). Head colouring only slightly different from that of the male. Face ochreous to pale ochreous brown (much faded in alcohol- preserved specimens), grey microtomentose and dull; bordering stripe on parafacialia and gena darker, pale brown to brown. Mouthparts with dark brown clypeus; palpus ochreous to pale brown (but faded to dirty whitish yellow in alcohol-preserved specimens), darkest on outer side basally, lighter on inner side and apex; proboscis ochreous to pale brown, labellae dirty yellow. Chaetotaxy as in male but pvt slightly to distinctly convergent. Antenna not darkened, entirely yellow or orange-yellow as in male. Lateral rows of ac microsetae often longer, reaching far behind level of anterior dc. Ctenidial spine on $f_{1}$ distinctly longer than maximum width of $t_{1} ; t_{2}$ with ventroapical seta longer than in male; $f_{3}$ without posteroventral row of erect setae. Wing measurements: length 2.58-3.02 mm, maximum width 0.85-1.03 mm; $\mathrm{Cs}_{3}: \mathrm{Cs}_{4}$ $=1.21-1.62 ; \mathrm{r}-\mathrm{m} \backslash \mathrm{dm}-\mathrm{cu}: \mathrm{dm}-\mathrm{cu}=2.21-3.05$.

Abdomen somewhat broader and preabdominal terga more transverse and shorter than in male; fine transverse 


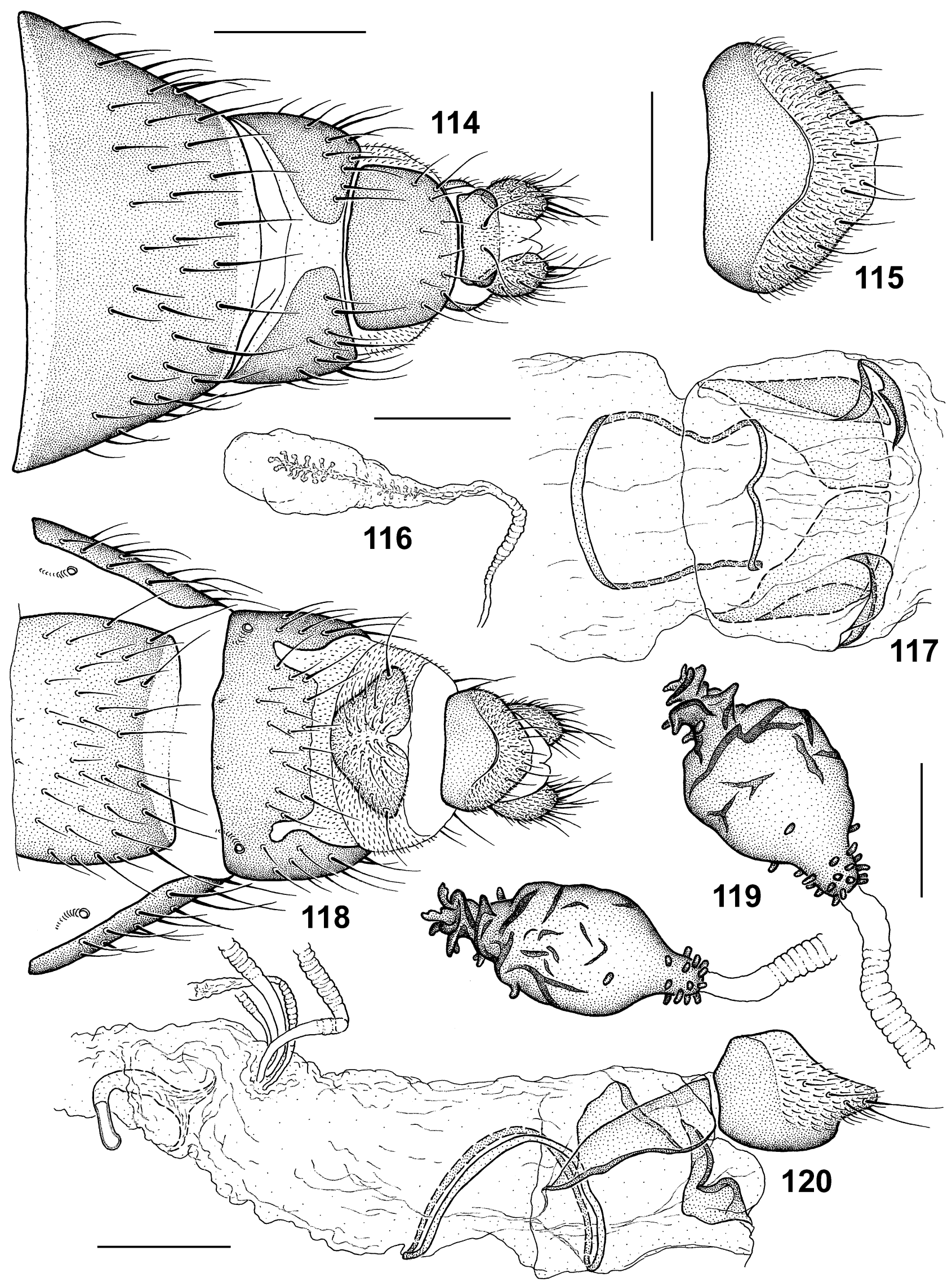

Figs 114-120. Quametopia amplistylus sp. n., female paratype (Canada: Nova Scotia): 114 - postabdomen, dorsally; 115 - S10, ventrally; 116 - accessory gland; 117 - sclerites of the female genital chamber, ventrally; 118 - postabdomen, ventrally; 119 - spermathecae; 120 - genital chamber and S10, laterally. Scales: Figs 114, $118=0.2 \mathrm{~mm}$, Fig. $119=0.05 \mathrm{~mm}$, others $=0.1 \mathrm{~mm}$. 

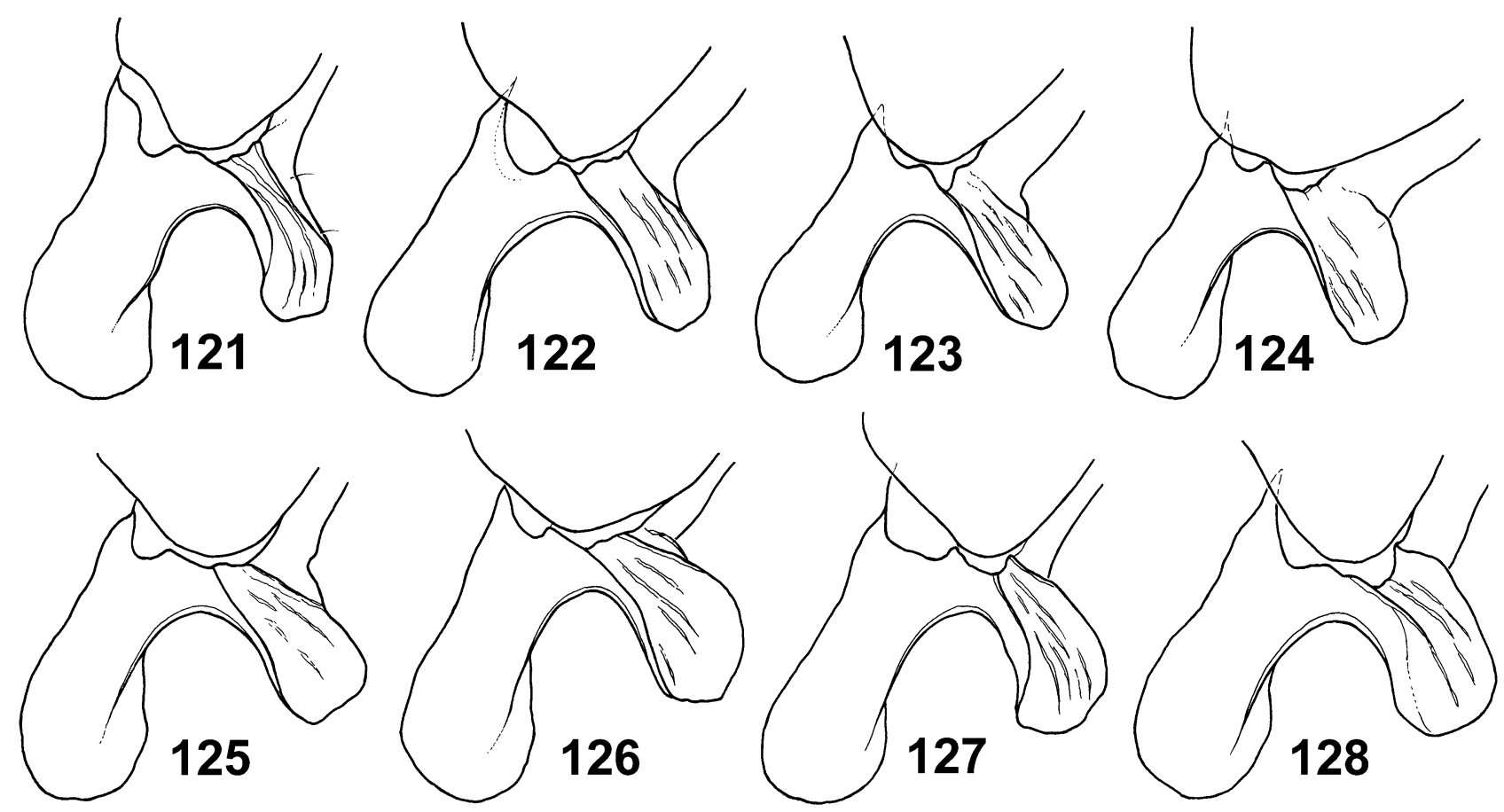

Figs 121-128. Quametopia terminalis (Loew), variability of male gonostylus (sublaterally, widest extension): 121 - lectotype; 122 - Maine (Seal Harbor); 123 - Maryland (Bethesda); 124 - Maryland (Plummers Is.); 125 - Massachusetts (Woods Hole); 126 Illinois (Macomb); 127 - Ontario (Guelph); 128 - Ontario (Sault Ste. Marie). Scale: $0.1 \mathrm{~mm}$.

microsculpture of terga much reduced, only visible on $\mathrm{T} 1-\mathrm{T} 2$ and, yet poorer, at base of T3. T1 and T2 largely sparsely microtomentose but $\mathrm{T} 2$ with bare stripe at posterior margin. T3 with some sparse microtomentum only anteromedially in basal third. T4-T6 bare, glabrous and shiny. S1 reduced and pigmented as in $Q$. clintonia sp. n. All S2-S5 slightly to distinctly wider than long; S3-S4 longest and least transverse, S5 shorter and most transverse.

Postabdomen (Figs 114, 118) most similar to that of $Q$. clintonia $\mathrm{sp}$. n. The (very slight and partly overlapping) differences are as follows. S6 wider (more transverse) and usually more densely setose. Tergosternum T7+S7 slightly more transverse, with more setae on ventral part (original S7). T8 usually slightly wider anteriorly, with broadly rounded posterior corners (Fig. 114). S8 (on Fig. 118 with posterior side oriented ventrally due to exposed genitalia) with posteromedial bulge and (more dorsal) incision, as in relatives. Internal structures of genital chamber (Figs 117,120 ) very similar to those of $Q$. clintonia sp. n., but dorsal pair of posterior sclerites shorter and anterior annular sclerite usually longer. Ventral receptacle (Fig. 120) also most similar to that of $Q$. clintonia sp. n. with duct basally wider (often poorly visible because of membranous, hyaline nature of this structure). Accessory gland (Fig. 116) possibly larger than in relatives, elongately vesiculate with a set of stalked globuli inside, on ringed but hardly dilated duct. Spermathecae (1+1) most resembling those of $Q$. clintonia sp. n. but usually more robust (with larger maximum diameter) and distal tapered end of spermatheca usually shorter, less curved or straight and provided with more projections
(Fig. 119). T10 (Fig. 114) often longer (less transverse) than that of $Q$. clintonia sp. n. S10 differing from that of $Q$. clintonia sp. n. in having anterior bare part smaller (Fig. 115) and strongly abruptly separated (cf. Fig. 120) from posterior micropubescent part. Cerci short, similar to those of relatives, usually wider in dorsal view (Fig. 114) but this much depends on the condition of the genitalia of the respective specimens (cerci are in different position during copulation, oviposition and at rest).

Type material. Holotype $\widehat{\delta}$ labelled: "Gr. Smoky Mt. Nat. Pk., N.C., 18.VI.1957, J.R. Vockeroth", "Clingman's Dome, 6300' 6642'”, "Holotypus ơ, Quametopia amplistylus sp. n., J. Roháček \& K.N. Barber det. 2010" (red label) (CNCI, genit. prep.). Paratypes: CANADA: Nova Scotia: Cape Breton Highlands N[ational] P[ark], Lone Shielding [sic - "Shieling"], PG729861, 18.-21.vii.1983, F[light] I[nterception] T[rap], 1 ऊ $(\mathrm{Bd} \& \mathrm{Bj}$, DEBU, left wing detached and preserved in microtube); same locality, PG861731, 19.viii.1983, pan traps, 1 ( $\mathrm{Sr}$, DEBU, genit. prep.); same locality, North Mt., $400 \mathrm{~m}$, PG766864, P[an] T[rap]/FIT in forest \& ferns, 11.-19.vii.1983, 40,4 (Ms, LEMQ, 1 t with head glued to point, left wing detached and preserved with genit. prep., all but $2 \hat{\sigma}$ with genit. prep.). UNITED STATES OF AMERICA: Massachusetts: Petersham, vii.1926, 10, 1 ㅇ (Me, USNM, genit. prep.). Michigan: Cheboygan Co., 4.vii.1951, 1 đ (Dr, USNM, genit. prep.). New Hampshire: Mt. Monadnock, 26.vii.1926, 1 ô, 1 \% (Me, USNM, genit. prep.); Mt. Washington, Auto Road 5800', 14.viii.1958 (Vo, CNCI, genit. prep.). North CarolinaTennessee: Great Smoky Mt. N.P., Clingman's Dome, 6300' 6642', 8.vii.1957, $10^{\star}$ (Mo, CNCI, genit. prep., right wing detached and preserved with genit. prep.).

Not included in type series. CANADA: Newfoundland and Labrador: Portugal C $[\mathrm{o}] \mathrm{v}[\mathrm{e}]$, pasture sweep, 1.vii.1987, 1 \% (We, DEBU, genit. prep.). UNITED STATES OF AMERICA: 

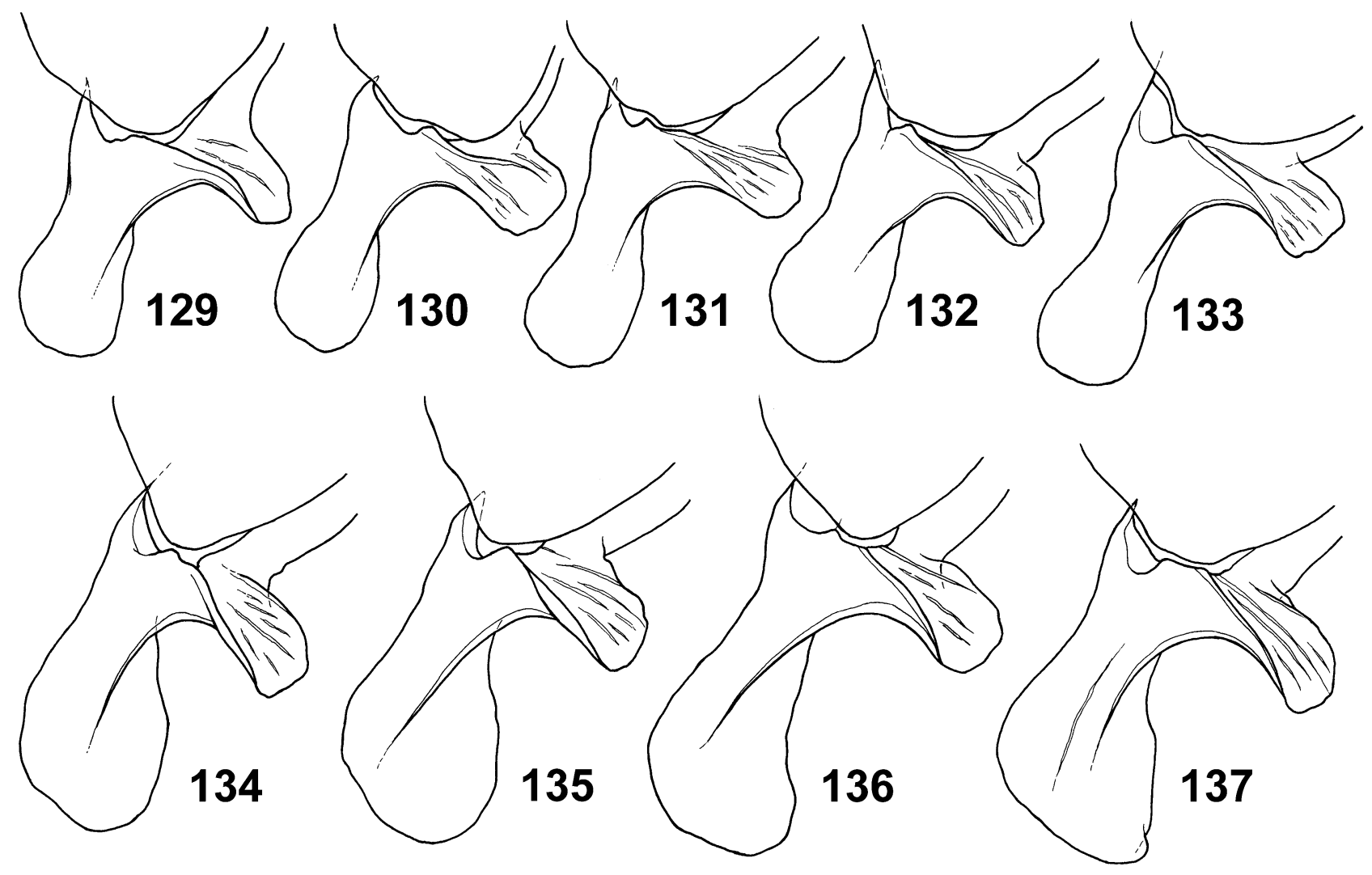

Figs 129-137. 129-133: Quametopia clintonia sp. n., paratypes, variability of male gonostylus (sublaterally, widest extension): 129 - Ontario (Dubreuilville); 130 - Ontario (Greenwater Provincial Park); 131 - Ontario (Dubreuilville); 132 - Ontario (Iroquois Falls); 133 - New York (Whiteface Mtn.). 134-137: Quametopia amplistylus sp. n., paratypes, variability of male gonostylus (sublaterally, widest extension): 134 - Michigan (Cheboygan Co.); 135 - New Hampshire (Mt. Monadnock); 136 - Nova Scotia (Cape Breton Highlands); 137 - New Hampshire (Mt. Washington). Scale: $0.1 \mathrm{~mm}$.

New Hampshire: Jefferson Notch, creek margin, 30.vii.1961, 2 ㅇ (Wi, USNM, both genit. prep.); Mt. Wash[ington], Dolly Copp, 4.vii.1936, 1 (Me, USNM, genit. prep.); Mt. Wash[ington], [no date], 1 ㅇ (Sl, USNM, genit. prep.). New York: Adirondacks, Avalanche [Pass?] Tr[ai]l, 30.vii.1929, 1 ㅇ (Me, USNM, genit. prep.).

Discussion. As noted above, $Q$. amplistylus sp. n. is very similar and closely related to $Q$. clintonia $\mathrm{sp}$. $\mathrm{n}$. It differs from the latter species in the male sex mainly by the distally expanded anterior lobe of gonostylus, more robust phallapodeme, short internal spines in saccus and more widened apex of filum of distiphallus. In addition, the male has very slightly convergent to distinctly parallel pvt setae, a condition unusual in the Anthomyzidae as a whole. This is, however, not true for the female sex, where the pvt setae are slightly to distinctly convergent. Because of the strong resemblance of female postabdominal characters, females of $Q$. amplistylus sp. n. sometimes cannot be identified confidently (see also in discussion under $Q$. clintonia sp. n.).

Biology. This species seems to be the rarest member of the genus Quametopia being collected sporadically and usually not in series. This surely is due to the unknown habitat and host-plant association ( $Q$. clintonia sp. n. was also very rarely collected until its association with $C$. borealis was recognized). Clintonia borealis should not be ruled out as the host for $Q$. amplistylus sp. n. as well, at least in the south and east of the plant's range. Adults were recorded in June and (mainly) July, the majority of specimens being captured by means of pan and flight intercept traps in "forest with ferns" in undergrowth.

Distribution. Known only from eastern North America, the species was found in Canada (NL, NS) and USA (MA, MI, NC, $\mathrm{NH}, \mathrm{NY},[\mathrm{TN}])$. Based on data labels, it is known to co-occur with $Q$. clintonia sp. n. [NS: Cape Breton Highlands National Park (within the same traps); NH: Mt. Washington, Auto Road 5800' (?Dolly Copp)] and with Q. terminalis (MA: Petersham). No specimens were ever collected with the many $Q$. clintonia sp. n. recorded from Ontario.

ACKNOWLEDGMENTS. We would like to express our sincerest gratitude to curators and/or owners of collections who enabled study of specimens (including types) under their care, viz. M. Barták (MBP), M. Buck and S.A. Marshall (DEBU), S.M. Clark (BYUC), J.M. Cumming (CNCI), Z.H. Falin (SEMC), C. Favret (INHS), D. Furth, W.N. Mathis, S.J. Swenson and the late H. Williams (USNM), S.D. Gaimari (CSCA), D.A. Grimaldi and T.C. Nguyen (AMNH), W.J. Hanson (EMUS), M. Kotrba (ZSMC), N. Penny, B. Fisher and K.J. Ribardo (CASC), P.D. Perkins and S. Cover (MCZC), M. v. Tschirnhaus (Bielefeld, Germany), and T.A. Wheeler and S. Boucher (LEMQ). W.J. Crins and B. Feilders (Ontario Ministry of Natural Resources, Peterborough, Canada) are thanked for authorizing field collections in provincially protected areas 
which were especially important for this project. J.-F. Landry $(\mathrm{CNCI})$ identified the tortricids, J. Read (CNCI) identified the figitids, while T.A. Wheeler provided advice on the colour variation in chloropids. S.J. Meades [Northern Ontario Plant Database, c/o Herbarium, Great Lakes Forestry Centre (GLFC), Sault Ste. Marie, Canada] kindly provided assistance with all things botanical while D.P. Kreutzweiser, M.T. Dumas and D. Doucet (GLFC) provided access to microphotography equipment. Our particular thanks are extended to M. Deml (Morávka, Czech Republic) for his magnificent macrophotographs of adults and puparia and preparation of colour plates. J. Ševčík and J. Řehulka (SMOC) kindly provided photographic equipment to the senior author (J.R.) for his field work in Ontario (2010) and S.A. Marshall (DEBU) and his family and E.F. Barber are thanked for various assistance and hospitality during this research stay. The junior author's contributions benefited from in-kind support from Natural Resources Canada, GLFC, in the form of the use of laboratory space and equipment. The study of the senior author was financially supported by the grant No. P506/10/1666 of the Czech Science Foundation.

\section{REFERENCES}

Czerny L. 1902: Bemerkungen zu den Arten der Gattungen Anthomyza Fll. und Ischnomyia Lw. Wien. Entomol. Ztg. 21: 249-256.

FERrar P. 1987: A Guide to the Breeding Habits and Immature Stages of Diptera Cyclorrhapha. Entomonograph 8 (Parts 1 and 2). E.J. Brill / Scandinavian Science Press, LeidenCopenhagen, $907 \mathrm{pp}$.

Gilligan T.M., Wright D.F. \& Gibson L.D. 2008: Olethreutine Moths of the Midwestern United States: An Identification Guide. Ohio Biological Survey, Columbus, OH, 334 pp.

Johnson C.W. 1925: List of the Diptera or two-winged flies. Fauna of New England, Part 15. Occ. Papers Boston Soc. Nat. Hist. 7: 1-326.

LoEw H. 1863: Diptera Americae septentrionalis indigena. Centuria quarta. Berlin. Entomol. Z. 7: 275-326.

MacKay M.R. 1959: Larvae of the North American Olethreutinae (Lepidoptera). Can. Entomol. 10 (Suppl.), 338 pp.

Marshall S.A., Buddle C.M., Sinclair B.J. \& Buckle D.J. 2001: Spiders, flies and some other arthropods of the Fathom Five National Marine Park islands and the upper Bruce Peninsula. In Parker S. \& Munawar M. (eds): Ecology, Culture and Conservation of a Protected Area: Fathom Five National Marine Park, Canada. Ecovision World Monograph Series. Backhuys Publishers, Leiden, pp. 191-229.

MeIJerE J.C.H. DE 1944: Over de Metamorphose van Metopia leucocephala Rossi, Cacoxenus indagator Löw, Palloptera saltuum L., Paranthomyza nitida Mg. en Hydrellia nigripes Zett. (Dipt.). Tijdschr. Entomol. 86[1943]: 57-61.

Melander A.L. 1913: A synopsis of the dipterous groups Agromyzinae, Milichiinae, Ochthiphilinae and Geomyzinae. J. N. Y. Entomol. Soc. 21: 283-300.

NyE I.W.B. 1958: The external morphology of some of the dipterous larvae living in the Gramineae of Britain. Trans. $R$. Entomol. Soc. London 110: 411-487.

Procter W. 1946: Biological Survey of the Mount Desert Region. Vol. 7. The Insect Fauna with References to Methods of Capture, Food Plants, the Flora, and other Biological Features. Wistar Institute of Anatomy and Biology, Philadelphia, PA, 566 pp.

RoHÁČEK J. 1986: A revision of Anthomyza macra Czerny and A. pleuralis Czerny (Diptera, Anthomyzidae). Ann. Naturhist. Mus. Wien (B) 88/89: 593-606.
RоHÁČEK J. 1992: Typhamyza gen. n. for Anthomyza bifasciata Wood, with description of immature stages (Diptera, Anthomyzidae). Boll. Mus. Reg. Sci. Nat. Torino 10: 187-207.

RoHÁČEK J. 1993: Two new Afrotropical genera of Anthomyzidae (Diptera), with descriptions of seven new species. Ann. Natal Mus. 34: 157-190.

RоHÁČEK J. 1998: Taxonomic limits, phylogeny and higher classification of Anthomyzidae (Diptera), with special regard to fossil record. Eur. J. Entomol. 95: 141-177.

RoHÁČEK J. 2004: Revision of the genus Amygdalops Lamb, 1914 (Diptera: Anthomyzidae) of the Afrotropical Region. Afr. Invertebr. 45: 157-221.

RoHÁČEK J. 2006: A monograph of Palaearctic Anthomyzidae (Diptera) Part 1. Čas. Slez. Muz. Opava (A) 55 (Suppl. 1), 328 pp.

RоHÁČEK J. 2008: Revision of the genus Amygdalops Lamb, 1914 (Diptera, Anthomyzidae) of the Oriental, Australasian and Oceanian Regions. Acta Zool. Acad. Sci. Hung. 54: 325-400.

RонÁČEK J. 2009: A monograph of Palaearctic Anthomyzidae (Diptera) Part 2. Čas. Slez. Muz. Opava (A) 58 (Suppl. 1), 180 pp.

RoHÁČ́K J. \& BÁEz M. 1988: Santhomyza biseta sp. n. (Diptera, Anthomyzidae) from the Canary Islands. Boll. Mus. Reg. Sci. Nat. Torino 6: 295-304.

ROHÁČEK J. \& BARBER K.N. 2009: New reduced-winged species of Mumetopia Melander, with analysis of the relationships of this genus, Chamaebosca Speiser and allied genera (Diptera: Anthomyzidae). Acta Soc. Zool. Bohem. 72[2008]: 191-215.

RohÁČ́K J. \& Freidberg A. 1993: The Anthomyzidae (Diptera) of Israel, with revision of Anagnota Becker. Israel $J$. Entomol. 27: 61-112.

SABrosky C.W. 1965: Family Anthomyzidae. In Stone A., Sabrosky C.W., Wirth W.W., Foote R.H. \& Coulson J.R. (eds): A Catalog of the Diptera of America North of Mexico. U.S. Department of Agriculture Handbook 276. USDA, Washington, DC, pp. 819-820.

Schmitt J., Eccleston J. \& Ehrhardt D.W. 1987: Dominance and suppression, size-dependent growth and self-thinning in a natural Impatiens capensis population. J. Ecol. 75: 651-665.

United States Department of Agriculture 2010: Plants database. Natural Resources Conservation Service, National Plant Data Center, Baton Rouge, LA, USA. <http://plants.usda.gov/ java/> [accessed 7 September 2010].

UteCH F.H. 2002: Clintonia. In: Flora of North America Editorial Committee (eds): Flora of North America North of Mexico. Vol. 26. Flora of North America Association, New York and Oxford, pp. 151-153.

Winn A.F. \& Beaulieu G. 1932: A Preliminary List of the Insects of the Province of Quebec. Part II, Diptera. Revised and Supplemented by C.E. Petch \& J.B. Matais. Supplement to 24th report of the Quebec Society for the Protection of Plants. Dominion Entomological Laboratory, Hemmington, Quebec, $100 \mathrm{pp}$.

ZATWARNICKI T. 1996: A new reconstruction of the origin of eremoneuran hypopygium and its implications for classification (Insecta: Diptera). Genus 7(1): 103-175.

Received September 22, 2010; revised and accepted November 22, 2010

APPENDIX ONLINE:

$<\mathrm{http}: / /$ www.eje.cz/supplfiles/eje1618suppl.pdf> 